\title{
Nanofluid Thermal Conductivity and Effective Parameters
}

\author{
Sarah Simpson, Austin Schelfhout, Chris Golden and Saeid Vafaei * \\ Mechanical Engineering Department, Bradley University, Peoria, IL 61625, USA; \\ ssimpson@mail.bradley.edu (S.S.); aschelfhout@mail.bradley.edu (A.S.); Chris.Golden.ME@gmail.com (C.G.) \\ * Correspondence: svafaei@fsmail.bradley.edu
}

Received: 6 November 2018; Accepted: 7 December 2018; Published: 26 December 2018

\begin{abstract}
Due to the more powerful and miniaturized nature of modern devices, conventional heat-transfer working fluids are not capable of meeting the cooling needs of these systems. Therefore, it is necessary to improve the heat-transfer abilities of commonly used cooling fluids. Recently, nanoparticles with different characteristics have been introduced to base liquids to enhance the overall thermal conductivity. This paper studies the influence of various parameters, including base liquid, temperature, nanoparticle concentration, nanoparticle size, nanoparticle shape, nanoparticle material, and the addition of surfactant, on nanofluid thermal conductivity. The mechanisms of thermal conductivity enhancement by different parameters are discussed. The impact of nanoparticles on the enhanced thermal conductivity of nanofluids is clearly shown through plotting the thermal conductivities of nanofluids as a function of temperature and/or nanoparticle concentration on the same graphs as their respective base liquids. Additionally, the thermal conductivity of hybrid nanofluids, and the effects of the addition of carbon nanotubes on nanofluid thermal conductivity, are studied. Finally, modeling of nanofluid thermal conductivity is briefly reviewed.
\end{abstract}

Keywords: nanoparticle; nanofluid; thermal conductivity

\section{Introduction}

Conventional heat-transfer fluids, such as water, oil, and Ethylene Glycol, are widely used in numerous industries, including the fields of transportation, medicine, supply, heating, ventilation, and air conditioning (HVAC), power generation, chemical production and air-conditioning [1-4]. However, the low thermal conductivity of working fluids is a major limiting factor in design, limiting the compactness, efficiency, and capability of systems. High heat flux devices, including X-rays, high powered lasers, computers, and microelectronics are examples of technologies which are limited by the heat-transfer capabilities of currently available cooling fluids $[2,5,6]$.

Miniaturization, power enhancement, and a possibility of increasing the efficiency of devices, motivated scientists to develop a new generation of working fluids, called suspension fluids. Initially, suspension fluids were fabricated by dispersing micro-scale particles within a base liquid. However, it has been found that suspending micro-scale sized solid particles in heat transfer fluids leads to problems such as sedimentation and erosion. By instead suspending nano-sized particles in heat transfer fluids, there is potential to avoid these problems while significantly enhancing the thermal conductivity [4]. Base fluids containing stably suspended nanoparticles, ranging from 1-100 nm in size, are called nanofluids [3,7]. Measurements of the thermal conductivities of micro-particle suspensions were first performed in the middle of the last century [8]. Generally, the nanofluid experiments need to be conducted with great care in a fume hood. It is necessary to be aware of particular dangers for humans and the environment before conducting any experiments using nanoparticles. Before conducting an experiment, the hazards identification, first aid measures, firefighting measures, 
accidental release measures, handling and storage, exposure controls and personal protection, physical and chemical properties, stability and reactivity, toxicological information, ecological information, disposal considerations, transport information and regulations need to be studied in detail, which nowadays can be found in Material Safety Data Sheets (MSDS).

Experimental data has shown that nanofluid thermal conductivity is a function of multiple parameters. This paper reviews and discusses the effects of different factors which influence the thermal conductivity of nanofluids, including the effects of characteristics of nanoparticles (size, shape, material), nanoparticle concentration, temperature, surfactant, and base liquid. The effects of the addition of carbon nanotubes on the thermal conductivity of a base liquid, along with the effects of adding multiple types of nanoparticles to a single base liquid to produce a hybrid nanofluid are also studied. Finally, the mechanisms which lead to increased nanofluid thermal conductivity are briefly discussed, along with the numerical models which describe these phenomena.

\section{Nanofluid Thermal Conductivity}

Experimentation has shown that nanofluid thermal conductivity is dependent upon base liquid [3,915], possible surfactant [16-23], concentration $[1,3,4,7-11,13,15,16,22-40]$, temperature $[5,8,10,12,13,25,28-$ $31,33,38-41]$, and characteristics of nanoparticles, such as nanoparticle size $[3,4,7,11,20,25,28,32,35,36,42]$ and nanoparticle shape $[16,25,43]$. Interestingly, in some cases, experimental results are controversial. It has been observed that nanoparticle size and shape significantly influence the thermal conductivity of nanofluids whereas, surprisingly, nanoparticle material does not have a significant impact. It has been observed that temperature and nanoparticle volume concentration also significantly influence the thermal conductivity of nanofluids. The following section will discuss the aforementioned parameters which influence nanofluid thermal conductivity.

\subsection{Effects of Nanoparticle Material on Nanofluid Thermal Conductivity}

Researchers have conducted experiments to explore the effects of nanoparticle material on the thermal conductivity of nanofluids, interestingly finding that nanoparticle material alone is not an influential parameter and it does not significantly influence nanofluid thermal conductivity $[8,26,32,36]$. Several researchers have suggested that factors other than the intrinsic thermal conductivity of nanoparticles, such as nanoparticle size and clustering [26,32,36], have a more significant impact on nanofluid thermal conductivity. For example, Yoo et al. [36] studied the thermal conductivities of $\mathrm{TiO}_{2}$-water, $\mathrm{Al}_{2} \mathrm{O}_{3}$-water, $\mathrm{Fe}-$ Ethylene Glycol, and $\mathrm{WO}_{3}$-Ethylene Glycol nanofluids using the transient hot-wire method. It was observed that $\mathrm{TiO}_{2}$-water nanofluid had a higher thermal conductivity than $\mathrm{Al}_{2} \mathrm{O}_{3}$-water nanofluid, despite the higher intrinsic thermal conductivity of $\mathrm{Al}_{2} \mathrm{O}_{3}$ in comparison to $\mathrm{TiO}_{2}$. It was suggested that this was a result of the smaller size of the $\mathrm{TiO}_{2}$ nanoparticles $(25 \mathrm{~nm})$ in comparison to the $\mathrm{Al}_{2} \mathrm{O}_{3}$ nanoparticles $(48 \mathrm{~nm})$, resulting in a higher surface area to volume ratio in the $\mathrm{TiO}_{2}$-water nanofluid. It was also observed that Fe-Ethylene Glycol nanofluid had a higher thermal conductivity than $\mathrm{WO}_{3}$-Ethylene Glycol nanofluid. The size of the Fe nanoparticles $(10 \mathrm{~nm})$ was also smaller than that of the $\mathrm{WO}_{3}$ nanoparticles $(38 \mathrm{~nm})$. It was suggested that the thermal conductivity of the suspended nanoparticles does not have a primary effect on the thermal conductivity of nanofluids, but the surface area to volume ratio does have a strong influence on the thermal conductivity of a nanofluid. It was also suggested that the thermal conductivities of nanofluids containing metallic nanoparticles are higher than that of those containing ceramic nanoparticles. Using the same method, Pang et al. [32] measured the thermal conductivities of $\mathrm{SiO}_{2}-$ methanol and $\mathrm{Al}_{2} \mathrm{O}_{3}$-methanol nanofluids. It was observed that $\mathrm{SiO}_{2}$-methanol nanofluid had a higher thermal conductivity despite alumina's higher intrinsic thermal conductivity. It was suggested that this was a result of the formation of larger nanoparticle clusters in the $\mathrm{SiO}_{2}-$ methanol nanofluid. These results agree with the idea that the thermal conductivity of nanofluids is impacted more significantly by factors other than the thermal conductivity of nanoparticles. In the same way, Xie et al. [26] measured the thermal conductivities of nanofluids composed of several oxide nanoparticles, including 
$\mathrm{MgO}, \mathrm{TiO}_{2}, \mathrm{ZnO}, \mathrm{Al}_{2} \mathrm{O}_{3}$ and $\mathrm{SiO}_{2}$, dispersed in Ethylene Glycol. Listed from highest to lowest, the intrinsic thermal conductivities of the nanoparticles were $\mathrm{MgO}, \mathrm{Al}_{2} \mathrm{O}_{3}, \mathrm{ZnO}, \mathrm{SiO}_{2}$, and $\mathrm{TiO}_{2}$. The thermal conductivities of the nanofluids, listed from highest to lowest, were $\mathrm{MgO}-\mathrm{Ethylene}$ Glycol, $\mathrm{Al}_{2} \mathrm{O}_{3}$-Ethylene Glycol, $\mathrm{TiO}_{2}$-Ethylene Glycol, $\mathrm{ZnO}-$ Ethylene Glycol, and finally $\mathrm{SiO}_{2}-\mathrm{Ethylene}$ Glycol nanofluid. These results also support the idea that the thermal conductivity of nanofluids is affected more significantly by factors other than the intrinsic thermal conductivity of nanoparticles. However, in some cases experimental data has shown controversial results, in which nanofluid thermal conductivity increased with nanoparticle thermal conductivity. For example, using the transient hot-wire method, Iqbal et al. [37] measured the thermal conductivities of spherical $\mathrm{Al}_{2} \mathrm{O}_{3}, \mathrm{SiO}_{2}$, and $\mathrm{ZrO}_{2}$ nanoparticles dispersed in water. Due to the high density of $\mathrm{ZrO}_{2}$, yttrium oxide was used as a surfactant to aid in stability. The thermal conductivities of the nanoparticles listed from highest to lowest are $\mathrm{Al}_{2} \mathrm{O}_{3}>\mathrm{ZrO}_{2}>\mathrm{SiO}_{2}$. It was observed that $\mathrm{Al}_{2} \mathrm{O}_{3}$-water nanofluid had the highest thermal conductivity, and $\mathrm{SiO}_{2}$-water nanofluid had the lowest. Also, Chopkar et al. [4] measured the thermal conductivities of nanofluids composed of $\mathrm{Ag}_{2} \mathrm{Al}$ and $\mathrm{Al}_{2} \mathrm{Cu}$ dispersed in both water and Ethylene Glycol. They obtained measurements using a thermal comparator, which worked based on the principle that the total heat transferred by a hot probe was a function of both the thermal conductivity of the fluid and the thermal conductivity of the solid nanoparticles. When an electrically heated source was brought into contact with the fluid, a metallic copper probe sensed the temperature change through an attached thermocouple. The temperature was then measured and recorded through a circuit covering the probe assembly and nanofluid. Thermal conductivity values recorded were very high, with a thermal conductivity of $1.44 \mathrm{~W} / \mathrm{mk}$ for $\mathrm{Ag}_{2} \mathrm{Al}$-water nanofluid at nanoparticle volume concentration, $\varphi=1.8 \%$, and a thermal conductivity of $1.35 \mathrm{~W} / \mathrm{mk}$ for $\mathrm{Al}_{2} \mathrm{Cu}$ nanofluid at the same nanoparticle volume concentration. Although no direct evidence was found, it was suggested that the formation of loose chain-like structures between nanoparticles may have caused the high thermal conductivity values by occupying more volume within the nanofluid than individual nanoparticles, thus allowing a greater area for heat transfer. It was observed that the nanofluids containing $\mathrm{Ag}_{2} \mathrm{Al}$ nanoparticles had higher thermal conductivities than those containing $\mathrm{Al}_{2} \mathrm{Cu}$ nanoparticles. Patel et al. [28] performed experiments to determine the thermal conductivities of $\mathrm{Al}_{2} \mathrm{O}_{3}$-water, $\mathrm{Al}_{2} \mathrm{O}_{3}$-Ethylene Glycol, $\mathrm{CuO}$-transformer oil, $\mathrm{Cu}$-water, $\mathrm{Cu}$-Ethylene $\mathrm{Glycol}$, $\mathrm{Al}$-water, and Al-transformer oil nanofluids. The transient hot-wire method was used to obtain measurements for the oxide nanofluids, and temperature oscillation equipment was used for the metallic nanofluids. It was observed that nanofluids containing metallic nanoparticles had higher thermal conductivities than those containing oxide nanoparticles, which supports the observation made by Yoo et al. [36]. Additionally, using the transient hot-wire method, Sundar et al. [13] measured the thermal conductivity of magnetic $\mathrm{Fe}_{3} \mathrm{O}_{4}$ nanoparticles dispersed in a mixture of Ethylene Glycol and water. It was stated that an advantage to using magnetic nanoparticles is the possibility of separating the particles from the base fluid after the particles are fully dispersed. From the observations discussed above, it can be suggested that the intrinsic thermal conductivity of nanoparticles does not always have a significant influence on the thermal conductivity of nanofluids. However, further experimentation should be completed in order to determine the parameters which overpower the impact of nanoparticle material on nanofluid thermal conductivity.

The thermal conductivities of water-based nanofluids containing various nanoparticles, are shown in Figure 1 as a function of temperature, at a nanoparticle volume concentration of $\varphi=2 \%$. It is observed that for a given temperature, the thermal conductivity of $\mathrm{CuO}-$ water nanofluid is higher than the thermal conductivity of $\mathrm{Cu}$-water nanofluid. These results contradict -the observations made by Milanese et al. [44], who observed a thermal conductivity of $0.706 \mathrm{~W} / \mathrm{mk}$ for $50 \mathrm{~nm} \mathrm{Cu}$ nanoparticles dispersed in water, and a thermal conductivity of $0.67 \mathrm{~W} / m k$ for $30 \mathrm{~nm} \mathrm{CuO} \mathrm{nanoparticles} \mathrm{dispersed}$ in water, at a nanoparticle volume concentration $\varphi=3 \%$ and a temperature of $30^{\circ} \mathrm{C}$. It is also observed that the thermal conductivity of nanodiamond-water nanofluid is very low despite the high intrinsic thermal conductivity of nanodiamond $1000 \mathrm{~W} / \mathrm{m} . \mathrm{k}$ within the temperature range of 
$27-52{ }^{\circ} \mathrm{C}$, for $\varphi=2 \%$, the thermal conductivity of nanodiamond-water nanofluid ranged from 0.66-0.69 W/m.k. Yegameha et al. [29] also observed relatively low values for the thermal conductivity of nanodiamond-water nanofluids. Within the temperature range of $20-60{ }^{\circ} \mathrm{C}$, for $\varphi=1 \%$, the thermal conductivity of nanodiamond-water nanofluid ranged from $0.67-0.80 \mathrm{~W} / \mathrm{m} . \mathrm{k}$. The thermal conductivities of nanofluids composed of various nanoparticles dispersed in water at room temperature are shown in Figure 2 as a function of nanoparticle volume concentration, $\varphi$, for concentrations below $\varphi=0.01 \%$. It is observed that for a given nanoparticle concentration, $5000 \mathrm{~nm}$ oxidized graphene nanofluid has higher thermal conductivity than the nanofluid composed of unoxidized graphene nanoparticles having the same size, despite the nanoparticles having the same thermal conductivity. This may be a result of the greater stability of the nanofluid containing oxidized graphene nanoparticles. It is also observed that the thermal conductivity of $5000 \mathrm{~nm}$ graphene-water nanofluid is higher than that of 15,000 nm graphene-water nanofluid, which is likely caused by the smaller size of the $5000 \mathrm{~nm}$ particles. The thermal conductivities of nanofluids composed of various nanoparticles dispersed in water at room temperature are shown in Figure 3 as a function of nanoparticle volume concentration, $\varphi$, for concentrations below $\varphi=1 \%$. It is observed that the thermal conducitivity of $\mathrm{TiO}_{2}$-water nanofluid is higher than that of $\mathrm{Al}_{2} \mathrm{O}_{3}$-water nanofluid. This may be a result of the smaller size of the $\mathrm{TiO}_{2}$ nanoparticles. The thermal conductivities of nanofluids composed of various nanoparticles dispersed in water at room temperature are shown in Figure 4 as a function of nanoparticle volume concentration, $\varphi$, for concentrations below $\varphi=5 \%$. Despite the low thermal conductivity of $\mathrm{Fe}_{3} \mathrm{O}_{4}$ in comparison to other oxide nanoparticles, it is observed that the thermal conductivity of $\mathrm{Fe}_{3} \mathrm{O}_{4}$-water nanofluid is unexpectedly high. This may be a result of more significant clustering and alignment of the $\mathrm{Fe}_{3} \mathrm{O}_{4}$ nanoparticles in comparison to other oxide nanoparticles dispersed in water [1]. It is also observed that the thermal conductivity of Al-water nanofluid is higher than the thermal conductivities of nanofluids containing oxide nanoparticles, other than $\mathrm{Fe}_{3} \mathrm{O}_{4}$. This may be a result of the higher intrinsic thermal conductivity of metals in comparison to metal oxides. The thermal conductivities of water-based nanofluids containing various nanoparticles are shown in Figure 5 as a function of temperature, at a nanoparticle volume concentration of $\varphi=1 \%$. It is observed that for a given temperature, the thermal conductivity of $\mathrm{Fe}_{3} \mathrm{O}_{4}$-water nanofluid is higher than that of the $\mathrm{CuO}-$ water nanofluid. This observation is inconsistent with Figure 1, in which it is observed that the thermal conductivity of $\mathrm{CuO}$-water nanofluid is slightly higher than that of $\mathrm{Fe}_{3} \mathrm{O}_{4}$-water nanofluid for a given temperature, at $\varphi=2 \%$. The thermal conductivities of nanofluids composed of various nanoparticles dispersed in Ethylene Glycol at room temperature are shown in Figure 5 as a function of nanoparticle volume concentration, $\varphi$, for concentrations below $\varphi=5 \%$. It is observed that nanodiamond-Ethylene Glycol nanofluid has a higher thermal conductivity than other nanofluids, besides $\mathrm{MgO}-$ Ethylene Glycol nanofluid, for a given nanoparticle volume concentration. The higher thermal conductivity of nanodiamond-Ethylene Glycol nanofluid may be a result of the combination of the high thermal conductivity of nanodiamond, and the strong compatibility between nanodiamond particles and Ethylene Glycol base fluid, which is caused by the carboxyl and hydroxyl groups on the surfaces of the nanodiamond particles having strong interactions with polar Ethylene Glycol in an alkaline environment (having a $\mathrm{PH}$ value higher than 7.0) [45]. It was also observed that for concentrations greater than $\varphi=1 \%$, the thermal conductivity of $\mathrm{Al}_{2} \mathrm{O}_{3}$-Ethylene Glycol nanofluid was higher than that of $\mathrm{CuO}$-ethylene nanofluid. The opposite was observed for $\mathrm{Al}_{2} \mathrm{O}_{3}$-water and $\mathrm{CuO}-$ water in Figure 4. The thermal conductivities of nanofluids composed of various nanoparticles dispersed in Ethylene Glycol at room temperature are shown in Figures 6 and 7 as a function of nanoparticle volume concentration, $\varphi$, for concentrations below $\varphi=1 \%$. The Fe-Ethylene Glycol and $\mathrm{WO}_{3}$-Ethylene Glycol nanofluids contained no surfactant, whereas Gum Arabic surfactant was used in the Ag-Ethylene Glycol nanofluid. It was observed that the Gum Arabic surfactant did not have a significant impact on the thermal conductivity of the Ag-Ethylene Glycol nanofluid. The thermal conductivity of Ag-Ethylene Glycol nanofluid was not able to be tested at concentrations higher than those shown due to agglomeration and settling. The settling of nanoparticles resulted in 
lower concentrations of particles dispersed near the hot wire, leading to measurements showing a lower rate of increase in thermal conductivity at higher nanoparticle volume concentrations [23]. It is also observed that the thermal conductivity of Fe-Ethylene Glycol nanofluid is higher than that of $\mathrm{WO}_{3}$-Ethylene Glycol nanofluid. This may be a result of the smaller size of the Fe nanoparticles, and the metallic properties of the Fe nanoparticles. The thermal conductivity of nanoparticles is given in Table 1.

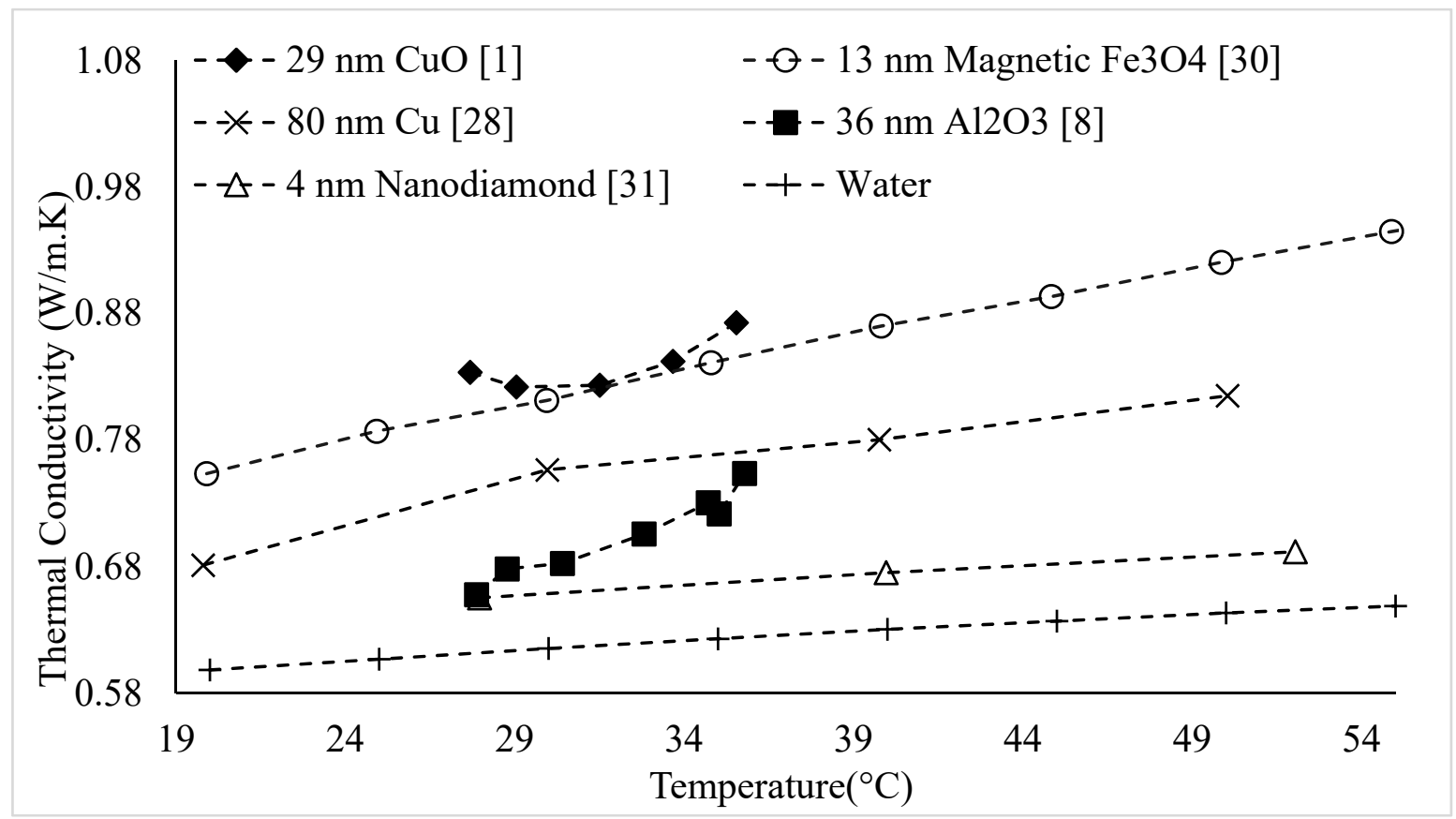

Figure 1. Variation of water-based nanofluid thermal conductivity as a function of temperature for different nanoparticles at $\varphi=2 \%$.

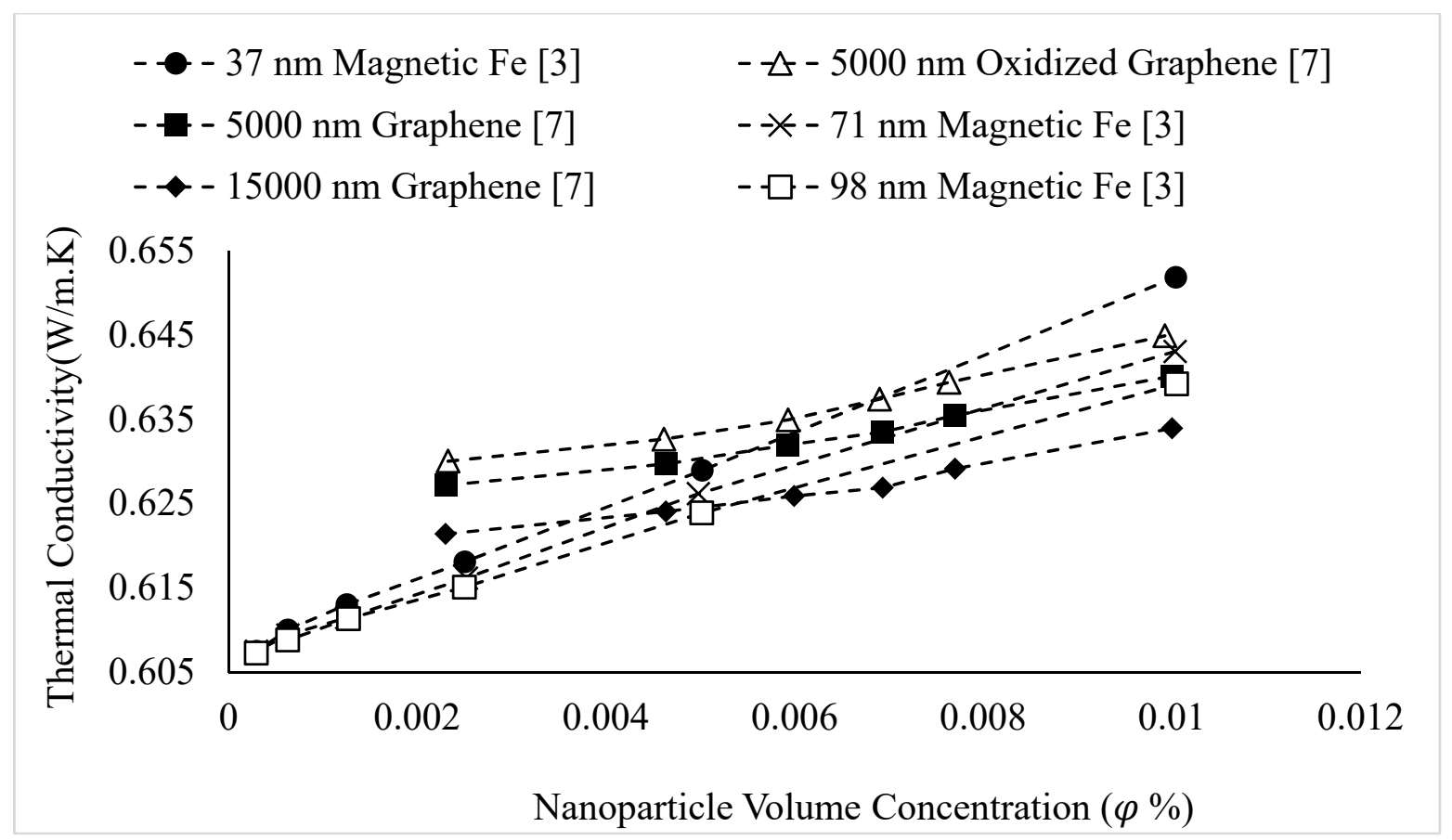

Figure 2. Variation of water-based nanofluid thermal conductivity as a function of nanoparticle volume concentration, $\varphi$, for different nanoparticles at room temperature. 


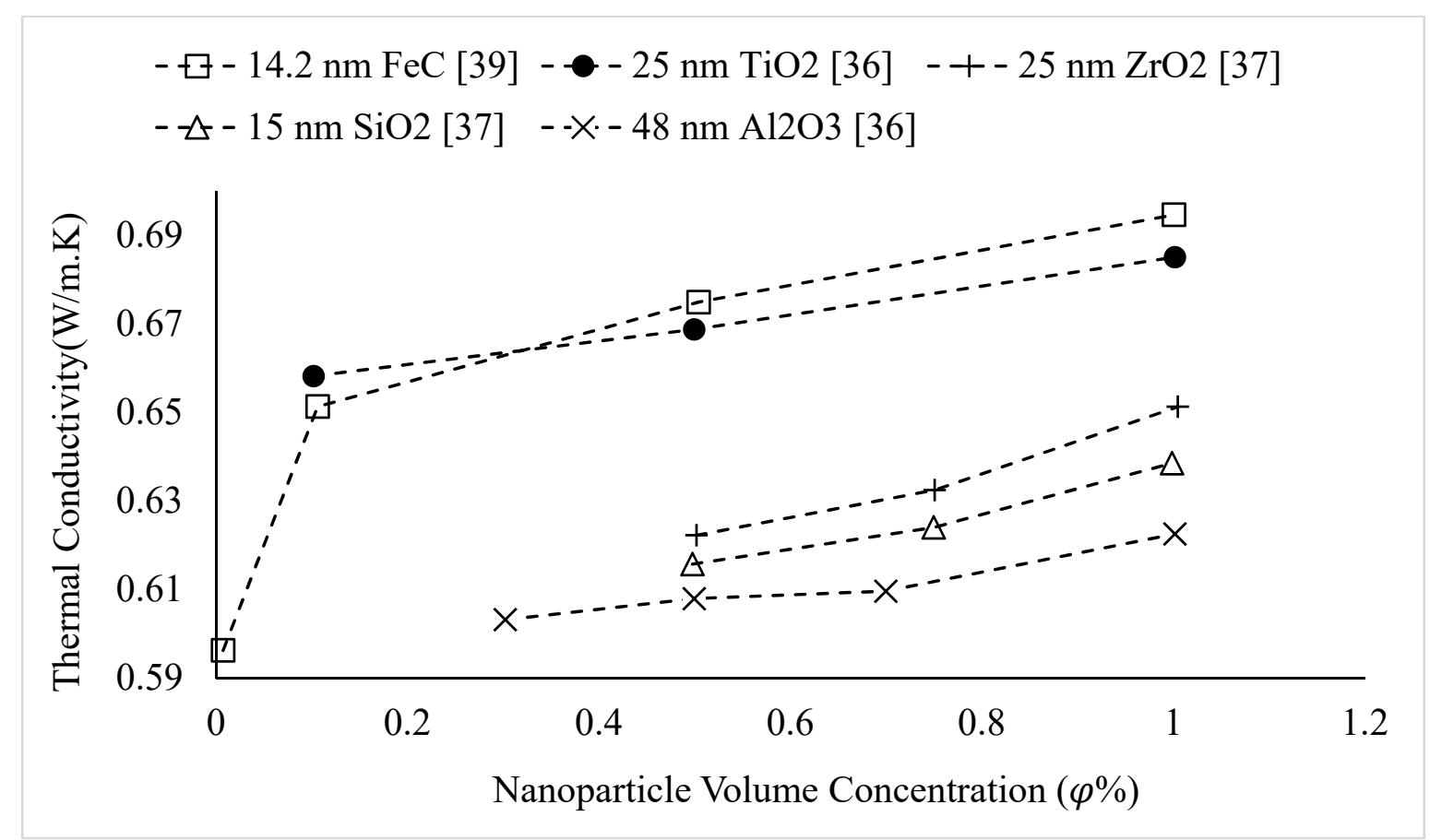

Figure 3. Variation of water-based nanofluid thermal conductivity as a function of nanoparticle volume concentration, $\varphi$, for different nanoparticles at room temperature.

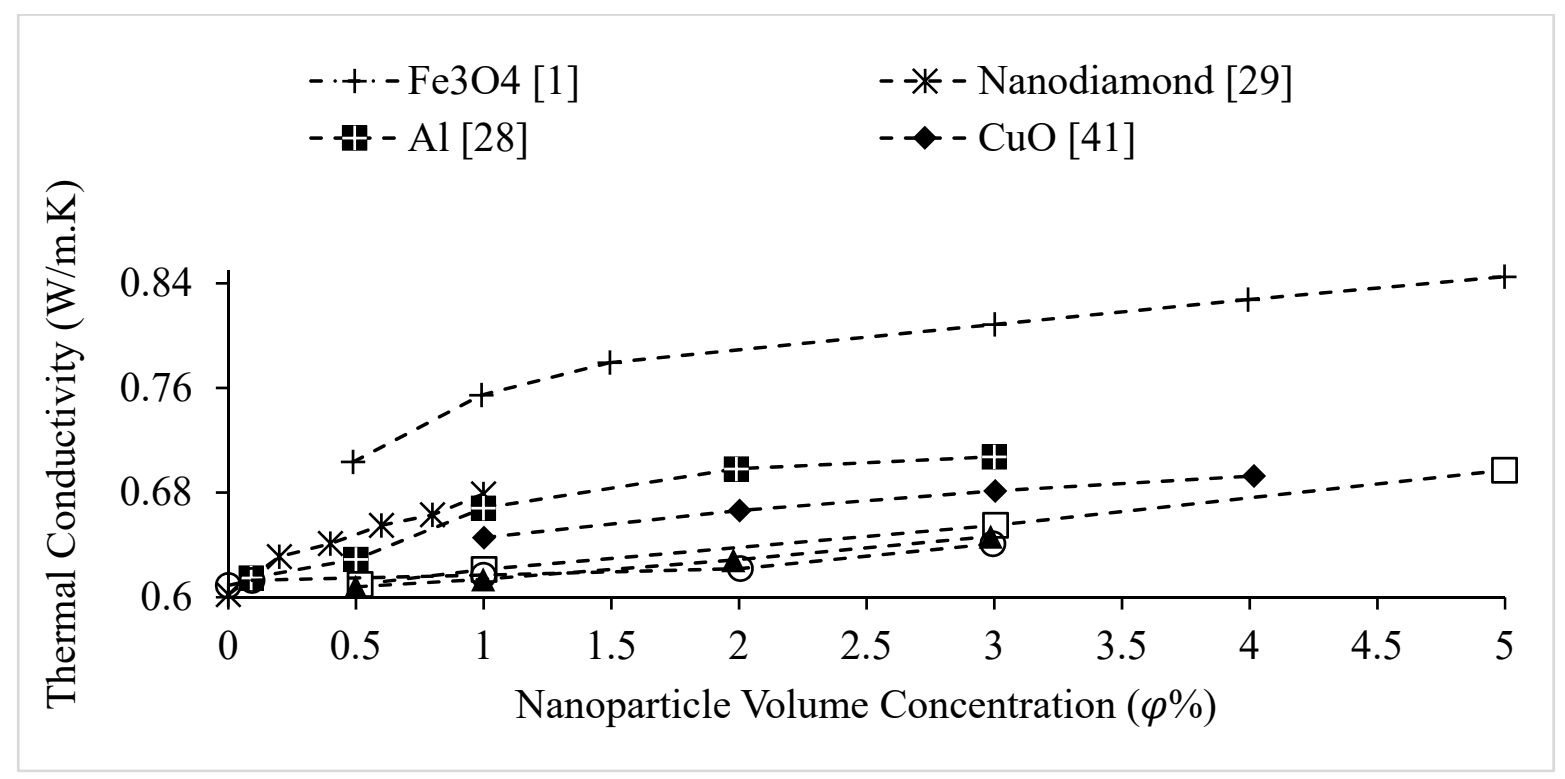

Figure 4. Variation of water-based nanofluid thermal conductivity as a function of nanoparticle volume concentration, $\varphi$, for different nanoparticles at room temperature. 


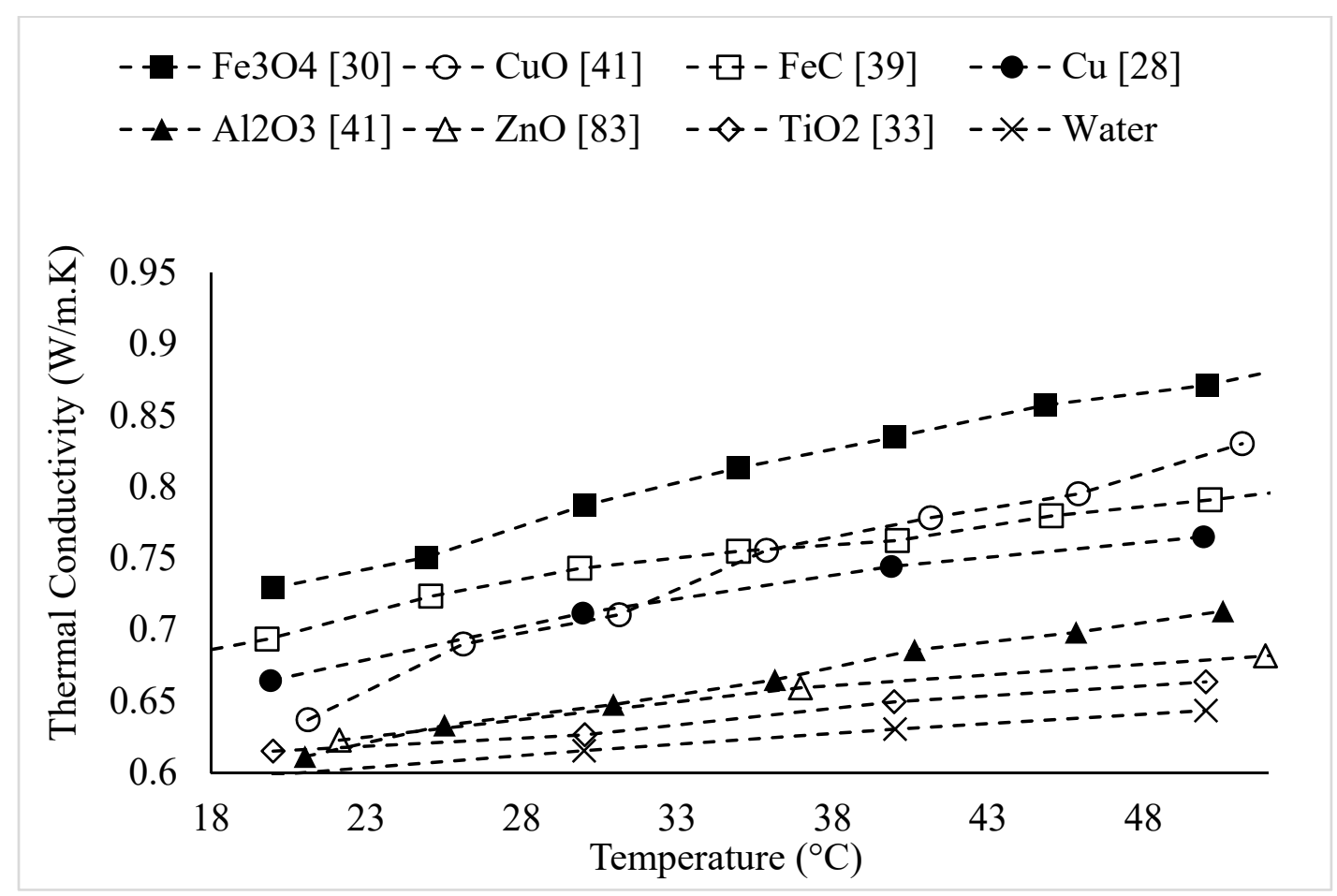

Figure 5. Variation of water-based nanofluid thermal conductivity as a function of temperature for different nanoparticles at $\varphi=1 \%$.

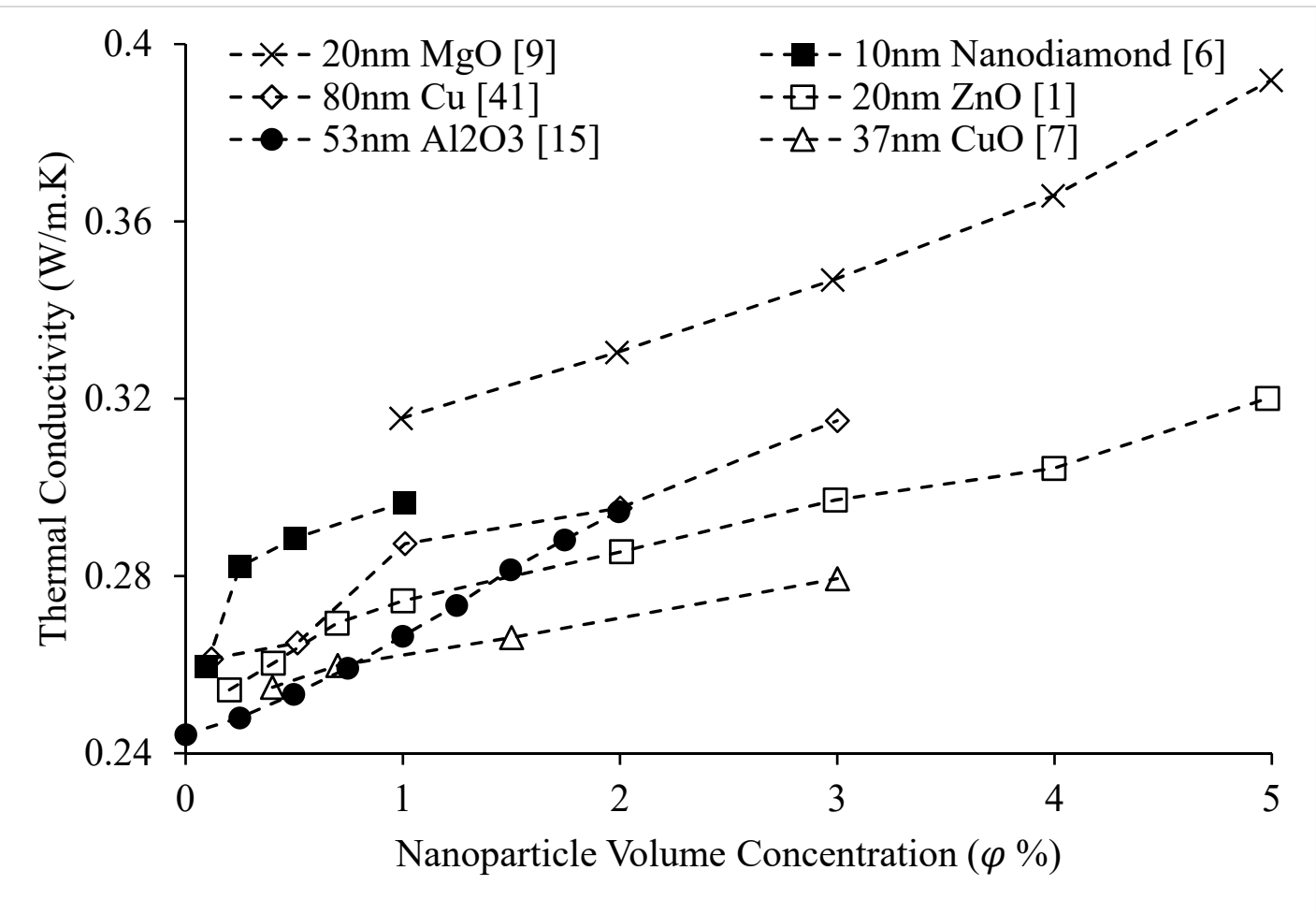

Figure 6. Variation of Ethylene Glycol-based nanofluid thermal conductivity as a function of nanoparticle volume concentration, $\varphi$, for different nanoparticles at room temperature. 


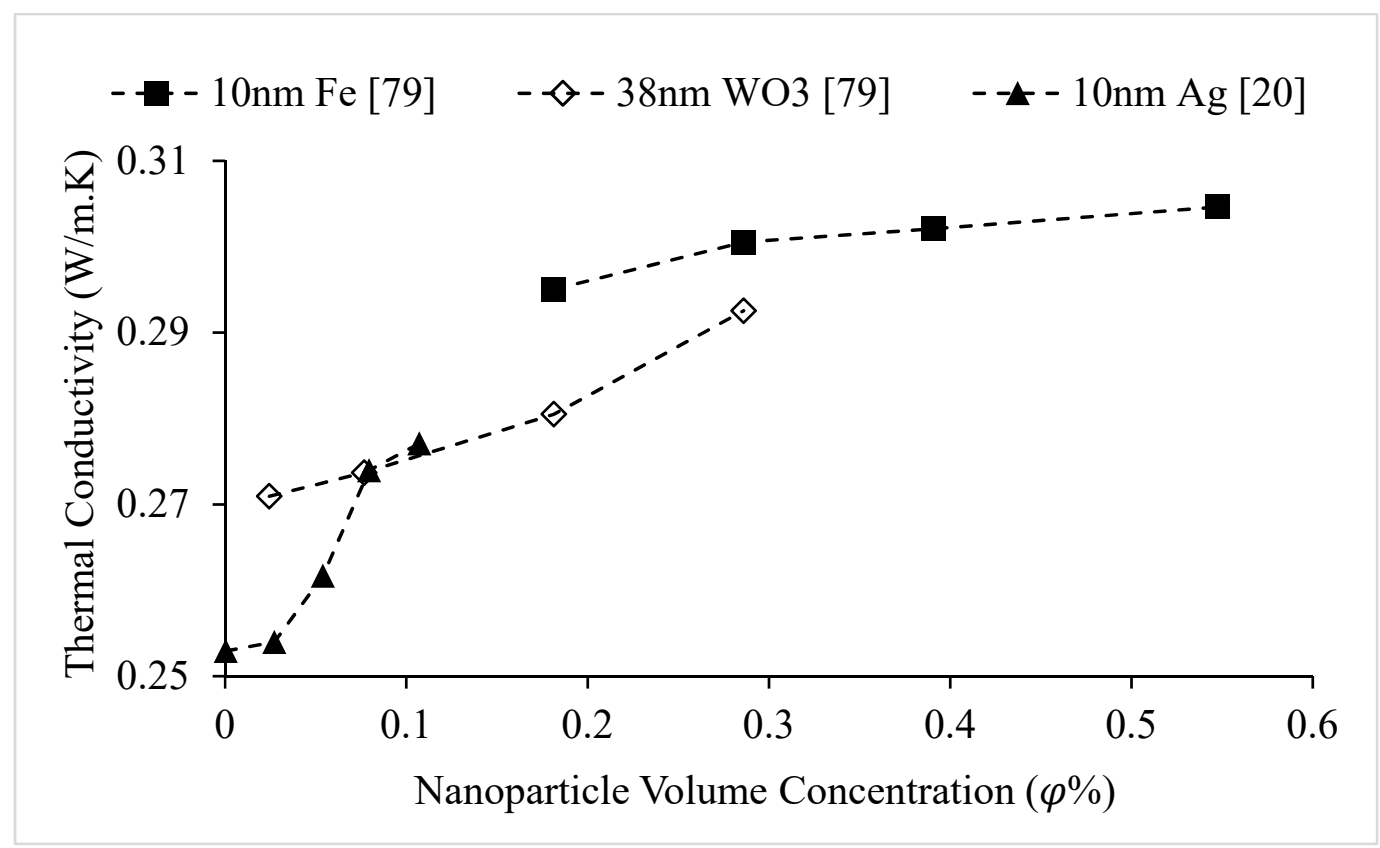

Figure 7. Variation of Ethylene Glycol-based nanofluid thermal conductivity as a function of nanoparticle volume concentration, $\varphi$, for different nanoparticles at room temperature.

Table 1. Nanoparticle thermal conductivity.

\begin{tabular}{ccc}
\hline Reference & Nanoparticle Material & $\begin{array}{c}\text { Nanoparticle Thermal Conductivity at Room } \\
\text { Temperature W/m.k }\end{array}$ \\
\hline Park et al. [7] (2014) & $\mathrm{Graphene}$ & 3000 \\
\hline Seyhan et al. [23] (2017) & $\mathrm{Ag}$ & 429 \\
\hline \multirow{2}{*}{ Iqbal et al. [37] (2017) } & $\mathrm{SiO}_{2}$ & 1.4 \\
& $\mathrm{ZrO}_{2}$ & 2.2 \\
\hline & $\mathrm{MgO}$ & 48.4 \\
Xie et al. [26] (2010) & $\mathrm{TiO}_{2}$ & 8.4 \\
& $\mathrm{ZnO}$ & 13 \\
& $\mathrm{Al}_{2} \mathrm{O}_{3}$ & 36 \\
& $\mathrm{SiO}_{2}$ & 10.4 \\
\hline Lee et al. [34] (2011) & $\mathrm{SiC}_{2}$ & 490 \\
\hline Chopkar et al. [4] (2008) & $\mathrm{Al} \mathrm{Cu}_{2}$ & 319 \\
& $\mathrm{Ag} \mathrm{Al}_{2} \mathrm{Al}$ & 358 \\
\hline Patel et al. [28] (2010) & $\mathrm{Al}$ & 204 \\
\hline Sundar et al. [29] (2016) & $\mathrm{Cu}$ & 383 \\
\hline Senthilraja et al. [46] (2015) & $\mathrm{Nanodiamond}$ & 1000 \\
\hline Choi et al. [47] (2001) & $\mathrm{CuO}$ & 30 \\
\hline
\end{tabular}

\subsection{Effects of Nanoparticle Size on Nanofluid Thermal Conductivity}

Researchers have observed that a greater surface area to volume ratio in nanofluids, resulting from nanoparticles of smaller sizes, leads to increased thermal conductivity $[3,4,28,35,36]$. Wang et al. [11] measured the thermal conductivities of $\mathrm{Al}_{2} \mathrm{O}_{3}$ and $\mathrm{CuO}$ nanoparticles dispersed in water, Ethylene Glycol, engine oil, and vacuum pump fluid. Measurements were obtained using the one-dimensional steady-state parallel-plate method. An increase in thermal conductivity with the decrease of nanoparticle size was observed. It was suggested that this relationship could be partially explained by stochastic and electrostatic forces only, having a strong influence on very small particles. Also, Park et al. [7] measured the thermal conductivity of graphene-water nanofluid, using $5000 \mathrm{~nm}$ graphene, 15,000 $\mathrm{nm}$ graphene, and oxidized $5000 \mathrm{~nm}$ graphene. The thermal conductivity of the 
$5000 \mathrm{~nm}$ graphene nanofluid was higher for a given nanoparticle volume concentration. It was suggested that the thermal conductivity of nanofluids increases with the decrease of nanoparticle size. In addition, Patel et al. [28] measured the thermal conductivities of $\mathrm{Al}_{2} \mathrm{O}_{3}$-water and $\mathrm{Al}_{2} \mathrm{O}_{3}$-Ethylene Glycol nanofluids as a function of nanoparticle size. The results, which are shown in Figure 8, indicated an increase in thermal conductivity with the decrease of nanoparticle size. It was suggested that the thermal conductivity enhancement was a result of the increased surface area to volume ratio, $\mathrm{A} / \mathrm{V}$, with the decrease of nanoparticle size, allowing more effective heat transfer to the base fluid. It was also suggested that increased Brownian motion with smaller nanoparticles led to the increased thermal conductivity. It was observed that the magnitude of Brownian motion was on the order of $10^{-4}(\mathrm{~m} / \mathrm{s})$ for $\mathrm{Al}_{2} \mathrm{O}_{3}$-water nanofluid containing $150 \mathrm{~nm}$ particles and increased to the order of $10^{-2}(\mathrm{~m} / \mathrm{s})$ for $\mathrm{Al}_{2} \mathrm{O}_{3}$-water nanofluid containing $11 \mathrm{~nm}$ particles. Using a KD2 Pro Thermal Property Analyzer, Esfe et al. [3] measured the thermal conductivity of Fe-water nanofluid as a function of nanoparticle volume concentration $(\varphi)$, using $37 \mathrm{~nm}, 71 \mathrm{~nm}$, and $98 \mathrm{~nm}$ Fe particles. The KD2 Pro Thermal Property Analyzer works based on the transient short hot-wire method. It was observed that for a given $\varphi$, the thermal conductivity increased with the decrease of nanoparticle size. It was suggested that this increase was caused by the increased interfacial area between nanoparticles and base liquid for smaller particle sizes. Using the same method, Sharifpur et al. [42] studied the thermal conductivity of $\mathrm{Al}_{2} \mathrm{O}_{3}-$ glycerol nanofluid. Experiments were conducted using $\mathrm{Al}_{2} \mathrm{O}_{3}$ nanoparticles of three different diameters, including $31 \mathrm{~nm}, 55 \mathrm{~nm}$, and $134 \mathrm{~nm}$. The results showed a relatively significant increase in thermal conductivity with the decrease in nanoparticle size. It was suggested that this increase was related to increased Brownian motion in nanofluids containing smaller nanoparticles. The Brownian motion diffusion coefficient was calculated using the Einstein-Stokes equation. The coefficient increased as the nanoparticle size decreased, indicating more significant collisions between the nanoparticles and base liquid molecules for smaller nanoparticles, resulting in enhanced thermal conductivity. Moreover, using the KD2 Pro Thermal Analyzer, Paul et al. [35] measured the thermal conductivity of $\mathrm{Au}$-water nanofluid as a function of nanoparticle size. It was observed that the thermal conductivity increased with the decrease of nanoparticle size, which is shown in Figure 9. It was suggested that this increase was a result of increased Brownian motion and greater surface area to volume ratio for smaller nanoparticles. The thermal conductivities of $\mathrm{Ag}_{2} \mathrm{Al}$-water, $\mathrm{Ag}_{2} \mathrm{Al}$-Ethylene $\mathrm{Glycol}, \mathrm{Al}_{2} \mathrm{Cu}$-water, and $\mathrm{Al}_{2} \mathrm{Cu}$-Ethylene Glycol nanofluids were measured by Chopkar et al. [4], as a function of nanoparticle size, within the range of $30-120 \mathrm{~nm}$. The results indicated an increase in thermal conductivity with the decrease of nanoparticle size. It was suggested that this was a result of the larger surface area of nanoparticles and greater stability in suspensions in comparison to coarse particles. Pang et al. [32] measured the thermal conductivities of $\mathrm{SiO}_{2}$-methanol and $\mathrm{Al}_{2} \mathrm{O}_{3}$-methanol nanofluids as a function of nanoparticle volume concentration, $\varphi$. The $\mathrm{SiO}_{2}$ nanoparticles had diameters of 10-20 nm, and the $\mathrm{Al}_{2} \mathrm{O}_{3}$ nanoparticles had diameters of $40-50 \mathrm{~nm}$. Dynamic light scattering was used to measure the cluster sizes of the nanoparticles dispersed in methanol, and it was observed that the clustering size of $\mathrm{SiO}_{2}$ nanoparticles was $280-401 \mathrm{~nm}$, while that of the $\mathrm{Al}_{2} \mathrm{O}_{3}$ nanoparticles was $120-148 \mathrm{~nm}$ for a given condition. It was suggested that the larger formation of clusters in the $\mathrm{SiO}_{2}$ nanofluid was a result of the smaller size of $\mathrm{SiO}_{2}$ nanoparticles in comparison to the $\mathrm{Al}_{2} \mathrm{O}_{3}$ nanoparticles. It was observed that for a given $\varphi$, the $\mathrm{SiO}_{2}$-methanol nanofluid had a higher thermal conductivity. It was suggested that the higher thermal conductivity of $\mathrm{SiO}_{2}$-methanol nanofluid was a result of the larger cluster size of the nanoparticles in comparison to the clusters formed in the $\mathrm{Al}_{2} \mathrm{O}_{3}$-methanol nanofluid. Yoo et al. [36] measured the thermal conductivities of $\mathrm{TiO}_{2}$-water, $\mathrm{Al}_{2} \mathrm{O}_{3}$-water, Fe-Ethylene Glycol, and $\mathrm{WO}_{3}$-Ethylene Glycol nanofluids as a function of nanoparticle volume concentration, $\varphi$. It was observed that $\mathrm{TiO}_{2}$-water nanofluid had a higher thermal conductivity than $\mathrm{Al}_{2} \mathrm{O}_{3}$-water nanofluid for a given $\varphi$. It was also observed that Fe-Ethylene Glycol nanofluid had a higher thermal conductivity than $\mathrm{WO}_{3}-$ Ethylene Glycol nanofluid for a given $\varphi$. $\mathrm{TiO}_{2}$ has a lower intrinsic thermal conductivity than $\mathrm{Al}_{2} \mathrm{O}_{3}$; however, the $\mathrm{TiO}_{2}$ nanoparticles $\left(25 \mathrm{~nm}\right.$ ) were smaller in size than the $\mathrm{Al}_{2} \mathrm{O}_{3}$ nanoparticles $(48 \mathrm{~nm})$, resulting in a higher thermal conductivity for $\mathrm{TiO}_{2}$ nanofluid. It was also suggested that 
the smaller size of the Fe nanoparticles $(10 \mathrm{~nm})$ in comparison to that of the $\mathrm{WO}_{3}$ nanoparticles (38 $\mathrm{nm}$ ) contributed to the higher thermal conductivity of Fe-Ethylene Glycol nanofluid in comparison to that of $\mathrm{WO}_{3}$-Ethylene Glycol nanofluid. It was stated that these results showed the strong effect of surface area-to-volume ratio of nanoparticles on the thermal conductivity of nanofluids [36]. Using the transient hot-wire method, Maheshwary et al. [25] conducted experiments to determine the thermal conductivity of $\mathrm{TiO}_{2}$-water nanofluid. It was observed that the thermal conductivity increased with decrease in nanoparticle size. It was suggested that this relationship was related to greater Brownian motion for smaller nanoparticles. Xia et al. [20] measured the thermal conductivities of $\mathrm{Al}_{2} \mathrm{O}_{3}$-water nanofluids, using $13 \mathrm{~nm}$ and $20 \mathrm{~nm} \mathrm{Al}_{2} \mathrm{O}_{3}$ particles, containing both sodium dodecyl sulphate (SDS) and polyvinyl pyrrolidone (PVP) as surfactants. For a given surfactant concentration, it was observed that the nanofluids containing $13 \mathrm{~nm}$ particles had higher thermal conductivities. However, in some cases, researchers found that the thermal conductivity of nanofluids did not increase with the decrease in nanoparticle size. Xie et al. [48] measured the thermal conductivities of $\mathrm{Al}_{2} \mathrm{O}_{3}$-Ethylene Glycol nanofluids containing $5 \mathrm{~nm}, 25 \mathrm{~nm}, 58 \mathrm{~nm}$, and $101 \mathrm{~nm}$ particles using the transient hot-wire method. It was observed that the thermal conductivities of the nanofluids, from highest to lowest, were those containing $25 \mathrm{~nm}$ particles, $5 \mathrm{~nm}$ particles, $58 \mathrm{~nm}$ particles, and finally $101 \mathrm{~nm}$ particles. It was suggested that these results were caused by a combination of the surface area to volume ratio and phonon scattering. The scattering of the primary carriers of energy at the boundaries of nanoparticles is called phonon scattering [48]. As the nanoparticle size decreases, the surface area to volume ratio increases, which allows for more effective heat transfer at the solid-liquid interface, leading to increased thermal conductivity. However, the intrinsic thermal conductivity of the nanoparticles decreases due to phonon scattering when the nanoparticle size is close to that of the mean free path, which was estimated to be around $35 \mathrm{~nm}$. Although existing experimental data indicates that the effect of nanoparticle material on the thermal conductivity of nanofluids is not very strong $[26,32,36]$, it was suggested that phonon scattering had a significant impact on these experimental results. Beck et al. [49] measured the thermal conductivities of nanofluids composed of $8 \mathrm{~nm}, 12 \mathrm{~nm}, 16 \mathrm{~nm}, 46 \mathrm{~nm}, 71 \mathrm{~nm}$, $245 \mathrm{~nm}$, and $282 \mathrm{~nm} \mathrm{Al}{ }_{2} \mathrm{O}_{3}$ particles dispersed in water, and $12 \mathrm{~nm}, 16 \mathrm{~nm}, 245 \mathrm{~nm}$, and $282 \mathrm{~nm}$ $\mathrm{Al}_{2} \mathrm{O}_{3}$ particles dispersed in Ethylene Glycol using a liquid metal transient hot-wire device. It was observed that the thermal conductivity was almost constant with the decrease in nanoparticle size for nanofluids containing nanoparticles with a size greater than $50 \mathrm{~nm}$. For nanofluids containing particles having a size smaller than approximately $50 \mathrm{~nm}$, it was observed that the thermal conductivity of the nanofluid decreased with decrease in nanoparticle size. It was suggested that this was a result of the decreased intrinsic thermal conductivity of nanoparticles when the nanoparticles became small enough to be affected by phonon scattering. Nisha et al. [50] measured the thermal conductivities of nanofluids composed of $\mathrm{TiO}_{2}$ nanoparticles dispersed in water and polyvinyl alcohol (PVA) as a function of nanoparticle size, for nanoparticles, ranging from 5-100 nm. It was observed that the thermal conductivity of $\mathrm{TiO}_{2}-\mathrm{PVA}$ nanofluid increased with the decrease of nanoparticle size. It was suggested that this increase was a result of liquid adsorption layers forming around the surfaces of the nanoparticles. At smaller nanoparticles sizes, the adsorption layers formed an easy path for heat transfer, due to the large surface area to volume ratio of the nanoparticles and the high viscosity of the base fluid. As the nanoparticle size increased, the adsorption layers became thinner, making a less effective heat transfer path. It was also suggested that Kapitza resistance led to the decrease in thermal conductivity at larger nanoparticle sizes, due to thermal waves scattering at the base liquid-nanoparticle boundaries. However, it was observed that the thermal conductivity of $\mathrm{TiO}_{2}-\mathrm{water}$ nanofluid increased with increased nanoparticle size. It was suggested that this increase was caused by nanoparticle clustering. The conflicting relationships between PVA- and water-based nanofluids were explained by the higher viscosity of PVA in comparison to water allowing a thicker adsorption layer to form around the nanoparticles. From the experimental observations discussed above, it can be suggested that smaller nanoparticle size leads to increased thermal conductivity. However, more 
experimentation should be completed to determine the significance of phonon scattering in nanofluid thermal conductivity.

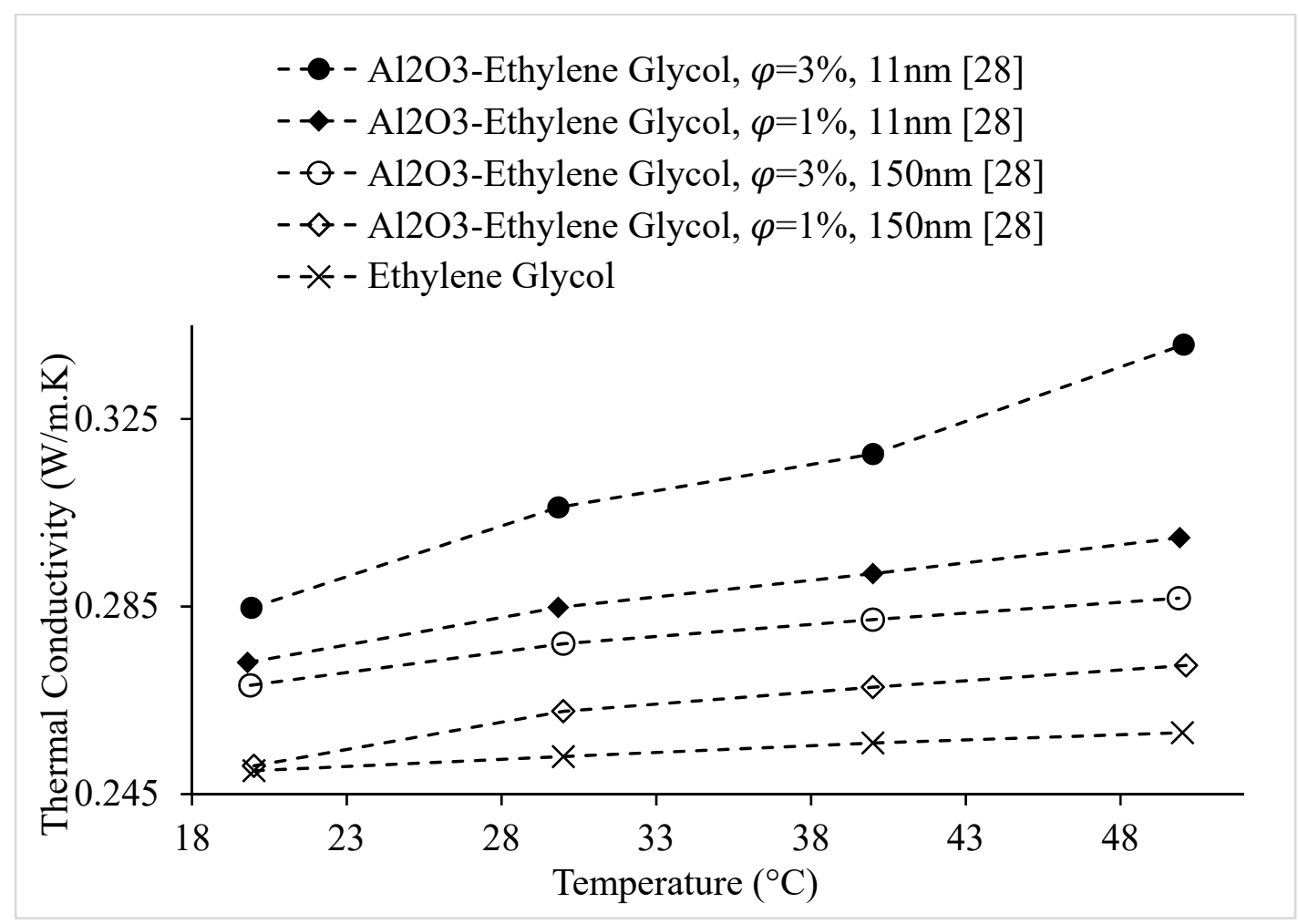

Figure 8. Variation of $\mathrm{Al}_{2} \mathrm{O}_{3}$-Ethylene Glycol nanofluid thermal conductivity as a function of temperature, for $\varphi=1 \%$ and $\varphi=3 \%$, with $11 \mathrm{~nm}$ diameter and $150 \mathrm{~nm}$ diameter particles.

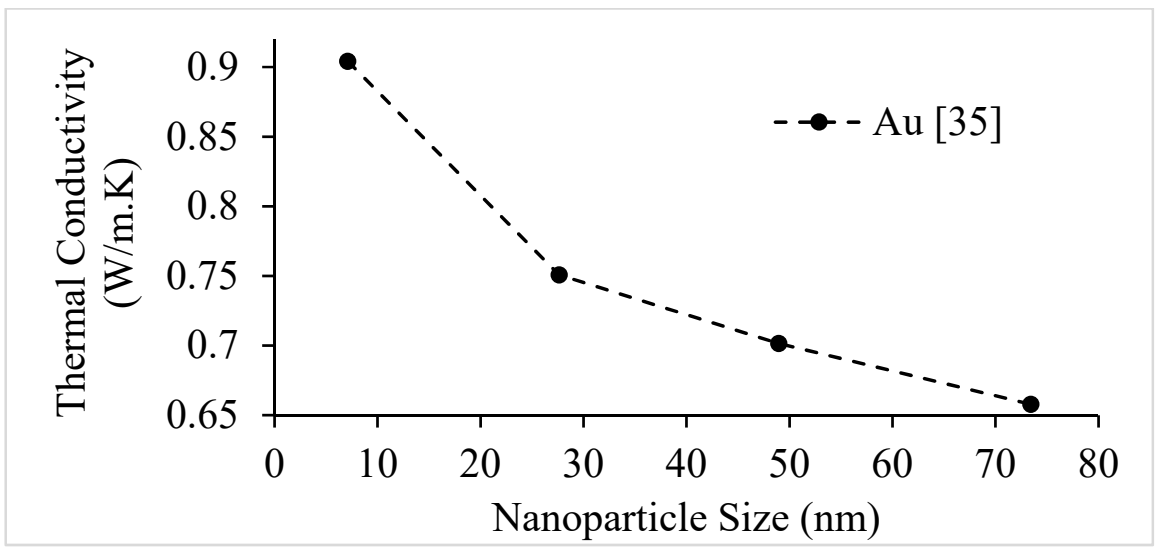

Figure 9. Variation of $\mathrm{Au}$-water nanofluid thermal conductivity at room temperature as a function of nanoparticle size, for a nanoparticle volume concentration of $\varphi=0.00026 \%$.

\subsection{Effects of Nanoparticle Shape on Nanofluid Thermal Conductivity}

Researchers have observed that nanofluids having nanoparticles with greater surface area to volume ratios, have higher thermal conductivities [25,43]. Maheshwary et al. [25] studied the thermal conductivity of $\mathrm{TiO}_{2}$-water nanofluid using cubic $(51.87 \mathrm{~nm})$, rod $(43.08 \mathrm{~nm})$, and spherical $(22.9 \mathrm{~nm})$ nanoparticles. It was observed that the nanofluid containing cubic nanoparticles had the highest thermal conductivity and that containing spherical nanoparticles had the lowest, which is shown in Figure 10. It was suggested that the significant impact of nanoparticle shape on thermal conductivity was related to the difference in surface area. Some benefits of using spherical nanoparticles in nanofluids include 
their superior stability to other shapes and fewer issues with clogging. A downside to using cubic nanoparticles is high cost. Similarly, using the transient hot-wire method, Murshed et al. [16] tested the thermal conductivity of $\mathrm{TiO}_{2}$-water nanofluid containing rod-shaped and spherical nanoparticles. The spherical nanoparticles had an average diameter of $15 \mathrm{~nm}$. The rod-shaped nanoparticles had an average diameter of $10 \mathrm{~nm}$ and an average length of $40 \mathrm{~nm}$. Cetyl trimethyl ammonium bromide (CTAB) was used as a surfactant to create a more stable nanofluid. For a given particle concentration, it was observed that the nanofluid containing rod-shaped nanoparticles had a higher thermal conductivity. It was suggested that this difference was related to the larger size of the rod-shaped nanoparticles in comparison to the spherical nanoparticles. Kim et al. [24] measured the thermal conductivity of $\mathrm{Al}_{2} \mathrm{O}_{3}$-water nanofluid, using brick, platelet, and blade shaped nanoparticles. It was observed that nanofluid containing brick-shaped nanoparticles had the highest enhancement in thermal conductivity, while nanofluid containing blade-shaped nanoparticles had the lowest. It was suggested that thermal conductivity is related to suspension stability which is affected by nanoparticle shape. The nanofluid containing brick-shaped nanoparticles had the highest stability, while nanofluid containing blade-shaped nanoparticles had the lowest stability. Timofeeva et al. [43] measured the thermal conductivity of nanofluid composed of $\mathrm{Al}_{2} \mathrm{O}_{3}$ nanoparticles dispersed in 50:50 volume Ethylene Glycol-water using the transient hot-wire method. It was observed that nanofluid containing cylinder-shaped nanoparticles $(80 \times 10 \mathrm{~nm})$ had the highest thermal conductivity, followed by that containing brick-shaped nanoparticles $(40 \mathrm{~nm})$. The nanofluid containing blade-shaped $(60 \times 10 \mathrm{~nm})$ nanoparticles had a lower thermal conductivity than those of cylindrical and brick-shaped nanofluids. It was suggested that increased nanoparticle surface area leads to higher thermal conductivity. Jeong et al. [40] conducted experiments to determine the thermal conductivity of $\mathrm{ZnO}$-water nanofluid using both spherical and rectangular nanoparticles. The results are shown in Figure 11. The spherical nanoparticles had an average size of 20-40 nm, and rectangular nanoparticles had an average size of 90-210 nm. For a given volume fraction and temperature, the thermal conductivity of nanofluid containing rectangular nanoparticles was higher. It was suggested that the relationship between thermal conductivity and nanoparticle shape was related to the change in effective aggregate radius of the nanofluid with the change of nanoparticle shape. It was suggested that nanoparticle shape has a stronger influence on thermal conductivity than nanoparticle size. From the above discussed experimental observations, it can be concluded the nanoparticles having greater surface area lead to higher nanofluid thermal conductivity. However, further experimentation should be completed in order to determine the effects of nanoparticle shape on nanofluid stability.

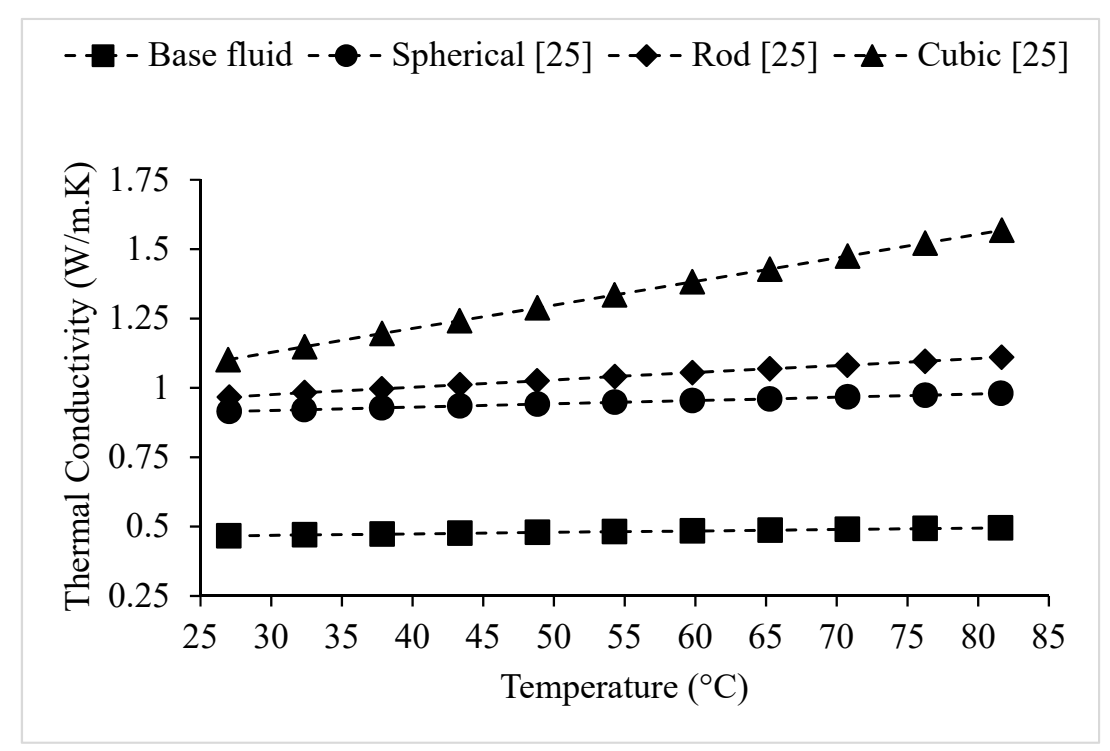

Figure 10. Effect of nanoparticle shape on the thermal conductivity of $\mathrm{TiO}_{2}$-water nanofluid at $\varphi=2.5 \%$, as a function of temperature. 


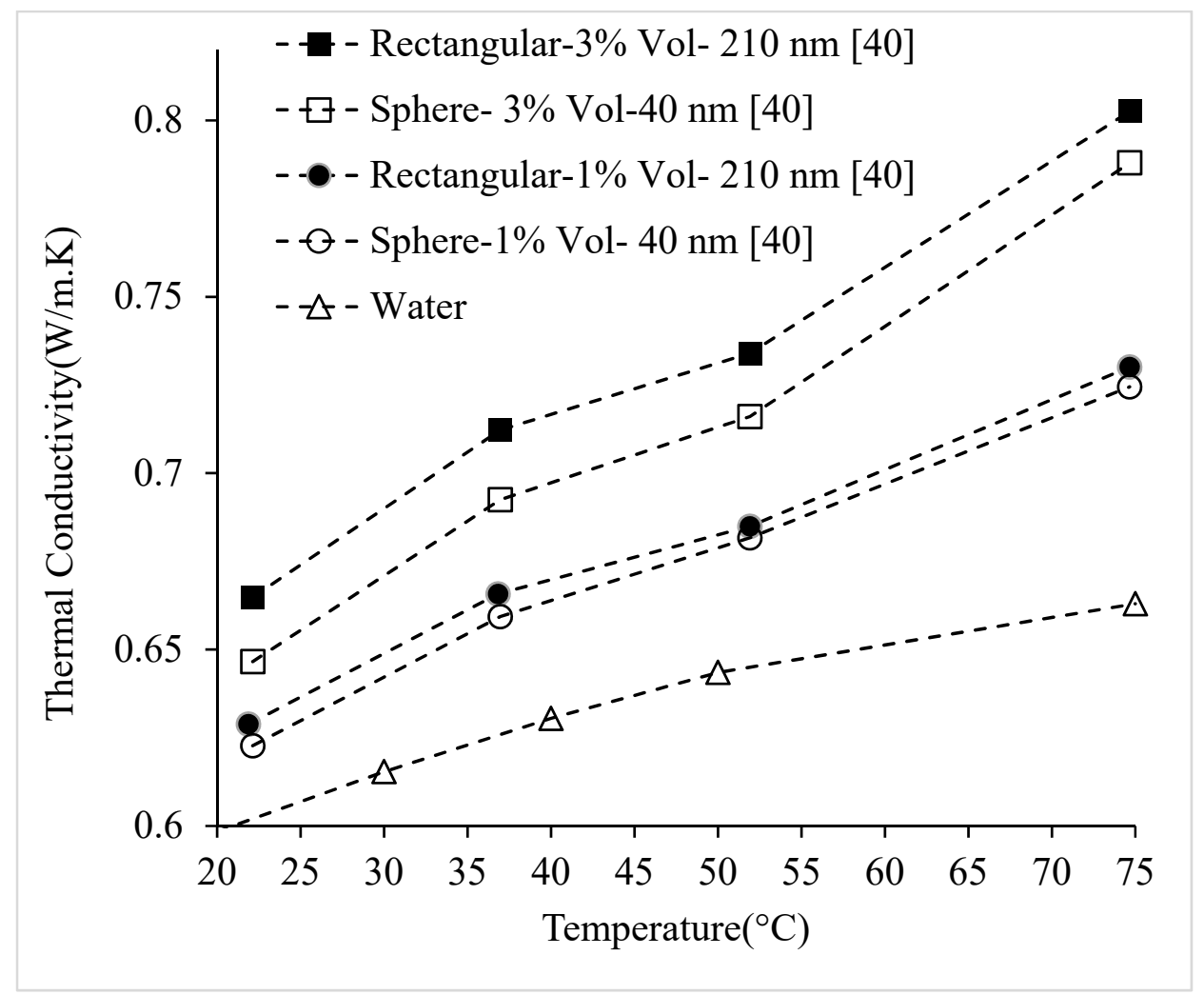

Figure 11. Effect of nanoparticle shape on the thermal conductivity of $\mathrm{ZnO}$-water nanofluid as a function of temperature.

\subsection{Effects of Base Liquid on Nanofluid Thermal Conductivity}

Researchers have observed that the thermal conductivity of nanofluids increases with the thermal conductivity of the base liquid [3,9-15]. For example, Barbés et al. [9] measured the thermal conductivities of $\mathrm{CuO}$-water and $\mathrm{CuO}$-Ethylene Glycol nanofluids. It was observed that for a given volume fraction and temperature, the thermal conductivity of $\mathrm{CuO}$-water nanofluid was higher. Also, Agarwal et al. [10] measured the thermal conductivities of $\mathrm{CuO}$ nanofluids, mixing $\mathrm{CuO}$ nanoparticles with water, Ethylene Glycol, and engine oil. The results are shown in Figure 12. The observations agreed with those of Barbés et al. [9], with the thermal conductivity of CuO-water nanofluid being higher than that of CuO-Ethylene Glycol nanofluid. The results showed that $\mathrm{CuO}-$ engine oil nanofluid had the lowest thermal conductivity. It was suggested that the variation in nanofluid thermal conductivity with different base fluids was related to the different thermal conductivities of the base fluids and the strength of interactions between the $\mathrm{CuO}$ nanoparticles and base fluids [10]. Wang et al. [11] measured the thermal conductivities of $\mathrm{CuO}-$ water, $\mathrm{CuO}-\mathrm{Ethylene}$ Glycol, $\mathrm{Al}_{2} \mathrm{O}_{3}$-water, $\mathrm{Al}_{2} \mathrm{O}_{3}$-Ethylene Glycol, $\mathrm{Al}_{2} \mathrm{O}_{3}$-pump fluid, and $\mathrm{Al}_{2} \mathrm{O}_{3}$-engine oil nanofluids. The observations also reinforced the findings of Barbés et al. [9] and Agarwal et al. [10], with the thermal conductivities of water-based nanofluids being higher than those of Ethylene Glycol-based nanofluids for both $\mathrm{CuO}$ and $\mathrm{Al}_{2} \mathrm{O}_{3}$ nanoparticles, at a given volume fraction. $\mathrm{Al}_{2} \mathrm{O}_{3}$-engine oil and $\mathrm{Al}_{2} \mathrm{O}_{3}$-Pump Fluid nanofluids had lower thermal conductivities than $\mathrm{Al}_{2} \mathrm{O}_{3}$-Ethylene Glycol nanofluid. The thermal conductivity of $\mathrm{Al}_{2} \mathrm{O}_{3}$-engine oil nanofluid was slightly higher than that of the pump fluid-based nanofluid. It was suggested that the thermal conductivity of a nanofluid increases with the thermal conductivity of the base liquid [11]. Additionally, Agarwal et al. [12] observed that the thermal conductivity of $\mathrm{Al}_{2} \mathrm{O}_{3}$-water nanofluid was higher than that of $\mathrm{Al}_{2} \mathrm{O}_{3}$-Ethylene Glycol nanofluid, which agrees with the findings of Wang et al. [11]. Chopkar et al. [4] measured the thermal conductivities of $\mathrm{Al}_{2} \mathrm{Cu}$ and $\mathrm{Ag}_{2} \mathrm{Al}$ nanoparticles dispersed in Ethylene Glycol and water. It was again observed that water-based nanofluids had higher thermal conductivities than Ethylene 
Glycol-based nanofluids [4]. Sundar et al. [13] measured the thermal conductivity of magnetic $\mathrm{Fe}_{3} \mathrm{O}_{4}$ nanoparticles dispersed in 20\%:80\%, 40\%:60\% and 60\%:40\% by weight Ethylene Glycol-water mixtures. The results, shown in Figure 13, indicated that the thermal conductivity decreased as the amount of Ethylene Glycol in the mixture increased. It was suggested that this was a result of the lower thermal conductivity of Ethylene Glycol in comparison to water. Additionally, Sundar et al. [14] measured the thermal conductivity of nanodiamond particles dispersed in $20 \%: 80 \%, 40 \%: 60 \%$ and $60 \%: 40 \%$ by weight Ethylene Glycol-water mixtures. The results, shown in Figure 14, reinforce the results shown in Figure 13 for nanofluid containing $\mathrm{Fe}_{3} \mathrm{O}_{4}$ particles. Yu et al. [15] studied the variation of thermal conductivity as a function of temperature for aluminum nitride-Ethylene Glycol and aluminum nitride-propylene glycol nanofluids in comparison to that of the base liquids (Ethylene Glycol and propylene glycol). The thermal conductivity of aluminum nitride-Ethylene Glycol nanofluid was higher for a given temperature, which is consistent with the conclusion that the thermal conductivity of a nanofluid increases with the thermal conductivity of the base liquid. The thermal conductivities of the nanofluids were higher than that of the base fluids for a given temperature. The slope of the thermal conductivity as a function of temperature for each nanofluid and respective base fluid were nearly the same.

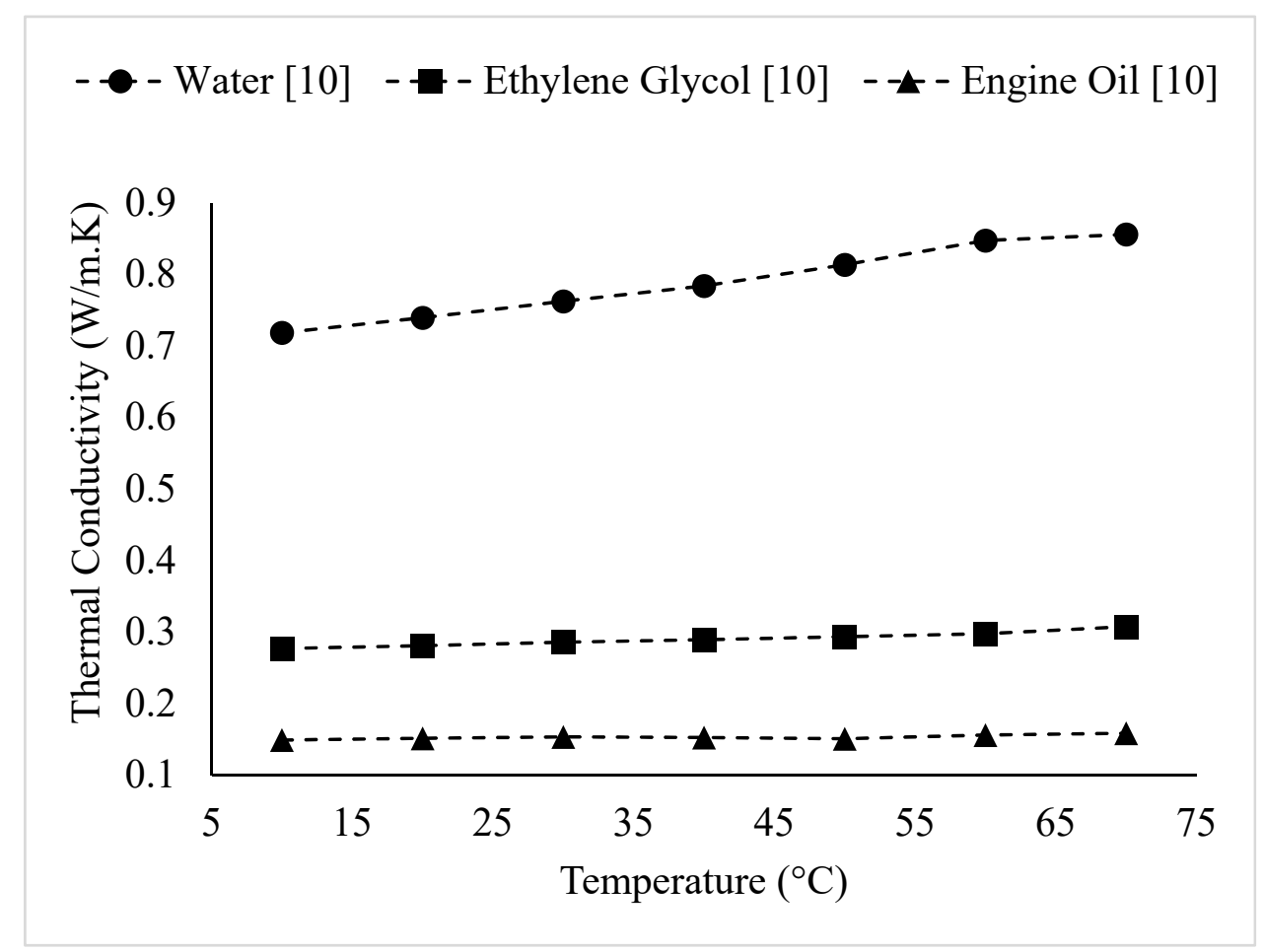

Figure 12. Variation of $\mathrm{CuO}$ nanofluid thermal conductivity as a function of temperature for different base liquids, at $\varphi=2 \%$. 


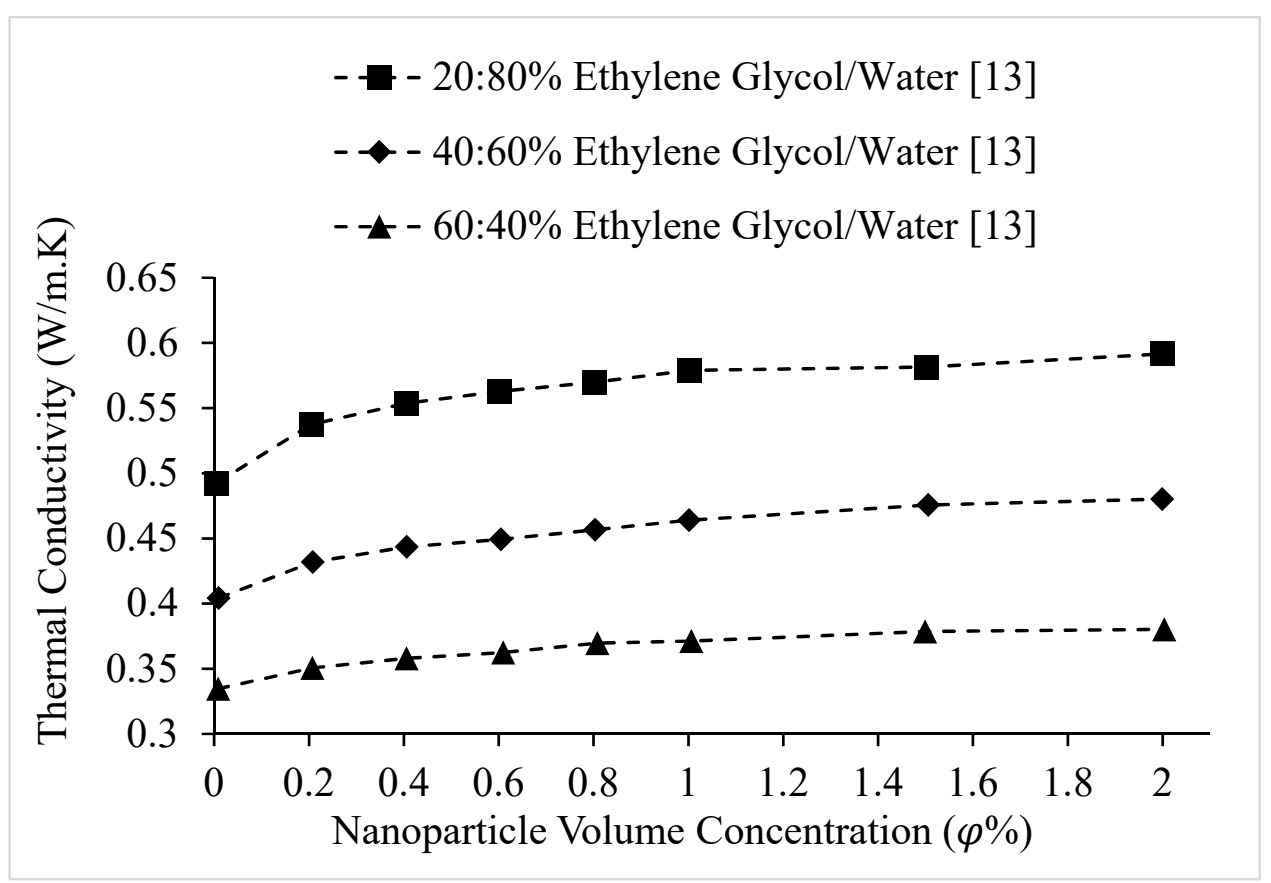

Figure 13. Variation of $\mathrm{Fe}_{3} \mathrm{O}_{4}$ nanofluid thermal conductivity as a function of nanoparticle volume fraction, $\varphi$, for different weight concentrations of Ethylene Glycol/water base liquid, at $20^{\circ} \mathrm{C}$.

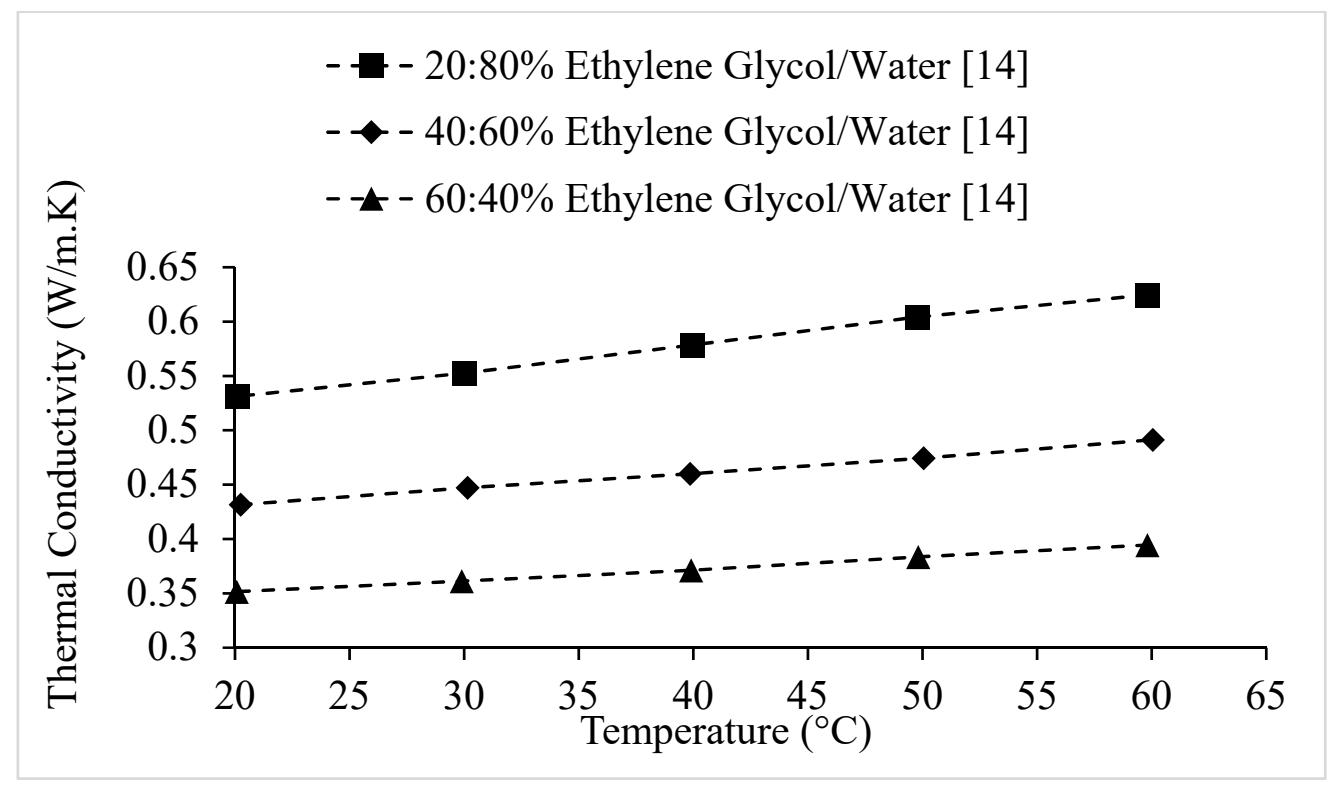

Figure 14. Variation of nanodiamond nanofluid thermal conductivity as a function of temperature, for different weight concentrations of Ethylene Glycol/water base liquid, at $\varphi=1 \%$.

Figures 15 and 16 show that the thermal conductivity of the base liquid has a significant impact on nanofluid thermal conductivity enhancement. The thermal conductivities of nanofluids composed of $\mathrm{CuO}$ nanoparticles dispersed in various base liquids are shown in Figure 16 as a function of nanoparticle volume concentration, $\varphi$. The thermal conductivities of the base fluids are shown at $\varphi=0 \%$. It is observed that the thermal conductivity of nanofluids increases with the thermal conductivity of the base fluid. The low rate of increase in thermal conductivity with concentration for engine oil-based nanofluid may be a result of weak interactions between the $\mathrm{CuO}$ nanoparticles and engine oil causing a weak interfacial layer. The observations of Figure 16 are reinforced by Figure 15. Figure 15 shows the thermal conductivities of nanofluids composed of $\mathrm{Al}_{2} \mathrm{O}_{3}$ nanoparticles dispersed 
in various base liquids as a function of nanoparticle volume concentration, $\varphi$. The thermal conductivity of base liquids is given in Table 2 .

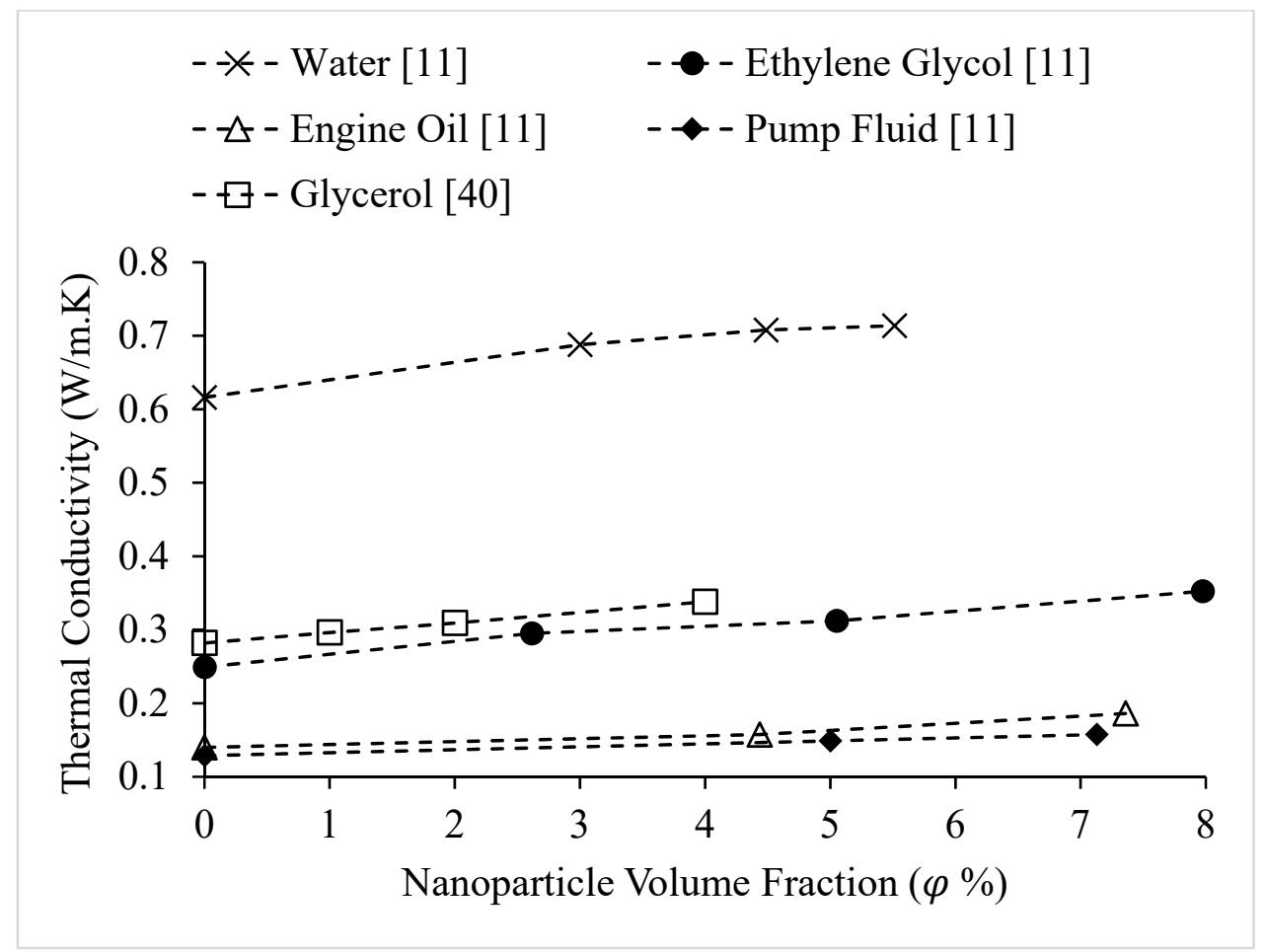

Figure 15. Variation of alumina nanofluid thermal conductivity as a function of nanoparticle volume fraction, $\varphi$, for different base liquids, at room temperature.

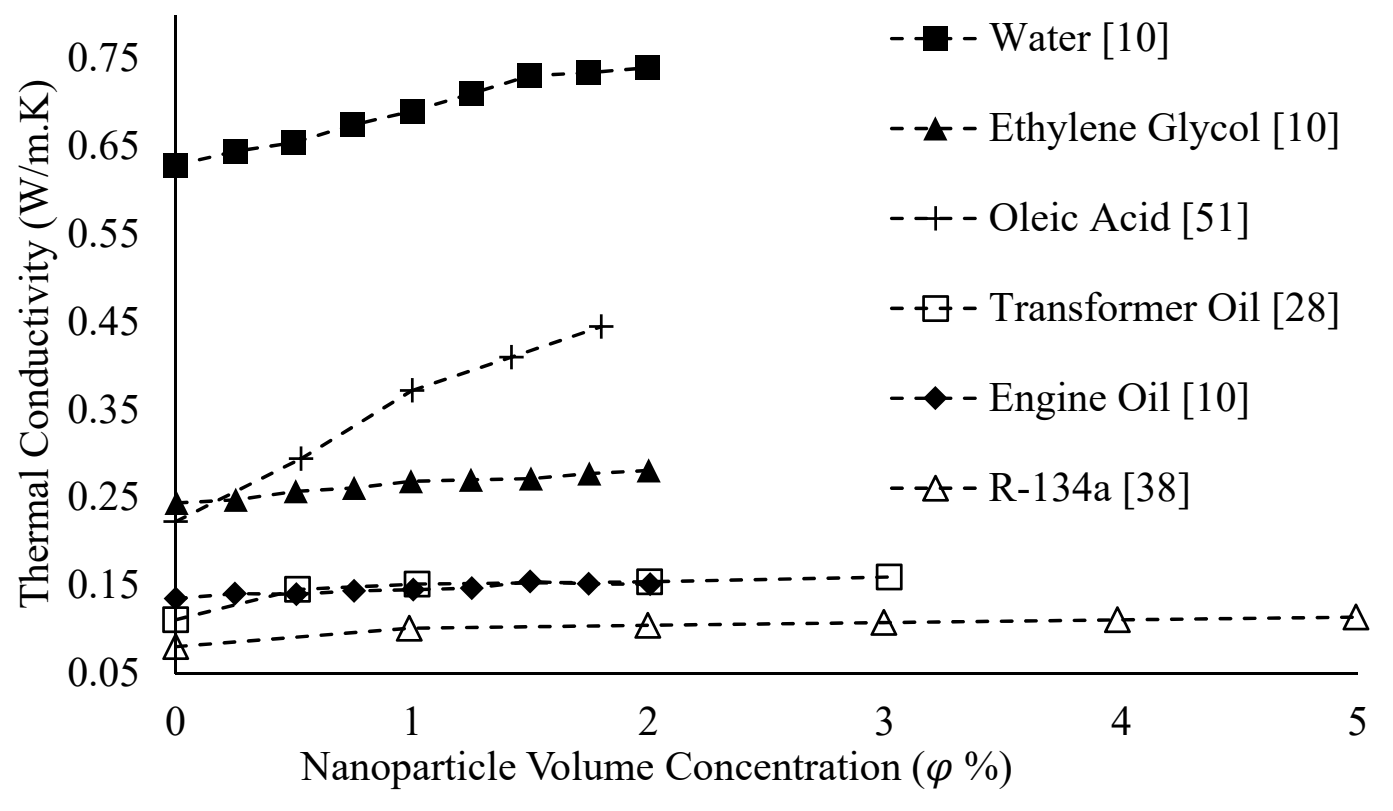

Figure 16. Variation of $\mathrm{CuO}$ nanofluid thermal conductivity as a function of nanoparticle volume fraction, $\varphi$, for different base liquids, at room temperature. 
Table 2. Thermal conductivity of base liquids.

\begin{tabular}{cccc}
\hline Reference & Base Liquid & Temperature $\left({ }^{\circ} \mathbf{C}\right)$ & Thermal Conductivity (W/m.K) \\
\hline Wang et al. [11] (1999) & Pump Fluid & 24 & 0.1287 \\
\hline Sharifpur et al. [42] (2017) & Glycerol & 20 & 0.2837 \\
\hline & & 20 & 0.111 \\
Patel et al. [28] (2010) & Transformer Oil & 30 & 0.11 \\
& & 40 & 0.109 \\
& & 50 & 0.108 \\
\hline & & 10 & 0.6136 \\
& & 20 & 0.6286 \\
& & 30 & 0.6396 \\
& & 40 & 0.6578 \\
& & 50 & 0.6714 \\
& & 60 & 0.6825 \\
& & 70 & 0.6948 \\
\hline \multirow{2}{*}{ Agarwal et al. [10] (2016) } & & 10 & 0.2408 \\
& & 20 & 0.2438 \\
& & 30 & 0.2459 \\
& & 40 & 0.2479 \\
& & 50 & 0.2494 \\
& & 60 & 0.2512 \\
& & 70 & 0.2533 \\
\hline & & 10 & 0.1389 \\
& & 20 & 0.1399 \\
& & 30 & 0.1407 \\
& & 40 & 0.1419 \\
& & 50 & 0.143 \\
& & 60 & 0.143 \\
& & 70 & 0.146 \\
\hline & & 27 & 0.0803 \\
\hline
\end{tabular}

\subsection{Effects of Surfactant on Nanofluid Thermal Conductivity}

Scientists have studied the effects of various surfactants on the thermal conductivity of nanofluids [16-23]. Surfactant was mixed with the base liquid of various nanofluids in order to produce a uniform distribution of nanoparticles, and to prevent the agglomeration of nanoparticles. The high surface energy of nanoparticles leads to agglomeration and settling, thus resulting in a lack of stability in nanofluids. Low stability in nanofluids leads to low thermal conductivity. Thus, surfactants are added with the goal of creating more stable nanofluids, and in turn increasing the thermal conductivity [18]. Several researchers have observed that surfactants aid in preventing the agglomeration of nanoparticles but can lead to decrease thermal conductivity at higher concentrations. Using the transient hot-wire method, Murshed et al. [16] measured the thermal conductivity of $\mathrm{TiO}_{2}$-water nanofluid using oleic acid $(\mathrm{OA})$ and $C T A B$ as surfactants. The surfactants were used at very low concentrations, between 0.01 and 0.02 volume percent, in order to avoid altering the heat transfer characteristics of the nanofluid. CTAB was found to be a more effective surfactant in producing a stable nanofluid, by preventing nanoparticle clustering and in turn creating a homogeneous distribution of nanoparticles throughout the base liquid. Using a KD2 Pro Thermal Property Analyzer, Khairul et al. [17] measured the thermal conductivities of $\mathrm{CuO}-$ water and $\mathrm{Al}_{2} \mathrm{O}_{3}$-water nanofluids containing sodium dodecyl benzene sulfonate (SDBS) surfactant as a function of surfactant weight concentration. The addition of the negatively charged surfactant altered the surface charges of the positively charged $\mathrm{CuO}$ and $\mathrm{Al}_{2} \mathrm{O}_{3}$ nanoparticles, creating repulsion forces between the nanoparticles. The repulsion forces prevented clustering of the nanoparticles, and in turn led to a more stable nanofluid with higher thermal conductivity. It was suggested that ideal thermo-physical properties can be obtained by creating optimal surface charges on the nanoparticles. It was observed that the thermal conductivity of the nanofluid increased up to $0.1 \mathrm{~W} \%$ for $\mathrm{Al}_{2} \mathrm{O}_{3}$-water nanofluid, and up to $0.15 \mathrm{~W} \%$ for $\mathrm{CuO}$-water nanofluid. Above these concentrations, the thermal conductivity of the nanofluid decreased significantly. It was suggested that this decrease was caused by the greater 
amount of surfactant on the surfaces of the nanoparticles leading to a narrower available area for heat transfer. Wang et al. [18] measured the thermal conductivities of $\mathrm{Al}_{2} \mathrm{O}_{3}$-water and $\mathrm{Cu}$-water nanofluids containing SDBS surfactant. Measurements were obtained using a hot-disk thermal constant analyzer, which worked based on the transient plane source method. It was observed that higher stability in a nanofluid leads to higher thermal conductivity. It was suggested that finding the optimal $\mathrm{pH}$ and surfactant concentration can lead to increased thermal conductivity by altering the surface charges of the nanoparticles to prevent agglomeration. The thermal conductivity was measured as a function of surfactant concentration. It was observed that the thermal conductivity increased with surfactant concentration up to approximately $0.03 \mathrm{~W} \%$ surfactant for both nanofluids. Above this concentration, the thermal conductivity decreased with the increase of surfactant concentration. It was suggested that this decrease was caused by the amount of surfactant on the surfaces of the nanoparticles allowing a narrow area for heat transfer. Using a KD2 Pro Thermal Property Analyzer, Adabi et al. [19] measured the thermal conductivity of $\mathrm{Mg}(\mathrm{OH})_{2}$-water nanofluid. The stability of the nanofluid was tested using CTAB, SDS, and $\mathrm{OA}$ as surfactants at volume fractions of $0.02 \%$. It was observed that CTAB surfactant produced the most stable nanofluid. The nanofluid containing CTAB surfactant remained stable over a 30 days period, during which it was observed. $\mathrm{Mg}(\mathrm{OH})_{2}$-water nanofluid without surfactant only remained stable for 1 day. The thermal conductivity of the nanofluid without surfactant was not measured. However, it was suggested that due to the increase in stability of the nanofluid with the addition of surfactant, the thermal conductivity of $\mathrm{Mg}(\mathrm{OH})_{2}$-water nanofluid containing CTAB surfactant would be higher than that without. Xia et al. [20] measured the thermal conductivity of $\mathrm{Al}_{2} \mathrm{O}_{3}$-water nanofluid containing SDS and polyvinylpyrrolidone (PVP) as surfactants. Measurements were obtained using a hot-disk thermal constant analyzer. It was observed that the thermal conductivity of the base liquid, water, decreased with increasing surfactant concentration, for both SDS and PVP. The thermal conductivity of water decreased more rapidly with the increased concentration of PVP surfactant, in comparison to the addition of SDS surfactant. It was suggested that this difference was caused by the longer alkyl chain in the PVP solution. It was observed that the thermal conductivity of $\mathrm{Al}_{2} \mathrm{O}_{3}$-water nanofluid increased with the surfactant concentration up to a maximum point, and then began to decrease. It was suggested that this decrease was caused by supersaturated adsorption leading to weaker heat transfer between the nanoparticles, and greater amounts of surfactant on the nanoparticle surfaces, allowing a narrower area for heat transfer. It was observed that both surfactants improved the stability of the nanofluid by forming a layer on the surfaces of the nanoparticles which prevented agglomeration. Using the transient hot-wire method, Colangelo et al. [21] measured the thermal conductivities of $\mathrm{Al}_{2} \mathrm{O}_{3}$-therminol 66 nanofluid containing no surfactant and containing OA surfactant. Therminol 66 is usually applied in high temperature solar energy systems. It was observed that for the nanoparticle volume concentrations of $\varphi=0.3 \%$ and $0.7 \%$, the thermal conductivities of nanofluids containing surfactant were higher than those containing no surfactant, with a greater difference between the nanofluids with and without surfactant at $\varphi=0.3 \%$. However, for $\varphi=1 \%$, the thermal conductivity of the nanofluid containing no surfactant was higher than the thermal conductivity of the nanofluid containing surfactant. It was stated that the differences between the thermal conductivities of the nanofluids with and without surfactants were within the error of the measuring instrument for all nanoparticle volume concentrations tested. Therefore, it was suggested that the effect of surfactant on the thermal conductivity of nanofluids is negligible. It was stated that adding larger amounts of surfactant would not be beneficial in $\mathrm{Al}_{2} \mathrm{O}_{3}$-oil nanofluids, because it leads to a narrower heat transfer area, due to the amount of surfactant on the surfaces of the nanoparticles. It was observed that over a time period of 8 days, the nanofluid containing surfactant remained stable, while greater sedimentation was observed in the nanofluid containing no surfactant. It was suggested that the surfactant molecules on the surfaces of the nanoparticles created bonds between the nanoparticles and the base liquid, and limited aggregation, leading to more stable suspensions. Using a KD2 Pro Thermal Property Analyzer, Huminic et al. [39] measured the thermal conductivity of $\mathrm{FeC}$-water nanofluid as a function of temperature and nanoparticle volume concentration. Due to the carbon-rich nature of $\mathrm{FeC}$ particles, low viscosity carboxymethyl cellulose sodium salt was used as a surfactant. The surfactant 
was used in a concentration of $3 \mathrm{~g} / \mathrm{L}$. It was observed that the surfactant itself did not have a significant effect on the thermal conductivity of the base fluid. However, it was suggested that the surfactant may have indirectly influenced the thermo-physical properties of the nanofluid by improving the stability. Das et al. [33] tested the stability of $\mathrm{TiO}_{2}$-water nanofluid using CTAB, acetic acid (AA), OA, and SDS as surfactants. It was observed that only AA and CTAB surfactants produced stable nanofluids. In some cases, researchers have observed negative effects of surfactants on the thermal conductivity of nanofluids. Using a KD2 Pro Thermal Property Analyzer, Das et al. [22] measured the thermal conductivity of $\mathrm{Al}_{2} \mathrm{O}_{3}$-water nanofluid as a function of temperature and nanoparticle volume concentration. The stability of the nanofluid was tested using CTAB, SDBS, and SDS as surfactants. It was observed that SDS and CTAB surfactants did not increase stability of the nanofluid. SDBS surfactant showed the highest stability, yielding a more homogeneous distribution of nanoparticles within the base liquid. It also aided in the reduction of particle clustering. However, it was observed that the effective nanoparticle sizes were larger, due to surfactant layers on the surfaces of the nanoparticles. At a given temperature and volume fraction, the nanofluid containing SDBS surfactant had slightly lower thermal conductivity than the nanofluid containing no surfactant. Using the transient hot-wire method, Seyhan et al. [23] measured the thermal conductivities of Ag-Ethylene Glycol, Ag-hexane, and Ag-water nanofluids. OA, oleylamine, and Gum Arabic were used as surfactants to aid in stability. It was observed that surfactant had no effect on the thermal conductivities of Hexane and Ethylene Glycol. The thermal conductivity of water decreased with the addition of Gum Arabic surfactant, due to the lower thermal conductivity of the surfactant in comparison to water. From the experimental observations discussed above, it can be suggested that surfactant, when used at an optimum concentration, can create uniform, stable suspensions in a nanofluid, which in turn leads to increased thermal conductivity. However, further experimentation should be completed in order to determine the optimum surfactant concentration.

The effects of various surfactants on the thermal conductivities of nanofluids composed of $\mathrm{CuO}$, $\mathrm{Cu}$, and $\mathrm{Al}_{2} \mathrm{O}_{3}$ nanoparticles dispersed in water at room temperature are shown in Figure 17. It is observed that the thermal conductivity of nanofluids increases with surfactant concentration up to a maximum value, and then decreases. The decrease in thermal conductivity at higher concentrations of surfactant may be a result of the greater amount of surfactant present on the surfaces of the nanoparticles allowing a narrower area for heat transfer. Brief discussion of effects of surfactant on thermal conductivity of nanofluids is given in Table 3.

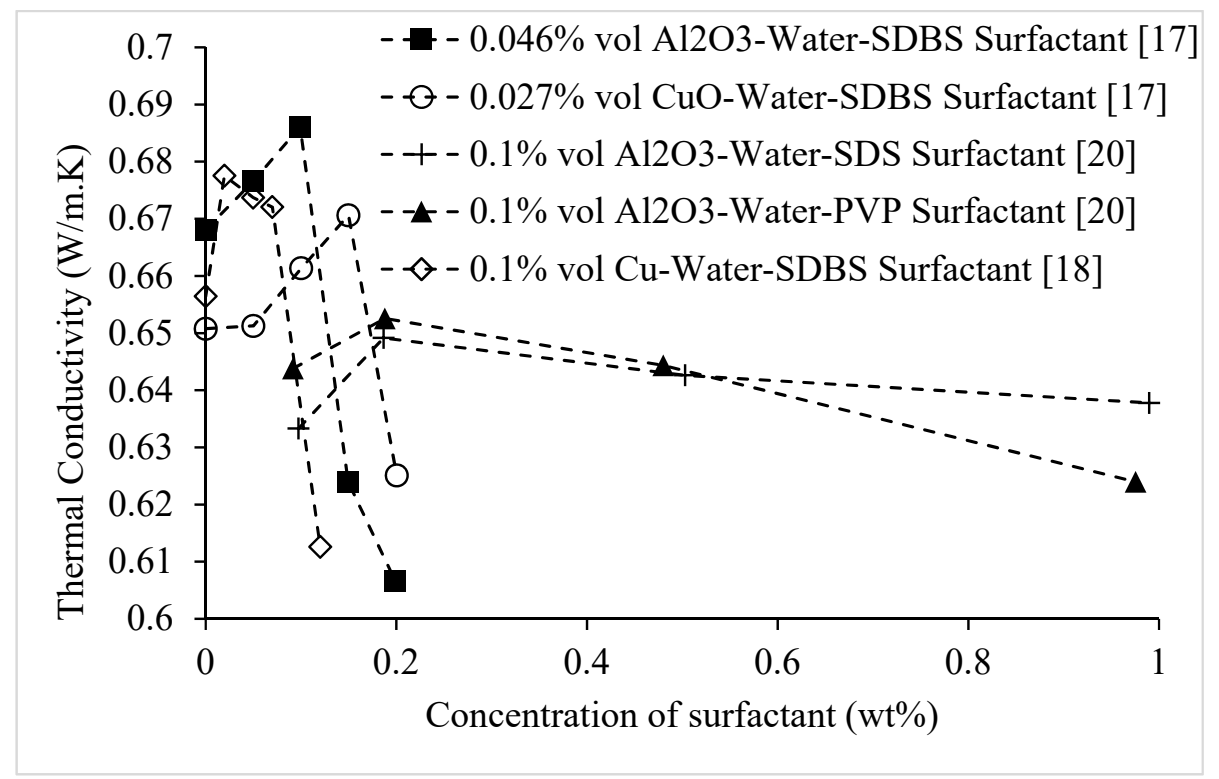

Figure 17. Effect of surfactant on the thermal conductivity of $\mathrm{CuO}$-water and $\mathrm{Al}_{2} \mathrm{O}_{3}$-water nanofluids at room temperature, as a function of surfactant weight concentration. 
Table 3. Effects of surfactant on nanofluids.

\begin{tabular}{|c|c|c|c|c|}
\hline Reference & $\begin{array}{c}\text { Nanoparticle } \\
\text { Material }\end{array}$ & Base Liquid & Surfactant & Remarks \\
\hline $\begin{array}{l}\text { Huminic et al. } \\
\text { [39] (2015) }\end{array}$ & $\mathrm{FeC}$ & Water & $\begin{array}{l}\text { Low-viscosity } \\
\text { carboxymethyl cellulose } \\
\text { sodium salt }\end{array}$ & $\begin{array}{c}\text { Due to the carbon-rich nature of the } \\
\text { nanoparticles, it was necessary to add } \\
\text { surfactant in order to create a stable } \\
\text { nanofluid. } \\
\text { The thermal conductivity of water containing } \\
\text { surfactant was nearly the same as water } \\
\text { containing no surfactant. Therefore, it was } \\
\text { suggested that the thermal conductivity of } \\
\text { the nanofluid was not affected by the } \\
\text { surfactant. }\end{array}$ \\
\hline $\begin{array}{l}\text { Das et al. [22] } \\
\quad(2017)\end{array}$ & $\mathrm{Al}_{2} \mathrm{O}_{3}$ & Water & $\begin{array}{l}\text { Cetyl trimethyl } \\
\text { ammonium bromide } \\
\text { (CTAB), sodium dodecyl } \\
\text { benzene sulfonate } \\
\text { (SDBS), sodium dodecyl } \\
\text { sulphate (SDS) }\end{array}$ & $\begin{array}{l}\text { Of the } 3 \text { surfactants tested, only SDBS } \\
\text { produced a stable nanofluid. } \\
\text { Adding SDBS surfactant resulted in a more } \\
\text { homogeneous distribution of nanoparticles } \\
\text { within the base fluid, and less clustering. } \\
\text { It was observed that surfactant layers on the } \\
\text { nanoparticle surfaces led to an increase in } \\
\text { effective nanoparticle size. } \\
\text { The thermal conductivity of nanofluid } \\
\text { containing SDBS surfactant was slightly } \\
\text { lower than nanofluid containing no } \\
\text { surfactant for a given temperature and } \\
\text { concentration. }\end{array}$ \\
\hline $\begin{array}{l}\text { Das et al. [33] } \\
\quad(2016)\end{array}$ & $\mathrm{TiO}_{2}$ & Water & $\begin{array}{l}\text { CTAB, acetic acid (AA), } \\
\text { oleic acid (OA), SDS }\end{array}$ & $\begin{array}{c}\text { Of the } 4 \text { surfactants tested, only CTAB and } \\
\text { AA produced stable nanofluids. }\end{array}$ \\
\hline $\begin{array}{l}\text { Murshed et al. } \\
\text { [16] (2005) }\end{array}$ & $\mathrm{TiO}_{2}$ & Water & CTAB, OA & $\begin{array}{c}\text { CTAB surfactant produced a more stable and } \\
\text { homogeneous nanofluid than OA. } \\
\text { The addition of surfactant prevented } \\
\text { nanoparticle clustering, creating a } \\
\text { homogeneous distribution of nanoparticle } \\
\text { within the base liquid. }\end{array}$ \\
\hline $\begin{array}{l}\text { Colangelo et al. } \\
\qquad[21](2016)\end{array}$ & $\mathrm{Al}_{2} \mathrm{O}_{3}$ & Therminol & OA & $\begin{array}{l}\text { The difference in the thermal conductivities } \\
\text { of the nanofluids with and without surfactant } \\
\text { were within the error of the measuring } \\
\text { instrument. Therefore, it was suggested that } \\
\text { the surfactant did not have an effect on the } \\
\text { thermal conductivity of the nanofluid. } \\
\text { The surfactant kept the nanofluid stable over } \\
\text { time by preventing aggregation. }\end{array}$ \\
\hline $\begin{array}{l}\text { Asadi et al. [19] } \\
\qquad(2017)\end{array}$ & $\mathrm{Mg}(\mathrm{OH})_{2}$ & Water & CTAB, SDS, OA & $\begin{array}{c}\text { Of the } 3 \text { surfactants tested, CTAB produced } \\
\text { the most stable nanofluid. } \\
\text { The nanofluid containing CTAB surfactant } \\
\text { remained stable over the } 30 \text { days period } \\
\text { during which it was observed, whereas the } \\
\text { nanofluid containing surfactant only } \\
\text { remained stable for } 1 \text { day. } \\
\text { Although the thermal conductivity of the } \\
\text { nanofluid without surfactant was not } \\
\text { measured, it was suggested that the thermal } \\
\text { conductivity of samples containing } \\
\text { surfactant would be higher than those } \\
\text { without, due to the increased stability. }\end{array}$ \\
\hline
\end{tabular}


Table 3. Cont.

\begin{tabular}{|c|c|c|c|c|}
\hline Reference & $\begin{array}{c}\text { Nanoparticle } \\
\text { Material }\end{array}$ & Base Liquid & Surfactant & Remarks \\
\hline $\begin{array}{l}\text { Khairul et al. [17] } \\
\qquad \text { (2016) }\end{array}$ & $\begin{array}{c}\mathrm{CuO} \\
\mathrm{Al}_{2} \mathrm{O}_{3}\end{array}$ & Water & SDBS & $\begin{array}{l}\text { The negatively charged surfactant altered the } \\
\text { surface charges of the positively charged } \\
\text { nanoparticles, causing repulsion forces } \\
\text { between the nanoparticles. These forces } \\
\text { created a more stable nanofluid and led to } \\
\text { increased thermal conductivity. } \\
\text { It was suggested that an ideal surface charge } \\
\text { on the nanoparticles leads to ideal } \\
\text { thermo-physical properties. } \\
\text { Above the surfactant concentrations of } 0.1 \\
\mathrm{~W} \% \text { for } \mathrm{Al}_{2} \mathrm{O}_{3} \text {-water nanofluid, and } 0.15 \mathrm{~W} \% \\
\text { for CuO-water nanofluid the thermal } \\
\text { conductivity decreased significantly. It was } \\
\text { suggested that this decrease was caused by } \\
\text { greater amounts of surfactant on the surfaces } \\
\text { of the nanoparticles allowing a narrower area } \\
\text { for heat transfer. }\end{array}$ \\
\hline $\begin{array}{l}\text { Xia et al. [20] } \\
\quad(2014)\end{array}$ & $\mathrm{Al}_{2} \mathrm{O}_{3}$ & Water & $\begin{array}{l}\text { Polyvinyl pyrrolidone } \\
\text { (PVP) }\end{array}$ & $\begin{array}{l}\text { PVP surfactant produced a more stable } \\
\text { nanofluid than SDS surfactant. } \\
\text { The surfactant decreased the thermal } \\
\text { conductivity of the base liquid but improved } \\
\text { the stability of the nanofluid by preventing } \\
\text { agglomeration of the nanoparticles. }\end{array}$ \\
\hline $\begin{array}{l}\text { Wang et al. [18] } \\
\qquad(2009)\end{array}$ & $\mathrm{Al}_{2} \mathrm{O}_{3} \mathrm{Cu}$ & Water & SDBS & $\begin{array}{l}\text { It was suggested that obtaining an optimal } \\
\mathrm{pH} \text { value and surfactant concentration would } \\
\text { lead to enhanced thermal conductivity by } \\
\text { altering the surface charges of the } \\
\text { nanoparticles in order to create repulsion } \\
\text { forces and prevent agglomeration. } \\
\text { The thermal conductivity increased with } \\
\text { surfactant concentration but decreased } \\
\text { significantly at greater concentrations. It was } \\
\text { suggested that this decrease was a result of } \\
\text { greater amounts of surfactant on the surfaces } \\
\text { of the nanoparticles allowing a narrower area } \\
\text { for heat transfer. }\end{array}$ \\
\hline
\end{tabular}

\subsection{Effects of Concentration of Nanoparticles on Nanofluid Thermal Conductivity}

In general, experimental data has shown that nanofluid thermal conductivity increases with nanoparticle volume fraction $[1,3,4,7-11,13,15,16,22-40]$. However, in some cases researchers have observed a linear relationship between thermal conductivity and nanoparticle concentration $[3,9,15,22$, 37-40], whereas in other cases a non-linear relationship has been observed $[1,4,7,8,11,13,16,23,26-36]$. Using the transient line heat source method, Agarwal et al. [10] measured the thermal conductivities of $\mathrm{CuO}-$-water, $\mathrm{CuO}-$ Ethylene $\mathrm{Glycol}$, and $\mathrm{CuO}-$ engine oil nanofluids. For all nanofluids tested, the thermal conductivity increased with concentration. It was suggested that this relationship was a result of increased available surface area for heat transfer at higher nanoparticle concentrations. Using the transient hot-wire method, Kim et al. [24] studied the thermal conductivity of $\mathrm{Al}_{2} \mathrm{O}_{3}$-water nanofluid containing brick, platelet and blade nanoparticles. For all nanoparticle shapes, the thermal conductivity increased with the increase of nanoparticle concentration. Maheshwary et al. [25] measured the thermal conductivity of $\mathrm{TiO}_{2}$-water nanofluid as a function of nanoparticle volume concentration using nanoparticles of irregular shape with the same average size. It was observed that the thermal conductivity increased with particle concentration. It was suggested that nanoparticle concentration had a more significant effect on thermal conductivity than particle shape and size. In many experiments, a non-linear relationship between the concentration of nanoparticles and nanofluid thermal conductivity has been observed, which is likely due to greater agglomeration at higher nanoparticle concentrations. Xie et al. [26] measured the thermal conductivity of MgO-Ethylene Glycol nanofluid as a function of nanoparticle concentration. It was observed that at concentrations below $\varphi=1 \%$, change in thermal conductivity for the nanofluid was more rapid than at higher concentrations. This result was attributed to increased particle agglomeration at higher concentrations. Using the 
transient hot-wire method, Seyhan et al. [23] measured the thermal conductivity of hydrophobic Ag-hexane and hydrophilic Ag-Ethylene Glycol nanofluids as a function of nanoparticle concentration. For both nanofluids, the thermal conductivity increased with the increase of particle concentration, however, the rate of increase in thermal conductivity slowed at higher concentrations. It was suggested that the decelerated rate of increase was related to agglomeration and settling of nanoparticles at higher concentrations. Using the same method, Yu et al. [27] studied the thermal conductivity of $\mathrm{ZnO}-$ Ethylene Glycol nanofluid. A non-linear increase in thermal conductivity with nanoparticle concentration was observed. Two different linear relationships were found, one at lower concentrations, and one at higher concentrations. The linear relationship at lower concentrations had a higher slope than the linear relationship at higher concentrations. Patel et al. [28] measured the thermal conductivities of $\mathrm{CuO}$-transformer oil, $\mathrm{Al}_{2} \mathrm{O}_{3}$-water, $\mathrm{Cu}$-Ethylene Glycol, and $\mathrm{Al}$-water nanofluids as a function of nanoparticle concentration. For all nanofluids tested, the thermal conductivity increased with concentration. However, it was observed that the increase in thermal conductivity was relatively higher at low nanoparticle concentrations, which reinforces the observations of Xie et al. [26], Seyhan et al. [23], and Yu et al. [27]. Sundar et al. [29] measured the thermal conductivity of nanodiamond-water nanofluid using the transient hot-wire method. It was observed that the thermal conductivity increased with concentration. However, contrary to the previously discussed observations, it was observed that the enhancement in thermal conductivity was greater at higher concentrations. It was suggested that this was caused by agglomeration of the nanodiamond particles. Agarwal et al. [12] measured the thermal conductivities of $\mathrm{Al}_{2} \mathrm{O}_{3}$-water and $\mathrm{Al}_{2} \mathrm{O}_{3}$-Ethylene Glycol nanofluids using KD2 Pro equipment which worked based on the transient line heat source method. For both nanofluids, the thermal conductivity increased with nanoparticle concentration. The Ethylene Glycol-based nanofluid showed a more rapid increase. At higher concentrations, the results showed a more significant increase in thermal conductivity with nanoparticle concentration, which agrees with the observations of Sundar et al. [29]. It was suggested that Ethylene Glycol-based nanofluid would be a more appropriate choice for applications involving rapid changes in particle concentration. Harikrishnan et al. [51] measured the thermal conductivity of $\mathrm{CuO}$-oleic acid nanofluid using the LFA 447 NanoFlash Analyzer. It was observed that at low concentrations, the thermal conductivity increased linearly with concentration. At higher concentrations, the thermal conductivity increased non-linearly with concentration. It was suggested that this relationship was a result of nanoparticle agglomeration at high concentrations. Murshed et al. [16] measured the thermal conductivity of $\mathrm{TiO}_{2}$-water nanofluid containing CTAB surfactant. The results showed a non-linear increase in thermal conductivity with the increase of particle concentration at concentrations below $\varphi=2 \%$, and a linear increase at higher concentrations. It was suggested that the non-linear relationship at lower particle concentrations was caused by the surfactant. Using the transient line heat source method, Yeganeha at al [31] measured the thermal conductivity of nanodiamond-water nanofluid. It was observed that the thermal conductivity increased non-linearly with nanoparticle volume fraction. At higher volume concentrations, a stronger non-linear relationship was observed. It was suggested that the thermal conductivity could be improved by increasing the dispersion quality of the nanofluid. In the same way, Zhu et al. [1] measured the thermal conductivity of $\mathrm{Fe}_{3} \mathrm{O}_{4}$-water nanofluid. A non-linear increase in thermal conductivity with nanoparticle volume fraction was observed. Pang et al. [32] conducted experiments to determine the thermal conductivities of $\mathrm{SiO}_{2}$-methanol and $\mathrm{Al}_{2} \mathrm{O}_{3}$-methanol nanofluids. A non-linear increase in thermal conductivity with the increase of volume fraction was observed. $\mathrm{Li}$ et al. [8] measured the thermal conductivities of $\mathrm{CuO}$-water and $\mathrm{Al}_{2} \mathrm{O}_{3}$-water nanofluids as a function of volume fraction. It was observed that the thermal conductivity of both nanofluids increased non-linearly with nanoparticle volume concentration. Using a KD2 Pro Thermal Property Analyzer, Das et al. [33] measured the thermal conductivity of $\mathrm{TiO}_{2}$-water nanofluid. The results are shown in Figure 18. It was observed that for a given temperature, the thermal conductivity increased non-linearly with nanoparticle concentration. Using the same method, Lee et al. [34] measured the thermal conductivity of SiC-water nanofluid as a function of nanoparticle volume concentration. The results showed a non-linear increase 
in thermal conductivity with increased nanoparticle volume fraction. Using the transient hot-wire method, Sundar et al. [13] measured the thermal conductivity of nanofluids composed of magnetic $\mathrm{Fe}_{3} \mathrm{O}_{4}$ nanoparticles dispersed in 20\%:80\%, 40\%:60\% and 60\%:40\% by weight Ethylene Glycol-water. The results indicated a non-linear increase in thermal conductivity with the increase of nanoparticle concentration. Additionally, Sundar et al. [30] measured the thermal conductivity of magnetic $\mathrm{Fe}_{3} \mathrm{O}_{4}$-water nanofluid containing CTAB surfactant. The results showed a non-linear increase in thermal conductivity with nanoparticle concentration. Paul et al. [35] studied the thermal conductivity of Ag-water nanofluid. The results showed a non-linear increase in the thermal conductivity with nanoparticle concentration. Park et al. [7] measured the thermal conductivity of Graphene-water nanofluid using $5000 \mathrm{~nm}$ graphene, 15,000 nm graphene, and oxidized $5000 \mathrm{~nm}$ graphene. The thermal conductivity increased non-linearly with increased nanoparticle volume fraction for all, with the oxidized $5000 \mathrm{~nm}$ graphene having the highest rate of increase. Yoo et al. [36] measured the thermal conductivities of $\mathrm{TiO}_{2}$-water, $\mathrm{Al}_{2} \mathrm{O}_{3}$-water, Fe-Ethylene Glycol, and $\mathrm{WO}_{3}$-Ethylene Glycol nanofluids as a function of nanoparticle volume fraction. For each nanofluid, the thermal conductivity increased non-linearly with the nanoparticle concentration. Wang et al. [11] measured the thermal conductivities of nanofluids composed of $\mathrm{Al}_{2} \mathrm{O}_{3}$ and $\mathrm{CuO}$ nanoparticles dispersed in water, Ethylene Glycol, engine oil, and vacuum pump fluid. It was observed that the thermal conductivity increased non-linearly with the nanoparticle concentration for all nanofluids tested. Chopkar et al. [4] measured the thermal conductivities of $\mathrm{Ag}_{2} \mathrm{Al}$-water, $\mathrm{Ag}_{2} \mathrm{Al}$-Ethylene $\mathrm{Glycol}, \mathrm{Al}_{2} \mathrm{Cu}$-water, and $\mathrm{Al}_{2} \mathrm{Cu}-\mathrm{Ethylene} \mathrm{Glycol}$ nanofluids. The results showed a non-linear increase in thermal conductivity with nanoparticle concentration. However, some researchers have observed a linear relationship between nanoparticle concentration and thermal conductivity $[3,9,15,22,37-40]$. Iqbal et al. [37] studied the thermal conductivities of $\mathrm{Al}_{2} \mathrm{O}_{3}$-water, $\mathrm{SiO}_{2}$-water and $\mathrm{ZrO}_{2}$-water nanofluids. It was observed that the thermal conductivity increased almost linearly with the nanoparticle concentration for all tested nanofluids. It was suggested that this increase was related to increased activity between nanoparticles and the base fluid. Esfe et al. [3] measured the thermal conductivity of Fe-water nanofluid as a function of nanoparticle concentration. An almost linear increase in thermal conductivity with the increase of nanoparticle volume concentration was observed. It was suggested that this relationship was a result of the agglomeration of nanoparticles creating particle-free areas in the base liquid with high thermal resistance [3]. Alawi et al. [38] measured the thermal conductivity of CuO-R-134a nanofluid. The results showed a linear increase in thermal conductivity with concentration. It was observed that the increase in thermal conductivity with concentration was much sharper than the increase with temperature. Using a KD2 Pro Thermal Properties Analyzer, Huminic et al. [39] studied the thermal conductivity of $\mathrm{FeC}$-water nanofluid as a function of nanoparticle weight concentration. It was observed that for a given temperature, the thermal conductivity increased almost linearly with nanoparticle concentration. It was suggested that this increase could be partially explained by the increased interaction between particles at higher concentrations. Barbe's et al. [9] measured the thermal conductivities of $\mathrm{CuO}$-water and $\mathrm{CuO}$-Ethylene Glycol nanofluids using a differential heat-flow $\mathrm{C} 80 \mathrm{D}$ microcalorimeter containing special calorimetric vessels, which worked based on the steady-state coaxial cylinder method. It was found that for a given temperature, the relative thermal conductivity increased almost linearly with volume fraction. Using the transient short hot-wire method, Yu et al. [15] measured the thermal conductivities of aluminum nitride (AIN)-Ethylene Glycol and AIN-propylene glycol nanofluids. An almost linear increase in thermal conductivity with nanoparticle concentration was observed. Das et al. [22] measured the thermal conductivity of $\mathrm{Al}_{2} \mathrm{O}_{3}$-water nanofluid using a KD2 Pro Thermal Property Analyzer. It was observed that the thermal conductivity increased almost linearly with nanoparticle volume concentration. Using the transient hot-wire method, Jeong et al. [40] measured the thermal conductivity of $\mathrm{ZnO}$-water nanofluid as a function of nanoparticle concentration. The results showed an almost linear increase in thermal conductivity with nanoparticle concentration. It can be concluded from the experimental findings, discussed above that the thermal conductivity of 
nanofluids increases with nanoparticle volume concentration. However, the rate of increase is different for various nanofluids due to the degree of agglomeration.

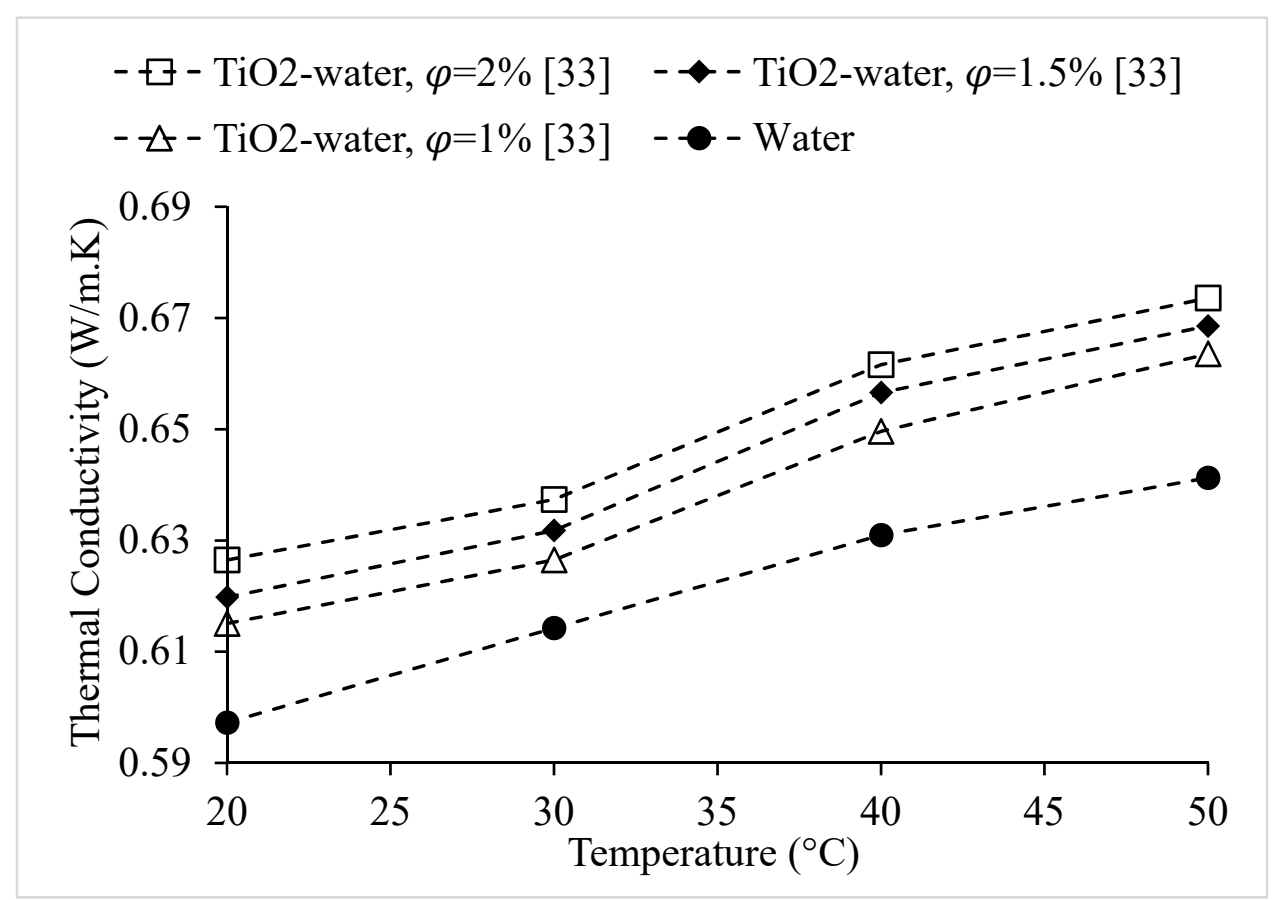

Figure 18. Variation of thermal conductivity of $\mathrm{TiO}_{2}$-water nanofluid at nanoparticle volume concentrations of $\varphi=1 \%, 1.5 \%$, and $2 \%$, as a function of temperature, ${ }^{\circ} \mathrm{C}$.

The effect of nanoparticle concentration on the thermal conductivity of water-based nanofluids at room temperature is shown in Figure 19. For all nanofluids, the thermal conductivity increases with nanoparticle volume concentration $(\varphi)$, while the rate of increase in thermal conductivity becomes smaller at higher concentrations. This decrease may be a result of nanoparticle clustering at higher concentrations. Figure 20 further reinforces the observations of Figure 19, showing that the thermal conductivity increases with nanoparticle volume concentration $(\varphi)$. It is observed that the rate of increase in thermal conductivity becomes slightly smaller at higher concentrations for nanodiamond nanofluids, whereas the rate of increases becomes larger at higher concentrations for $\mathrm{SiO}_{2}$ and $\mathrm{ZrO}_{2}$ nanofluids. 


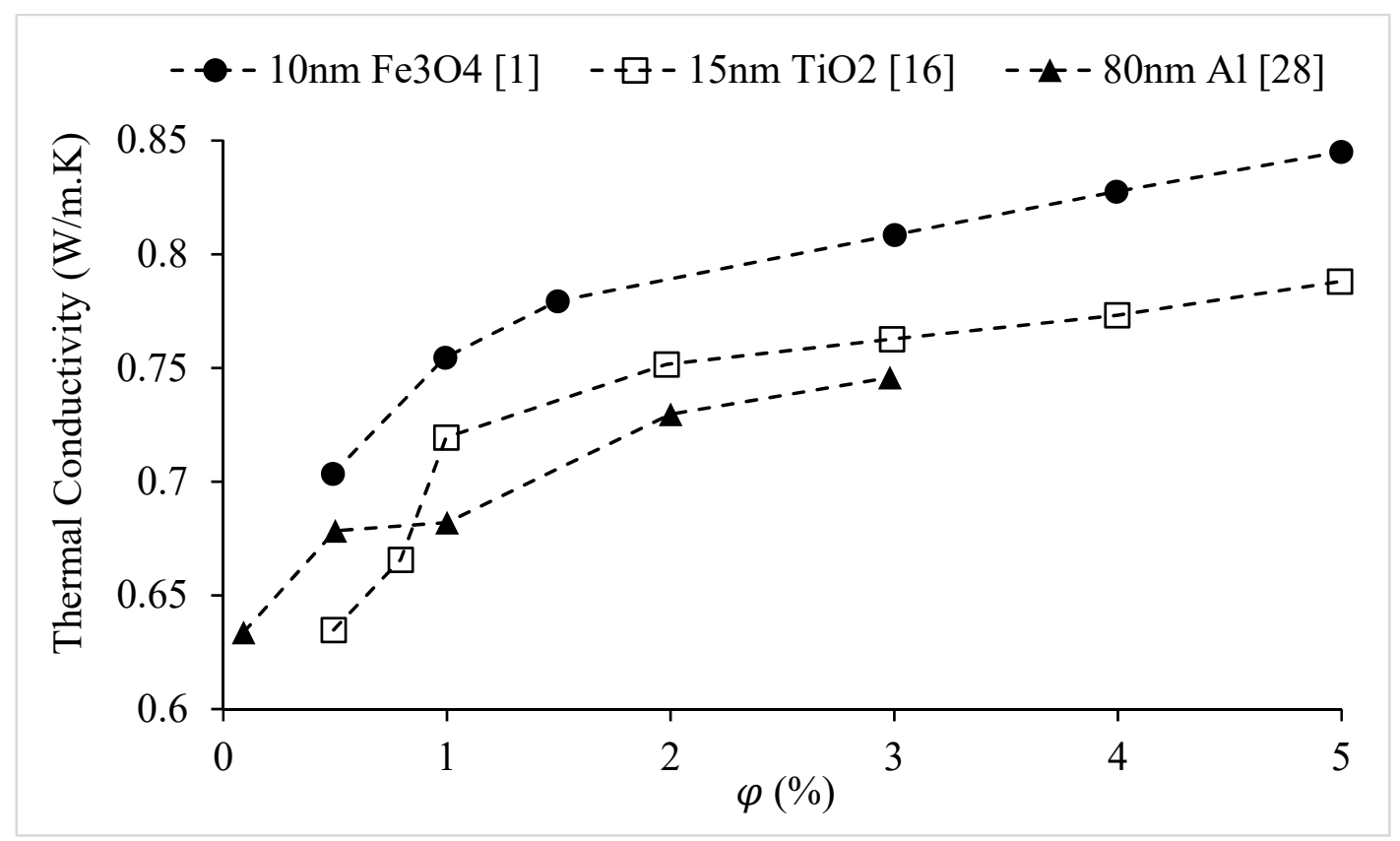

Figure 19. Variation of the thermal conductivity of water-based nanofluids at room temperature as a function of nanoparticle volume concentration, $\varphi$.

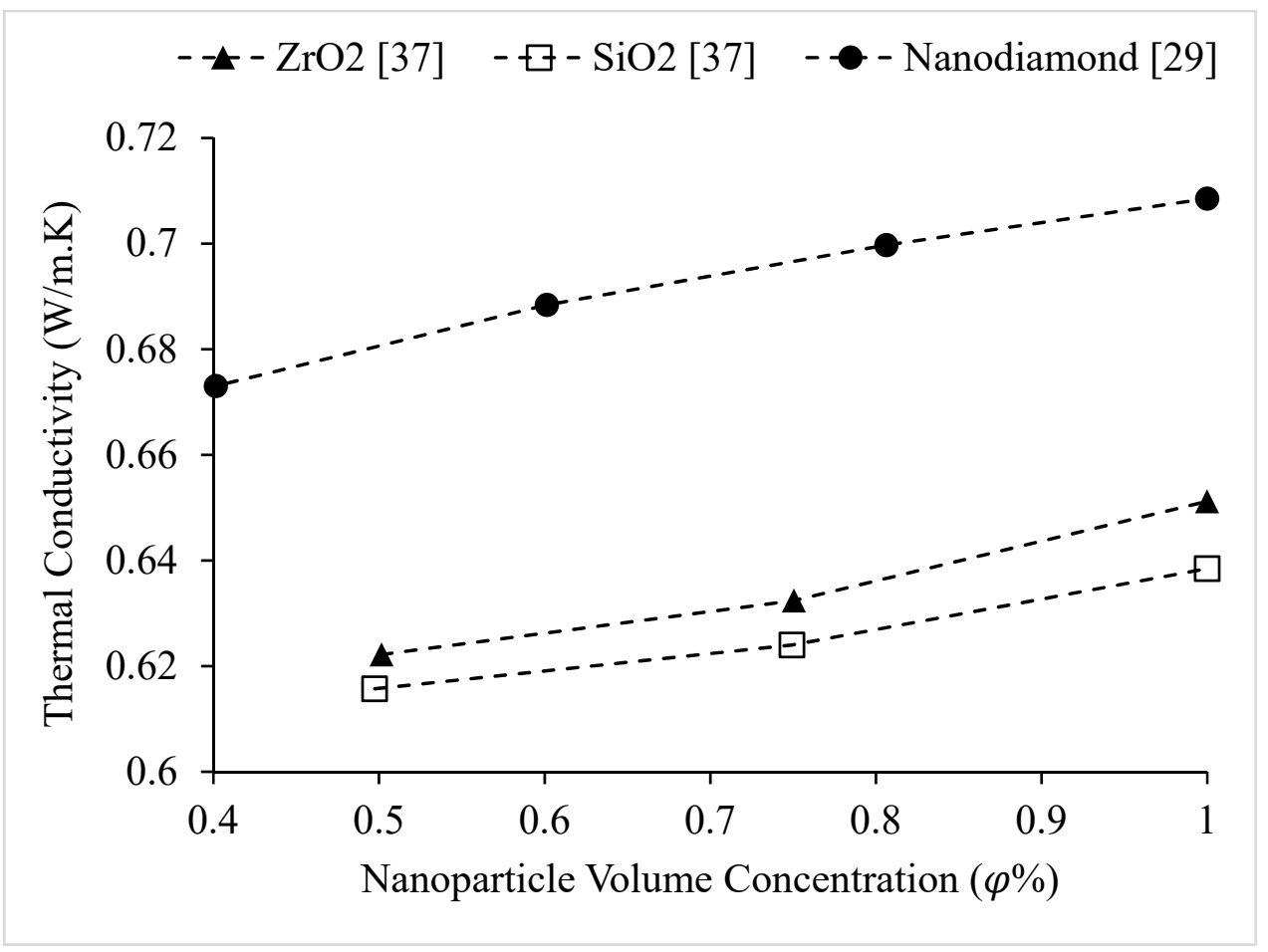

Figure 20. Variation of thermal conductivity of water-based nanofluids at room temperature as a function of nanoparticle volume concentration, $\varphi$, at concentrations below $\varphi=1 \%$.

\subsection{Effects of Temperature on Nanofluid Thermal Conductivity}

Researchers have conducted experiments to determine the effects of temperature on the thermal conductivity of nanofluids, concluding that the thermal conductivity of nanofluids increases with temperature $[5,8,10,12,13,22,25,28,30,31,33,38-41]$. For example, the thermal conductivity of $\mathrm{Al}_{2} \mathrm{O}_{3}$-water and $\mathrm{CuO}$-water nanofluids was measured and the results indicated that the rate of 
enhancement of the effective thermal conductivity increased significantly with respect to increasing temperature [8,41]. Also, Sundar et al. [13] measured the thermal conductivities of magnetic $\mathrm{Fe}_{3} \mathrm{O}_{4}$ nanoparticles dispersed in 20\%:80\%, 40\%:60\% and 60\%:40\% by weight Ethylene Glycol/water-based nanofluids. It was observed that the thermal conductivity increased with temperature [13]. In addition, using a KD2 Pro analyzer which worked based on the transient line heat source method, Yeganeh et al. [31] measured the thermal conductivity of nanodiamond-water nanofluid as a function of temperature. A significant increase in thermal conductivity with the increase of temperature was observed. In the same way, Huminic et al. [39] studied the thermal conductivity of FeC-water nanofluid. An increase in thermal conductivity with temperature was observed. Similarly, Das et al. [22] measured the thermal conductivity of $\mathrm{Al}_{2} \mathrm{O}_{3}$-water nanofluid and observed an increase with the increase of temperature. It was suggested that this increase was a result of intensified Brownian motion at higher temperatures. Brownian motion is caused by the random collisions of liquid molecules resulting in the random motion of nanoparticles within the base liquid, which in turn leads to greater heat transfer. It was also suggested that the increased microscopic motion caused by Brownian, van der Waals, and electrostatic forces had a significant impact on the increase in thermal conductivity. Also, using a KD2 Pro instrument, Das et al. [33] measured the thermal conductivity of $\mathrm{TiO}_{2}$-water nanofluid as a function of temperature. The results are shown in Figure 21. For each tested nanoparticle volume fraction, the thermal conductivity increased with temperature. The results showed that the temperature had a stronger influence on thermal conductivity at higher temperatures. It was suggested that this relationship was related to enhanced Brownian motion at higher temperatures. Using the same method, Agarwal et al. [12] measured the thermal conductivities of $\mathrm{Al}_{2} \mathrm{O}_{3}$-water and $\mathrm{Al}_{2} \mathrm{O}_{3}$-Ethylene Glycol nanofluids at temperatures ranging from $10-70{ }^{\circ} \mathrm{C}$. For both nanofluids, at a given nanoparticle volume concentration, the thermal conductivity increased with temperature. The increase was less significant for Ethylene Glycol-based nanofluid. It was suggested that the increase in thermal conductivity with temperature was related to more significant Brownian motion at higher temperatures. It was suggested that water-based nanofluid would be a more appropriate choice for applications involving a significant temperature increase, because the thermal conductivity increased almost constantly with the increase of both temperature and nanoparticle concentration. Using the transient hot-wire method, Raja et al. [5] measured the thermal conductivity of Ag-water nanofluids having nanoparticle volume concentrations less than $1 \%$. It was observed that the thermal conductivity increased with the increase of temperature. It was suggested that the thermal conductivity of nanofluids has a stronger dependence on temperature than base fluid thermal conductivity. Using the same method, Maheshwary et al. [25] measured the thermal conductivity of $\mathrm{TiO}_{2}$-water nanofluid as a function of temperature. For every combination of nanoparticle shape and concentration tested, it was observed that the thermal conductivity increased with temperature. Similarly, Sundar et al. [30] measured the thermal conductivity of magnetic $\mathrm{Fe}_{3} \mathrm{O}_{4}$-water nanofluid, containing CTAB surfactant. It was observed that the thermal conductivity increased with temperature. It was suggested that this increase was caused by increased Brownian motion at higher temperatures. Also, using the transient hot-wire method, Jeong et al. [40] measured the thermal conductivity of $\mathrm{ZnO}-$ water nanofluid. An increase in thermal conductivity with temperature was observed. In the same way, Sundar et al. [29] measured the thermal conductivity of nanodiamond-water nanofluid and observed an increase with temperature. It was suggested that this was a result of Brownian motion and micro-convection of the nanoparticles. Alawi et al. [38] measured the thermal conductivity of nanofluid composed of $\mathrm{CuO}$ nanoparticles dispersed in R-134a refrigerant. The results showed an increase in thermal conductivity with temperature. It was suggested that this increase was a result of increased Brownian motion at higher temperatures. It was also noted that the contribution of microconvection to heat transfer increases with the increase of Brownian motion, which also leads to enhanced thermal conductivity. Patel et al. [28] studied the thermal conductivities of $\mathrm{Al}_{2} \mathrm{O}_{3}$-Ethylene Glycol, $\mathrm{Cu}$-water, and Al-transformer oil nanofluids. It was observed that the thermal conductivity increased with temperature. It was suggested that this increase was a result of increased Brownian motion at higher 
temperatures. Also, using the transient line heat source method, Agarwal et al. [10] measured the thermal conductivities of $\mathrm{CuO}$-water, $\mathrm{CuO}-$ Ethylene $\mathrm{Glycol}$, and $\mathrm{CuO}-$-engine oil nanofluids as a function of temperature. The results showed an increase in thermal conductivity with temperature for each nanofluid tested. It was suggested that this increase was caused by increased Brownian motion at higher temperatures. However, several researchers have suggested that the effect of temperature on the thermal conductivity of nanofluids is solely a result of the increase in thermal conductivity of the base liquid [15,26,42]. Using the transient short hot-wire method, Yu et al. [15] measured the thermal conductivities of AIN-Ethylene Glycol and AIN-propylene glycol nanofluids within the temperature range on $10-60{ }^{\circ} \mathrm{C}$. A negligible change in thermal conductivity with the increase of temperature was observed. At a given temperature, the thermal conductivity of the nanofluid was almost identical to that of the base fluid. Additionally, Xie et al. [26] observed that the thermal conductivity of MgO-Ethylene Glycol nanofluid increased slightly with temperature. However, the thermal conductivity enhancement ratio remained almost constant. It was suggested that the change in thermal conductivity of nanofluids with temperature follows the trend of increase in the thermal conductivity of their respective base fluid. Also, Sharifpur et al. [42] measured the thermal conductivity of $\mathrm{Al}_{2} \mathrm{O}_{3}$-glycerol nanofluid as a function of temperature. The thermal conductivity did not vary significantly with temperature, and followed the pattern of the base fluid, glycerol. It was suggested that the effect of temperature on the thermal conductivity of nanofluids is dependent on the characteristics of the nanofluid. Seyhan et al. [23] measured the thermal conductivity of Ag-Ethylene Glycol, Ag-hexane, and Ag-water nanofluids as a function of temperature. The thermal conductivity of Ag-Hexane nanofluid decreased with temperature. The thermal conductivity of Ag-water nanofluid increased with temperature at lower concentrations, but decreased with the increase of temperature at higher concentrations. It was suggested that this change in the behavior of water-based nanofluid at higher temperatures was related to the presence of Gum Arabic surfactant. Water generally does not transfer energy between molecules, but rather the energy is stored within hydrogen bonds in large clusters of molecules that occur at lower temperatures [23]. The thermal conductivity of water then increases with temperature, unlike other liquids. The Gum Arabic surfactant created new places in which hydrogen bonding could occur, by adding several -OH groups to the mixture. This led to a decrease in the amount of hydrogen bonds between water molecules, creating a critical concentration above which the thermal conductivity of the nanofluid decreased. By the above discussed experimental results, it can be concluded that the thermal conductivity of nanofluids increases with the thermal conductivity of their respective base liquids. Through plotting various nanofluids along with their respective base liquids in Figures 21-23 below, it was observed that the thermal conductivity of nanofluids generally does not increase at the same rate as the thermal conductivity of base liquids. Thus, it can be suggested that the increase in nanofluid thermal conductivity with temperature is not solely a result of the increased thermal conductivity of the base liquid, but is also a result of Brownian motion and micro-convection due to the addition of nanoparticles.

The thermal conductivities of various water-based nanofluids, at $\varphi=2 \%$, are shown in Figure 5 as a function of temperature, in comparison to the thermal conductivity of water as a function of temperature. It is observed that the thermal conductivity of nanofluids increases with temperature, however not all nanofluids increase at the same rate. It is observed that for all nanofluids, other than nanodiamond-water nanofluid, the slopes of the nanofluid thermal conductivities as a function of temperature are different from the slope of increase in the thermal conductivity of water. Therefore, it can be suggested that the increase in thermal conductivity with temperature of a nanofluid is not only caused by the base liquid, but by the nanofluid as a whole. The data shown in Figure 14 further reinforces this suggestion, by showing that the thermal conductivities of $\mathrm{Al}_{2} \mathrm{O}_{3}$-Ethylene Glycol nanofluids also did not increase with temperature at the same rate as the base liquid, Ethylene Glycol. 


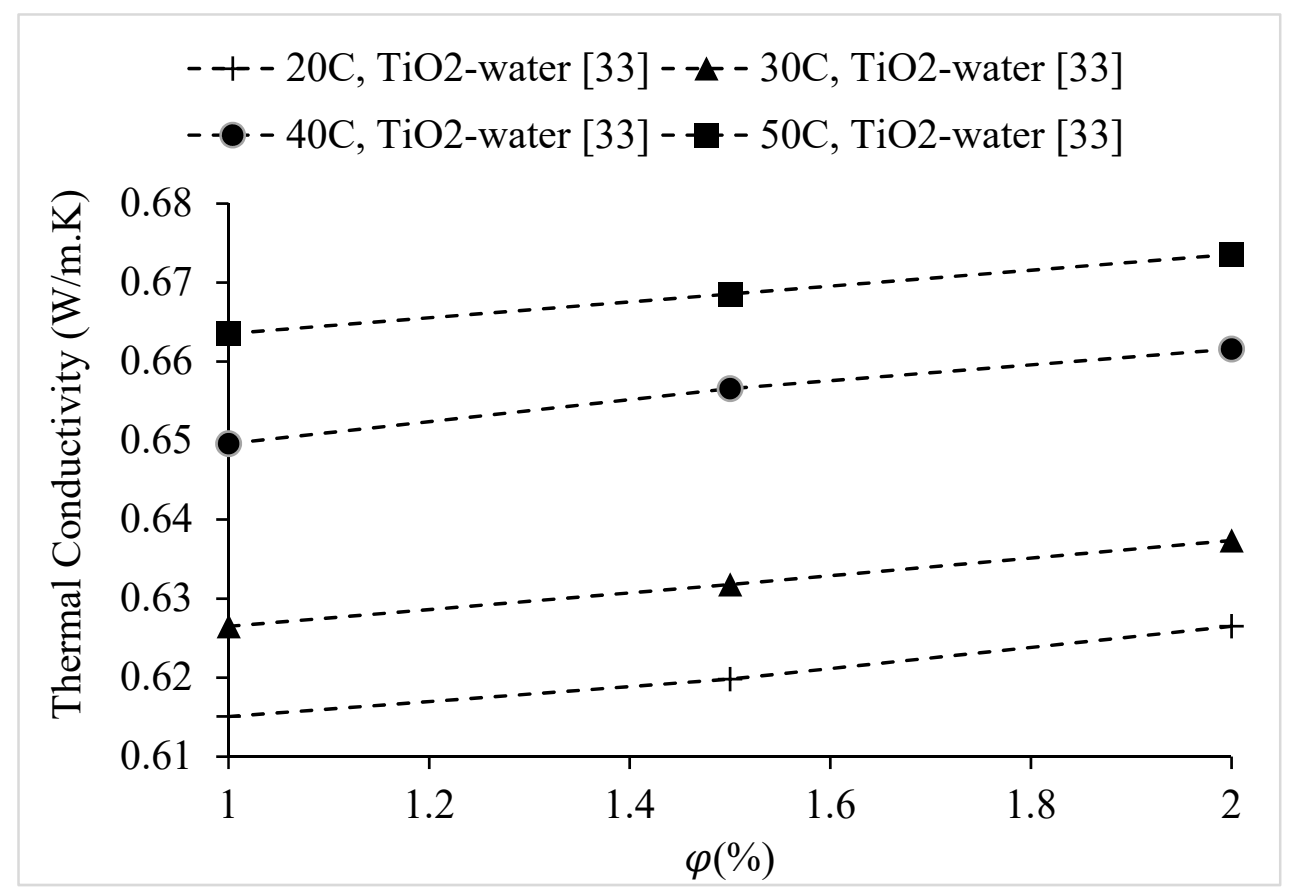

Figure 21. Variation of the thermal conductivity of $\mathrm{TiO}_{2}-$ water nanofluid at various temperatures, as a function of nanoparticle volume concentration, $\varphi$.

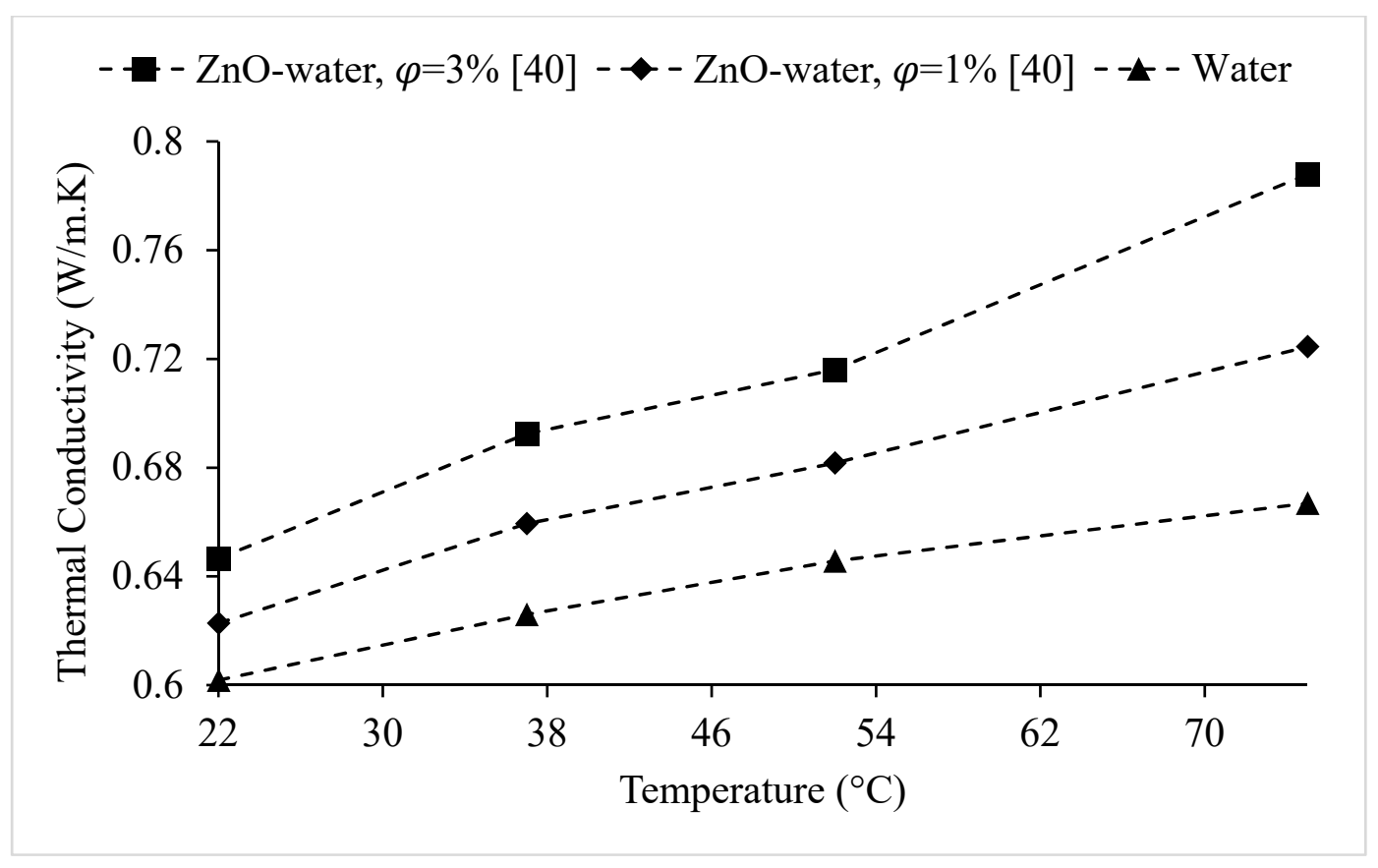

Figure 22. Variation of the thermal conductivity of $\mathrm{ZnO}$-water nanofluid at various nanoparticle volume concentrations, as a function of temperature. 


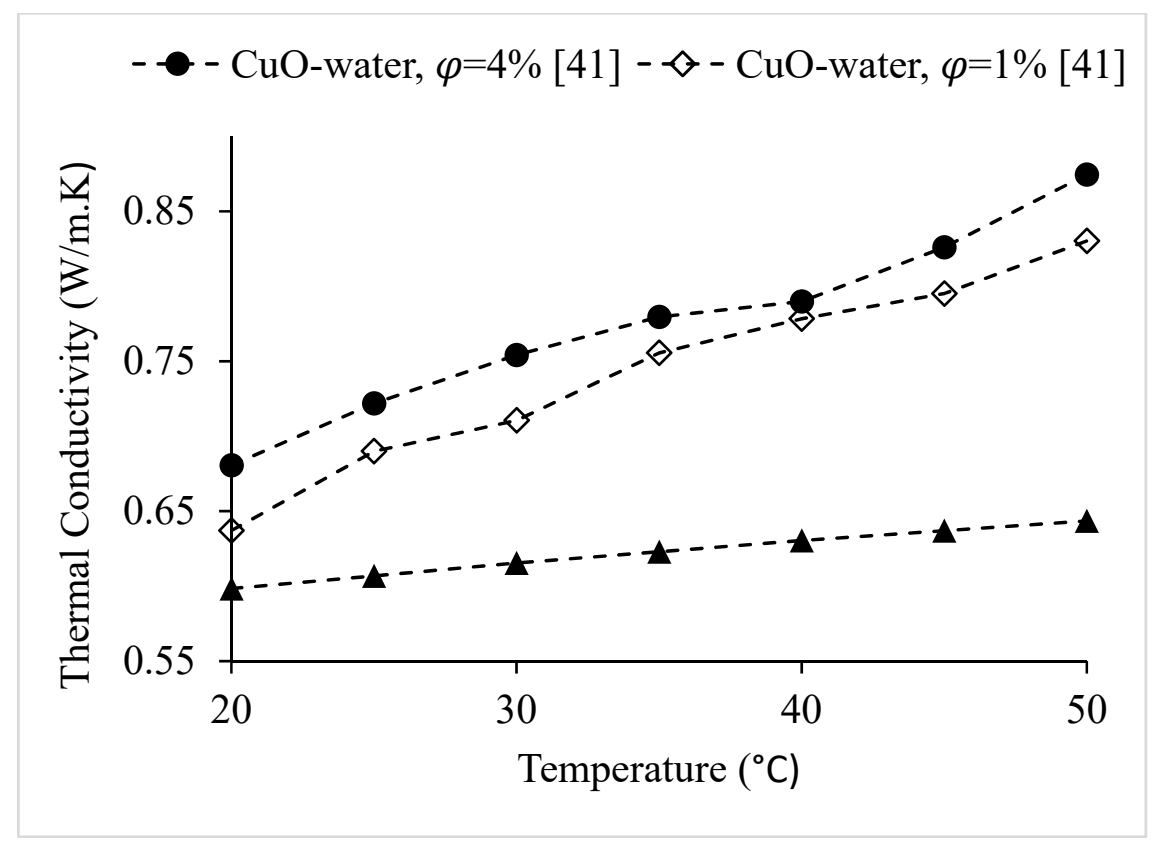

Figure 23. Variation of the thermal conductivity of $\mathrm{CuO}$-water nanofluid at various nanoparticle volume concentrations, as a function of temperature.

\subsection{Effects of Carbon Nanotubes on Nanofluid Thermal Conductivity}

Researchers have observed significant enhancements in nanofluids containing nanotubes, also observing that the thermal conductivities of nanofluids containing carbon nanotubes increases non-linearly with nanoparticle volume concentration, even at low concentrations, which differs from nanofluids containing metal and metal oxide nanoparticles. Carbon nanotubes are made up of a series of hollow carbon molecules, which together form either a singular cylinder or multiple concentric cylinders. The thermal conductivity of carbon nanotubes is dependent upon their diameters. Therefore, it was suggested that the variance in experimental data between different studies may be a result of the varying diameters of nanotubes [2]. Choi et al. [47] studied the thermal conductivity of multi-walled carbon nanotube (MWCNT)-synthetic poly ( $\alpha$-olefin) oil suspensions using the transient hot-wire method. It was observed that the thermal conductivity increased significantly, having a non-linear relationship, with nanotube volume concentration. It was suggested that the significant increase was a result of the organized structure at the solid-liquid interface allowing more efficient heat conduction. Although the theoretical models suggested a linear relationship between thermal conductivity and nanoparticle concentrations at the tested concentrations, it was suggested that the non-linear relationship was caused by the size and shape of the nanotubes. It was observed that nanotubes lead to greater enhancement in thermal conductivity of nanofluids than other nanostructured materials, reaching an enhancement of $2.5 \%$ at a nanoparticle volume concentration of $\varphi=1 \%$. Similarly, Wen et al. [2] measured the thermal conductivity of MWCNT-water nanofluid using a KD2 Pro Thermal Property meter, which worked based on the transient hot-wire method. Due to their hydrophobic surface, carbon nanotubes are prone to aggregation in water. Therefore, SDBS was added as a surfactant in a concentration of $20 \mathrm{~W} \%$ with respect to the MWNTs. The SDBS was able to maintain stability in the nanofluid up to approximately $60-70{ }^{\circ} \mathrm{C}$. It was observed that the thermal conductivity of the nanofluid increased with temperature, having a linear relationship at temperatures below $30^{\circ} \mathrm{C}$, and a non-linear relationship at higher temperatures. It was observed that the thermal conductivity also increased with nanoparticle volume concentration, having a non-linear relationship even at low concentrations. This observation is consistent with the observations of Choi et al. [47]. The non-linear increase at low concentrations differs from the common linear increase at low nanoparticle concentrations for nanofluids containing metal and metal-oxide nanoparticles. It was suggested 
that Brownian motion does not significantly contribute to the thermal conductivity enhancement in nanotube nanofluids. However, it was suggested that the ordered structure at the solid-liquid interface caused by interfacial layering allowed for more efficient heat transfer and, therefore, enhanced thermal conductivity. It was also suggested that nanotube networking contributed to the enhanced thermal conductivity, and may have also allowed ballistic transport of energy carriers, which also may have contributed to the increase in thermal conductivity. Additionally, Wen et al. [52] studied the thermal conductivity of MWCNT-water suspensions at low nanoparticle volume concentrations, below $\varphi=0.05 \%$. Experimental data was collected using a hot-disk TPS 500 Thermal Constant Analyzer. SDS was used as a surfactant in small concentrations, in order to prevent agglomeration of the nanotubes. The results are shown in Figure 24. It was observed that at $\varphi=0.01 \%$, the nanofluid thermal conductivity was only slightly higher than that of the base liquid for a given temperature. However, a much more significant enhancement was observed when the nanoparticle volume concentration was increased to $\varphi=0.03 \%$. It was suggested that at very low concentrations, carbon nanotubes will not form long chains. As the nanotube concentration increases, a percolation threshold will eventually be reached, at which the nanotubes will begin to network, and in turn the thermal conductivity enhancement will increase. It was suggested that in this experiment, the percolation threshold was at $\varphi=0.03 \%$. It was also suggested that at higher temperatures, Brownian motion significantly contributed to the increase in thermal conductivity, due to the inability of nanotubes to form chains at higher temperatures, as a result of nanofluid instability.

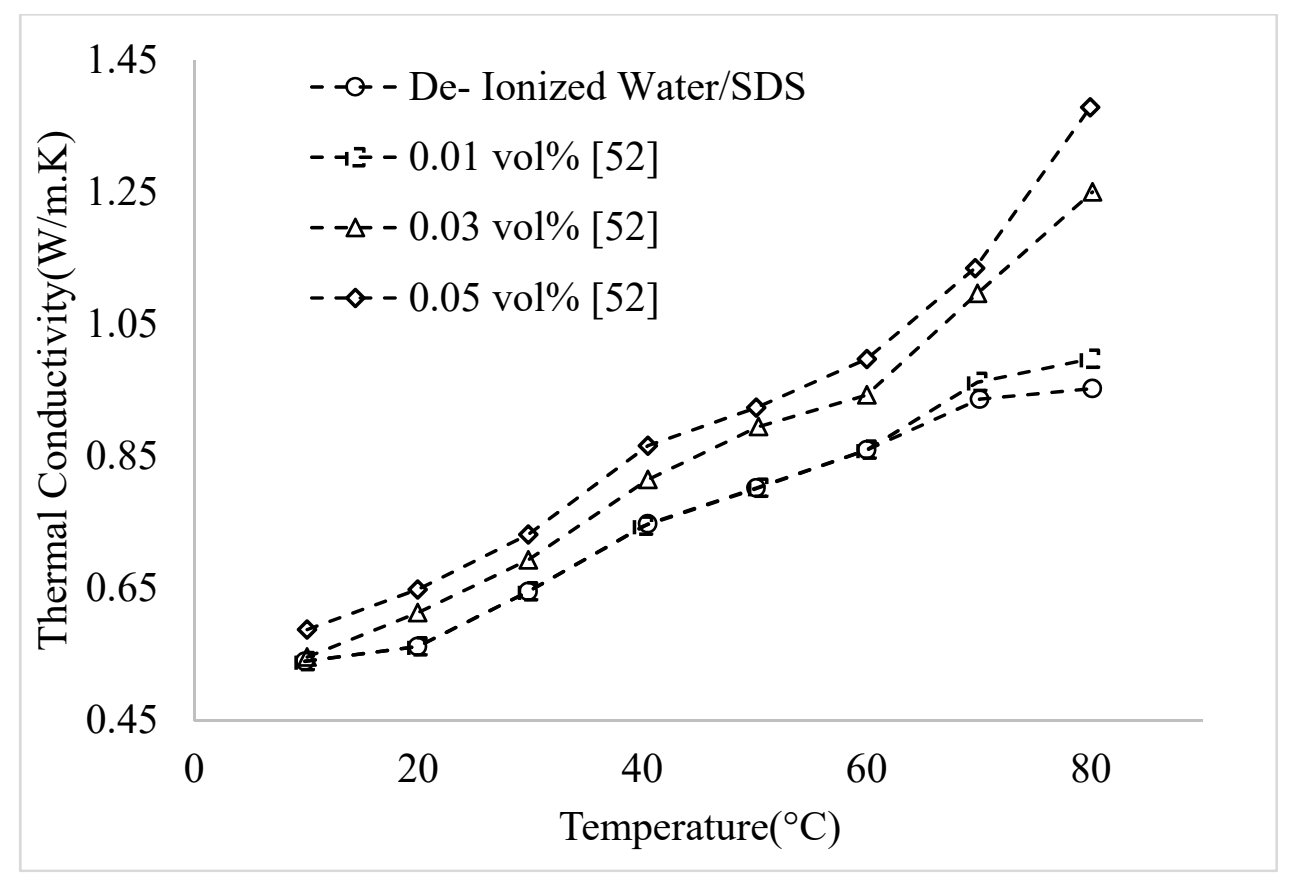

Figure 24. Variation of the thermal conductivity of multi-walled carbon nanotube (MWCNT)-water nanofluid at various nanoparticle volume concentrations, as a function of temperature.

Fadhillahanafi et al. [53] measured the thermal conductivity of MWCNT-water nanofluid using a KD2 Pro Thermal Analyzer. For each given nanotube concentration, the thermal conductivity of the nanofluid containing no surfactant was measured and compared with the nanofluid containing $0.1 \mathrm{~W} \%$ PVP surfactant. It was observed that in each case, the nanofluid containing surfactant had a higher thermal conductivity than that without. It was also observed that the thermal conductivity of the nanofluid increased with nanotube concentration. The low weight concentration of surfactant was chosen due to the surfactant resulting in a reduction of the thermal conductivity of water. It was suggested that the increased thermal conductivity with the addition of surfactant was a result of the surfactant increasing repulsive forces between the nanotubes, which minimized agglomeration, and 
thus prevented sedimentation. Therefore, it was suggested that the addition of surfactant, in order to increase the stability of nanofluids containing carbon nanotubes, is very important in producing carbon nanotube nanofluids with high thermal conductivity. In the same way, Rashmi et al. [54] measured the thermal conductivity of MWCNT-water nanofluid containing Gum Arabic surfactant. It was observed that the optimal concentration of surfactant in increasing the stability of the nanofluid was $1.0-2.5 \mathrm{~W} \%$. At higher surfactant concentrations, it was observed that the nanofluid stability decreased due to the aggregation of the Gum Arabic molecules. With the optimal surfactant concentration, it was observed that the nanofluid thermal conductivity increased non-linearly with the nanotube concentration. However, it was stated that the exact mechanism for this non-linear increase is unknown. In addition, Jana et al. [55] measured the thermal conductivity of oxidation treated carbon nanotube (CNT)-water nanofluids. A non-linear increase with concentration was observed. It was suggested that the non-linear trend was a result of the unpredictable size and shape of the nanotubes due to their tendency toward agglomeration as a result of their high aspect ratio. Also, using a KD2 Pro Thermal Properties Analyzer, Chai et al. [56] measured the thermal conductivity of MWCNTs dispersed in hydrogenated oil-based drilling fluid. It was observed that the thermal conductivity enhancement was greater at higher nanoparticle concentrations than at lower concentrations. Thus, it was suggested that nanotube concentration plays a significant role in nanofluid thermal conductivity enhancement. In the same way, Esfe et al. [57] conducted experiments to study the thermal conductivity of single-walled carbon nanotubes (SWCNTs) dispersed in Ethylene Glycol. The nanotubes were functionalized with $\mathrm{COOH}$ groups, making them hydrophilic and, therefore, creating a more stable nanofluid. By functionalizing the nanotubes, the need for surfactant was eliminated, thus preventing any negative effects that a surfactant may have. It was observed that the thermal conductivity increased non-linearly with temperature. It was also observed that the thermal conductivity increased with nanotube concentration. It was suggested that this increase was a result of a greater area for heat transfer with a greater concentration. Similarly, Dehkordi et al. [58] studied the thermal conductivity of 50-50 water-ethylene mixture containing $\mathrm{COOH}$ functionalized SWCNTs. It was observed that the thermal conductivity increased non-linearly with temperature, with a greater slope in the increase of temperature, for nanofluids have a higher nanotube concentration. It was suggested that the increase with temperature was a result of Brownian motion. Thus, at higher concentrations, the frequency of collisions of the nanoparticles increased, leading to greater enhancement in thermal conductivity. It was also observed that the nanofluid thermal conductivity increased with nanotube concentration, having a greater slope of increase below $\varphi=0.125 \%$. It was suggested that at lower concentrations, the thermal conductivity increase with nanotube concentration was a result of increased interaction between the nanotubes, while at higher concentrations, the nanotubes may have formed larger chains, leading to a lower surface area to volume ratio, and therefore a less significant increase in thermal conductivity. Additionally, the thermal conductivity of nanofluid composed of $\mathrm{Al}_{2} \mathrm{O}_{3}$ nanoparticles dispersed in the same base liquid was compared with the thermal conductivity of the SWCNT nanofluid. It was observed that the thermal conductivity of the nanofluid containing nanotubes was significantly higher. It was suggested that this was a result of the much higher thermal conductivity of the SWCNTs in comparison to $\mathrm{Al}_{2} \mathrm{O}_{3}$, and the higher specific surface area of the SWCNTs. However, some experimental data has been collected which shows a linear increase in the thermal conductivity of nanotube nanofluids with temperature. Xing et al. [6] studied the thermal conductivities of nanofluids composed of short SWCNTs, long SWCNT, and MWCNTs dispersed in water. It was observed that the thermal conductivity increased almost linearly with both temperature and nanotube concentration. It was also observed that for a given temperature and nanotube concentration, the long SWCNTs had the highest thermal conductivity, while the MWCNTs had the lowest. It was suggested that this was a result of the higher aspect ratio and surface area of the long SWCNTs. From the above discussed experimental findings, it can be suggested that the addition of carbon nanotubes to a base liquid results in significant thermal conductivity enhancement with both temperature and nanotube concentration. It can also be suggested that the increase in thermal conductivity with nanotube concentration differs 
from that of nanofluids containing metal and metal-oxide particles, by increasing non-linearly at low concentrations. However, further experimentation should be completed in order to determine whether the addition of surfactant or an oxidation treatment of the nanotubes leads to greater stability and thermal conductivity of the nanofluid.

Figure 25 shows the effect of various surfactants on the thermal conductivity of MWCNT-water nanofluid as a function of nanoparticle volume concentration, $\varphi$. It is observed that the nanofluid containing Gum Arabic surfactant has a significantly higher thermal conductivity than the nanofluids containing SDS, SDBS, and PVP surfactants. However, it is observed that in each case, the thermal conductivity increases almost linearly with nanoparticle concentration, which contradicts with the statement of Choi et al. [47], that the thermal conductivity of nanofluids containing carbon nanotubes increases non-linearly, even at low concentrations. However, experimental data has shown that this non-linear trend develops at concentrations above $\varphi=0.2 \%$ [2,53,54]. Figure 24 shows the thermal conductivity of MWCNT-water nanofluid, at various concentrations, as a function of temperature. It is observed that the trend of increase of the nanofluid with temperature differs from that of the base liquid at concentrations above $\varphi=0.01 \%$, and the thermal conductivity of the nanofluid increases with the nanotube concentration, thus clearly showing the positive impact of the addition of nanotubes on the thermal conductivity of the base liquid.

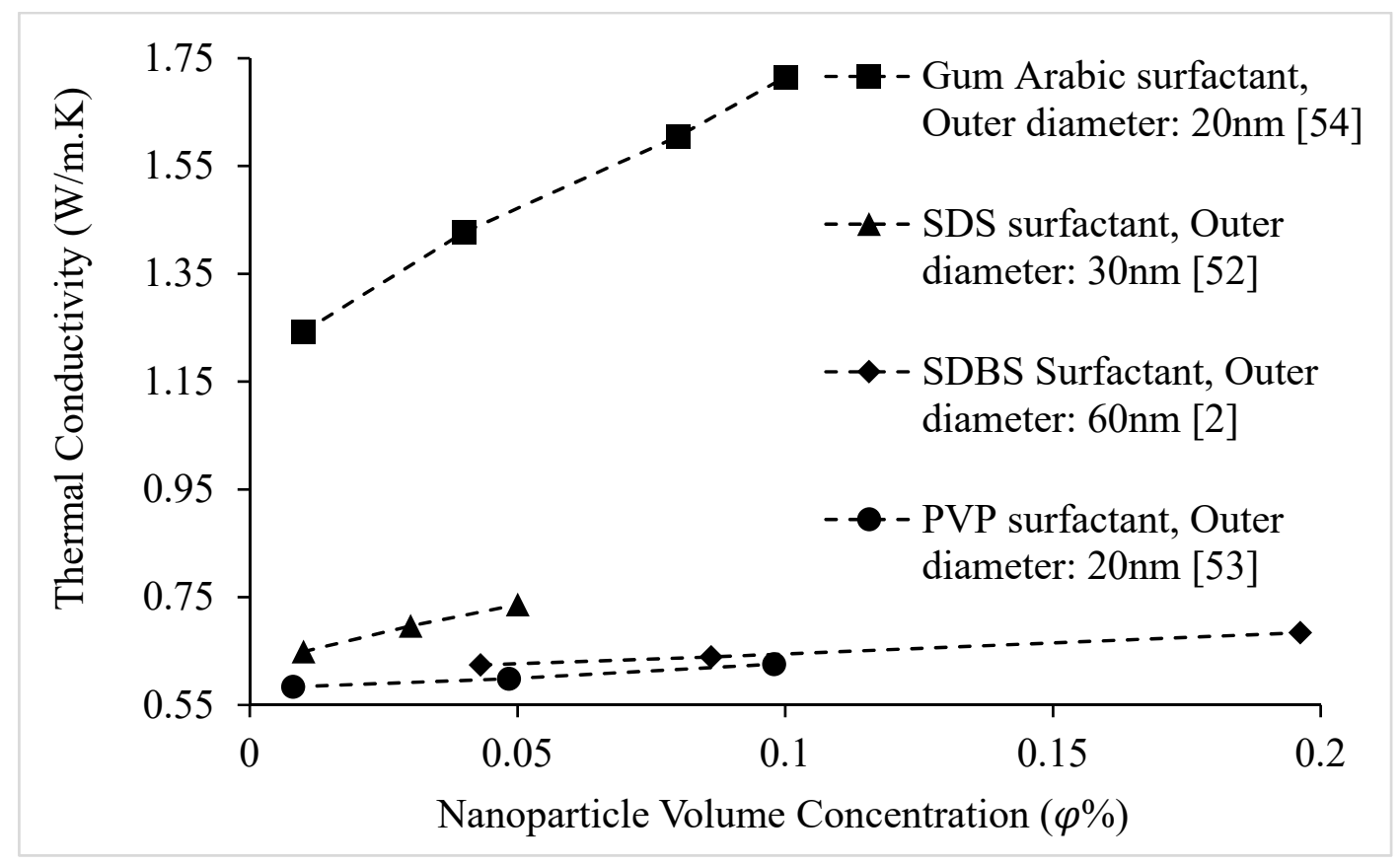

Figure 25. Effect of surfactant on the thermal conductivity of MWCNT-water nanofluid as a function of nanoparticle volume concentration, $\varphi$, at room temperature.

\subsection{Effects of Hybrid Nanoparticles on Nanofluid Thermal Conductivity}

Recently, researchers have conducted experiments on nanofluids containing multiple types of nanoparticles. These nanofluids are called hybrid nanofluids. Experimental data has shown that similarly to nanofluids containing one type of nanoparticle, the thermal conductivity of hybrid nanofluids generally increases with temperature and nanoparticle volume concentration [59-64]. In many cases, researchers combined metal or metal-oxide nanoparticles with various types of carbon nanotubes [55,59-62,65]. For example, using a KD2 Pro Thermal Properties Analyzer, Zadkhast et al. [65] tested the thermal conductivity of CuO-MWCNT-water nanofluid. It was observed that the thermal conductivity of the nanofluid increased with both temperature and nanoparticle volume concentration, having a more significant increase with temperature at higher 
nanoparticle concentrations. It was suggested that the increase with temperature was a result of increased Brownian motion, while the increase with concentration was a result of the greater area for heat transfer and possible clustering of the nanoparticles. In the same way, Esfe et al. [60] measured the thermal conductivity of SWCNT- $\mathrm{Al}_{2} \mathrm{O}_{3}$-water nanofluid. A non-linear increase with both temperature and concentration was observed, with a stronger dependence on temperature shown at higher nanoparticle concentrations. It was suggested that this was a result of increased collisions of the nanoparticles due to Brownian motion. Additionally, using a KD2 Pro Thermal Property Analyzer, Esfe et al. [62] measured the thermal conductivity of ZnO-MWCNT-50/50 Ethylene Glycol-water nanofluid. The results are shown in Figure 26. A non-linear increase with both temperature and concentration was observed. It was suggested that the increase with temperature was a result of Brownian motion, whereas the increase with nanoparticle volume concentration was a result of the increased surface area to volume ratio allowing for more effective heat transfer, along with a greater number of particles, resulting in a greater number of collisions. Through comparing the collected data for the hybrid nanofluid with previously collected data for MWCNT-water and ZnO-water nanofluids, it was observed that for a given concentration, the hybrid nanofluid had a greater thermal conductivity. Additionally, it was suggested that the hybrid nanofluid was a more efficient choice, due to its lower cost in comparison to a nanofluid containing solely MWCNTs in a higher concentration. Using the same method, Afrand et al. [61] conducted experiments to explore the effects of concentration and temperature on MgO-functionalized MWCNT-Ethylene Glycol nanofluid. A non-linear increase with concentration was observed. It was suggested that this increase was a result of clustering of the nanoparticles creating paths with low thermal resistance, thus leading to accelerated heat transfer, and therefore increased thermal conductivity. However, while the thermal conductivity continually increased, the percent enhancement was lower at concentrations above $\varphi=0.2 \%$. It was suggested that this was a result of increased van der Waals forces resulting in increased size of the clusters. It was suggested that the increased thermal conductivity with temperature was a result of increased Brownian motion. Using the thermal hot plate method, Trinh et al. [59] measured the thermal conductivity of Ethylene Glycol -based nanofluid containing nanoparticles composed of $\mathrm{Cu}$ bonded to the surfaces of MWCNTs and graphene sheets. A non-linear increase was observed with both temperature and nanoparticle concentration. It was suggested that the increase with temperature was a result of increased Brownian motion, while that with concentration was a result of the increased area for heat transfer. It was also suggested that the $\mathrm{Cu}$ and MWCNTs prevented stacking of the graphene sheets, also contributing to increased thermal conductivity. In addition, although experimental data has shown that the thermal conductivity of nanoparticles themselves does not have a significant influence on the thermal conductivity of nanofluids $[8,26,32,36]$, it was suggested that the combination of multiple materials having high thermal conductivity contributed to the enhanced thermal conductivity of the nanofluid. Jana et al. [55] measured the thermal conductivities of $\mathrm{Cu}$-water, $\mathrm{Au}$-water, $\mathrm{Cu}-\mathrm{CNT}$-water, and Au-CNT-water nanofluids using a TC-30 instrument which worked based on a modified hot-wire technique. The results showed a lower thermal conductivity for the hybrid nanofluids of Au-CNT-water and $\mathrm{Cu}-\mathrm{CNT}$-water nanofluids in comparison to the nanofluids containing a single type of nanoparticle. It was suggested that the decrease in thermal conductivity was a result of possible agglomeration, or a poor interaction between the Au and $\mathrm{Cu}$ with the CNT. Also, Leong et al. [66] measured the thermal conductivity of a hybrid nanofluid composed of $\mathrm{Cu}$ and $\mathrm{TiO}_{2}$ nanoparticles dispersed in a 50-50 Ethylene Glycol / water mixture. The data collected was compared with data for nanofluids composed of the same base liquid and each nanoparticle, individually. It was observed that the hybrid nanofluid containing PVP surfactant had a higher thermal conductivity in comparison to those containing Gum Arabic and SDS surfactants. It was observed that for a given concentration, temperature, and surfactant, the hybrid nanofluid containing PVP surfactant had a higher thermal conductivity than the nanofluids containing solely $\mathrm{Cu}$ or $\mathrm{TiO}_{2}$ nanoparticles. However, for the nanofluid containing Gum Arabic, both the nanofluid containing solely $\mathrm{Cu}$ nanoparticles and that containing solely $\mathrm{TiO}_{2}$ nanoparticles had higher thermal conductivities than the hybrid nanofluid, 
while for the SDS surfactant, the nanofluid containing solely $\mathrm{TiO}_{2}$ nanoparticles had a higher thermal conductivity than the hybrid nanofluid. Esfahani et al. [63] measured the thermal conductivity of $\mathrm{ZnO}-\mathrm{Ag}-$ water hybrid nanofluid. An increase in thermal conductivity with both temperature and nanoparticle volume concentration was observed; however, it was observed that the increase in nanoparticle concentration had a greater influence on thermal conductivity. It was suggested that the increase with temperature was a result of increased Brownian motion at higher temperatures, while that with concentration was a result of nanoparticle clustering allowing for more rapid heat transfer between the liquid and solid. Using a KD2 Pro, Kannaiyan et al. [64] studied the thermal conductivity of water-based and 50/50 water- Ethylene Glycol based hybrid nanofluid containing $\mathrm{CuO}$ and $\mathrm{Al}_{2} \mathrm{O}_{3}$ nanoparticles. An increase in thermal conductivity with both temperature and nanoparticle volume concentration was observed. It was also observed that the Water-based nanofluid had a higher thermal conductivity than the water- Ethylene Glycol based nanofluid, likely due to the higher thermal conductivity of water in comparison to Ethylene Glycol. In the same way, Hamid et al. [67] measured the thermal conductivity of hybrid nanofluid composed of $\mathrm{TiO}_{2}$ and $\mathrm{SiO}_{2}$ nanoparticles dispersed in a $60 \%: 40 \%$ by volume water- Ethylene Glycol mixture. The nanofluid was tested at the following various nanoparticle mixture ratios $\left(\mathrm{TiO}_{2}: \mathrm{SiO}_{2}\right): 20: 80,40: 60,50: 50,60: 40,80: 20$. It was observed that for each mixture ratio, the nanofluid thermal conductivity increased with temperature, likely due to increased Brownian motion and greater kinetic energy at higher temperatures. For a given temperature, the highest thermal conductivity was observed for the nanoparticle mixture ratio of 20:80, while the 50:50 nanofluid had the lowest thermal conductivity. The results showed an increase in nanofluid thermal conductivity with the increased amount of $\mathrm{SiO}_{2}$ nanoparticles in the mixture, with the exception of the 50:50 nanofluid. It was suggested that this was likely a result of the smaller size of the $\mathrm{SiO}_{2}$ nanoparticles $(22 \mathrm{~nm})$ in comparison to the $\mathrm{TiO}_{2}$ nanoparticles $\left(50 \mathrm{~nm}\right.$ ) allowing the $\mathrm{SiO}_{2}$ nanoparticles to fill in the spaces between the $\mathrm{TiO}_{2}$ nanoparticles, thus leading to increased contact area for conduction between molecules, and therefore an increased rate of heat transfer as a result of Brownian motion collisions. Parsian and Akbari [68] developed new experimental correlation for the thermal conductivity of Ethylene Glycol containing $\mathrm{Al}_{2} \mathrm{O}_{3}-\mathrm{Cu}$ hybrid nanoparticles. Additionally, Sundar et al. [14] measured the thermal conductivity of nanofluids composed of nanodiamond and $\mathrm{Co}_{3} \mathrm{O}_{4}$ nanoparticles dispersed in water and water- Ethylene Glycol mixtures of various concentrations. A linear increase in thermal conductivity with temperature and concentration was observed for each combination. However, higher thermal conductivity enhancement was observed for the water-based nanofluid in comparison to the nanofluids containing Ethylene Glycol. Through examining the experimental findings discussed above, it can be suggested that the thermal conductivity of hybrid nanofluids tends to increase with temperature and nanoparticle concentration, similarly to nanofluids containing a single type of nanoparticle, likely as a result of Brownian motion and an increased area for heat transfer at higher nanoparticle concentrations. However, further experimentation should be completed in order to determine how well various materials of nanoparticles interact with each other and with the base liquid in which they are dispersed. Additionally, further investigation should be completed in order to develop a better understanding of the exact mechanisms which lead to enhanced thermal conductivity in hybrid nanofluids. 


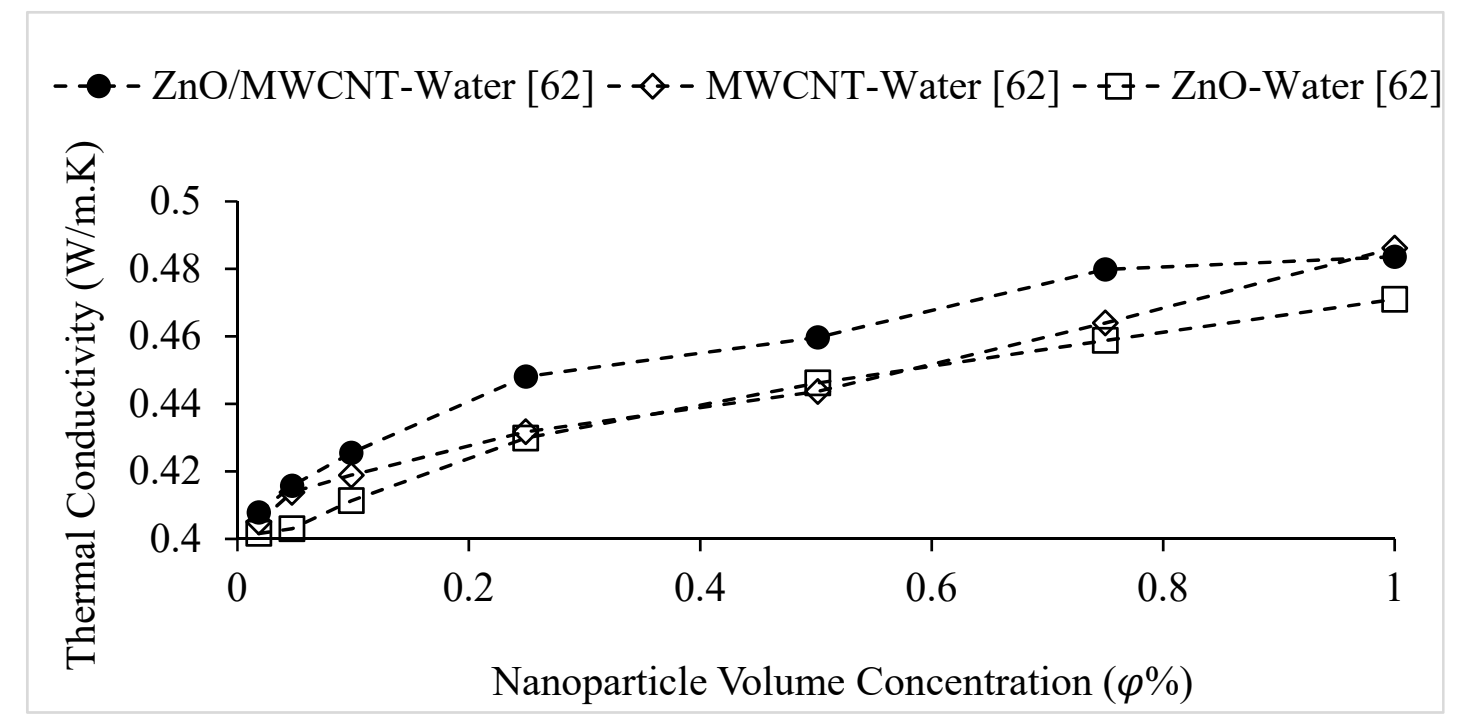

Figure 26. Comparison of the thermal conductivity of hybrid nanofluid to nanofluids containing single types of nanoparticles as a function of nanoparticle volume concentration, $\varphi$, in 50-50 Ethylene Glycol/water base liquid, at $40^{\circ} \mathrm{C}$.

\section{Nanofluid Thermal Conductivity Models}

As discussed in the previous sections, mechanisms such as Brownian motion, aggregation, and the formation of an orderly liquid layer around nanoparticles play a significant role in nanofluid thermal conductivity enhancement. The following section briefly describes these phenomena and their influence on nanofluids. A brief discussion of various numerical models which are used to obtain theoretical data regarding the thermal conductivity of nanofluids is also included.

\subsection{Effective Medium Theory}

A precise calculation to predict the thermal conductivity of nanofluids is nearly impossible due to the mixture's inherent complex properties. The effective medium theory is a static model that does not account for any dynamic or random motion within the mixture (see Figure 27). Predictions of a mixture's physical properties can be theoretically solved for by using the effective medium theory. The component's material properties, along with the specific composition ratios can be used to calculate the mixture's combined effective properties [69].

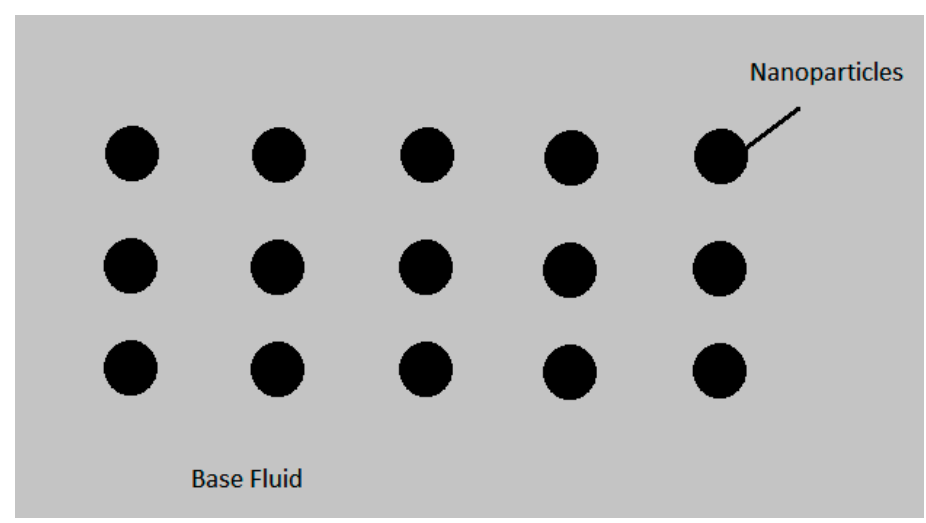

Figure 27. A representation of the effective medium theory showing the base fluid in grey, and the nanoparticles depicted as black circles. 
Most derived equations use the effective medium theory as the core theory to base equations off of. The effective medium theory yields the best results when predicting dilute suspensions containing nanoparticles having sizes within the micrometer and millimeter range. Without the incorporation of dynamic elements within the nanofluid, the theoretical results usually yield an underestimate for the overall thermal conductivity enhancement.

Maxwell's [70] theoretical work was the foundation behind most models for predicting the thermal conductivity of nanofluids. His model assumes that no particles are moving, and there are no interactions in-between the suspended nanoparticles. The Maxwell model only takes into consideration the thermal conductivity of the base fluid, the thermal conductivity of the nanoparticle and the nanoparticle volume fraction. The model is most accurate for suspensions with a low volume fraction and nanoparticles within the micrometer to millimeter size range. However, the practicality behind nanoparticles on the micrometer and millimeter size lead to issues concerning the stability of the nanofluid with the rapid settling of the nanoparticles. With an unstable nanofluid, the nanoparticles can settle out of the mixture. Maxwell's model usually underestimates the thermal conductivity enhancement due to nanofluids, however is still used as a comparison due to the model's simplicity.

A mathematical approach by Davis [71] attempted to solve for the heat conduction for a two-phase material. His mathematical model studied two spheres and the heat transfer between them. The model concludes that when perfectly conducting spheres are densely packed together, the effective heat transfer approaches infinity logarithmically. Unfortunately, the heat conduction between two spheres cannot be expanded to three or more spheres.

Maxwell's work was further expanded on by Hamilton and Crosser [72] who considered a factor for the shape of nanoparticles. Hamilton and Crosser introduced the term sphericity to describe how closely the nanoparticle's shape resembles that of a perfect sphere. The nanoparticle's shape only makes a significant impact when the thermal conductivity of the nanoparticle is significantly larger than the thermal conductivity of the base fluid. Regularly the shape of the nanoparticle has no major significance for the overall thermal conductivity when only using the effective medium theory. The only exception to the importance of the nanoparticle's shape is when the nanoparticle is highly porous.

\subsection{Layering Model}

One of the more significant mechanisms behind the increase in thermal conductivity of nanofluids is the formation of a layer of the base fluid around the nanoparticle. The formed layer around the nanoparticle is slightly denser than the surrounding base fluid, yet significantly less dense than the nanoparticle (see Figure 28) [73].

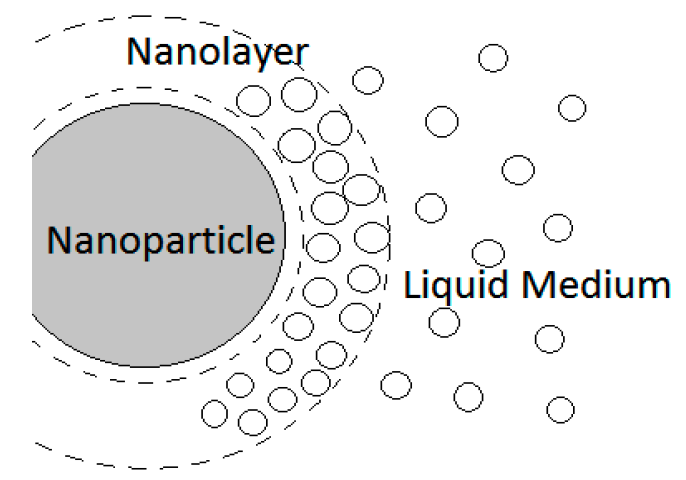

Figure 28. An illustration showing the formed interfacial nanolayer in between the nanoparticle and the base fluid. The nanoparticle is in grey, with the liquid medium molecules being depicted as white circles. The boundaries of the nanolayer are depicted as dashed lines around the nanoparticle.

When the base fluid layer forms in an ordered solid-like state, the formed layer exhibits a higher thermal conductivity than the surrounding base fluid. This interfacial layer acts as a thermal bridge 
between the solid nanoparticle, and the surrounding base fluid, aiding the heat transfer between the two materials [74]. Looking at the different interfacial structures, Xie et al. [73] developed an equation to describe the liquid molecule layering onto the nanoparticle's surface. One of the major struggles of the interfacial layer is the calculation of the layer's thermal conductivity. With smaller particle sizes the interfacial layer becomes more prominent. In their equation, the interfacial layer has a linearly distributed thermal conductivity. Yu and Choi [74] once again expanded the Maxwell model to include an interfacial layer. They proposed that the interfacial layer formed on the nanoparticle would act as a thermal bridge between the nanoparticle and the surrounding base fluid. The energy transport within the nanofluid was assumed to be predominantly diffusive. This assumption was made due to the mean free path of the base fluid molecules being smaller than the average interparticle distance. The interfacial layer around the nanoparticle was mathematically combined with the nanoparticle to form an equivalent nanoparticle. Yu and Choi focused specifically on the effects of the nanolayer and assumed that there was no particle interaction at lower nanoparticle fractions. With fewer nanoparticles in the nanofluid, the average distance between nanoparticles is greater, leading to a decrease in the probability of collisions and also decreasing the formation of clusters. The developed theoretical model does not account for the addition of surfactant. An added surfactant would change the nanofluid into a ternary system which cannot be calculated through the theoretical model. Similar models were introduced by others $[75,76]$.

\subsection{Aggregation Model}

Due to the stochastic motion of nanoparticles within a nanofluid, constant aggregation and dispersion occur. Particle aggregation is the clustering of particles which are dispersed within a liquid medium [69]. These clusters form irregularly and randomly within the mixture (see Figure 29).

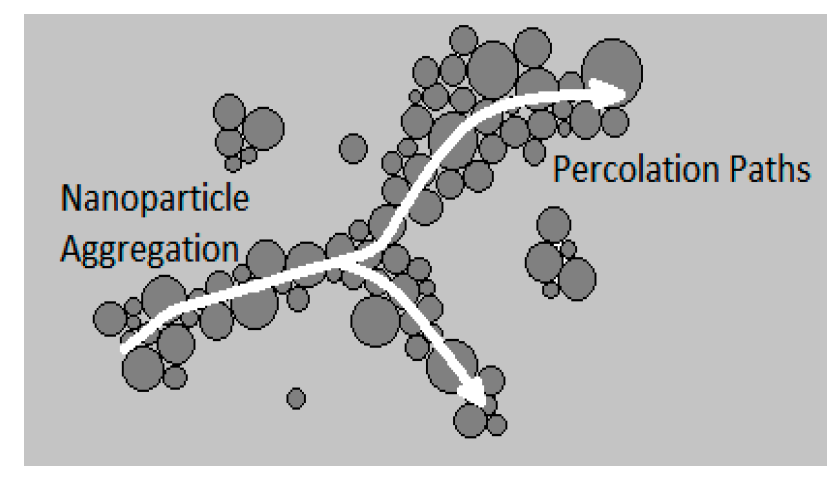

Figure 29. An illustration of randomly formed nanoparticle clusters due to particle aggregation. The white arrows show the heat percolation paths through the formed nanoparticle clusters.

The formation of aggregate clusters leads to reduced Brownian particle velocity within the nanofluid. Nanoparticle clusters having larger sizes impede movement due to increased fluid resistance exerted on the clusters from the surrounding base fluid. More importantly, the clusters reduce the stability of the nanofluid suspension, which can lead to settling of the nanoparticles. However, the nanoparticle clusters can be beneficial by increasing the contact between nanoparticles, thus leading to increase in thermal conductivity [77]. Different nanoparticle shapes and clusters were considered by $\mathrm{Lu}$ and $\mathrm{Lin}$ [78] to determine the thermal conductivity enhancement. The first model they developed was specifically for dilute and homogeneously spread nanoparticles, and was considered to be overly simplified. The second model developed took into consideration the formation of complex microstructures which yielded more accurate results over the simplified model. Wang et al. [77] specifically created models considering the aggregation and clustering of nanoparticles. Their equations were based on the effective medium theory, along with the fractal theory. At lower 
particle concentrations, the developed equation reduces to the effective medium theory. With higher particle concentration, the model relies on the Bruggerman model.

\subsection{Brownian Model}

Brownian motion describes the random, chaotic movements of particles within a fluid. This chaotic movement within the fluid is due to the continuous collisions between nanoparticles and the molecules of the base fluid. This chaotic movement within the nanofluid can induce localized convection, which can further enhance the heat transfer. Brownian motion is more prominent with smaller nanoparticles, where the collisions have a larger effect on the nanoparticles. The Brownian motion can lead to increased aggregation of nanoparticles (see Figure 30) [79,80].

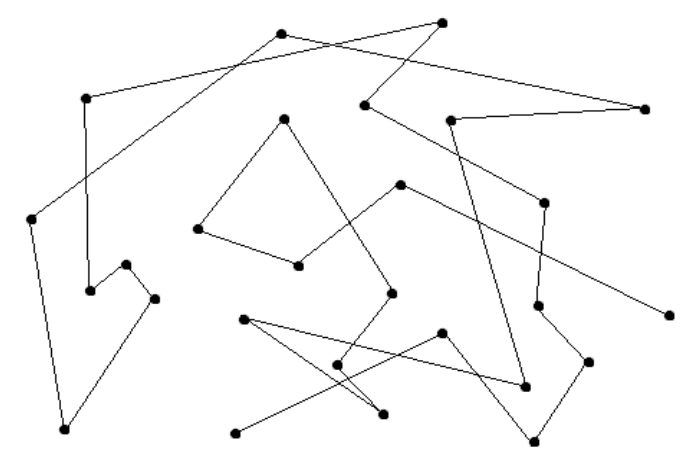

Figure 30. An illustration of the random motion of a singular nanoparticle caused by Brownian motion.

Bhattacharya et al. [81] combined the effects of convection and conduction in their thermal model. The Brownian motion in nanofluids can lead to convection like effects, which not only mix the particles but also can break apart formed clusters. Their model has the flexibility to allow for larger particle sizes that can be simulated through Maxwell's model where conduction is the driving mechanism. When the particle size decreases, other forces such as Brownian motion dominate. Kinetic theory was linked to temperature in addition to stationary heat transfer mechanics by Kumar et al. [82]. The stationary model was based on Fourier's law of diffusion through the nanoparticles and the base fluid. The Stokes-Einstein formula was used to calculate the average particle velocity based on the viscosity of the base fluid.

Through an order of magnitude analysis, Prasher et al. [83] concluded that convection induced by Brownian motion was the driving factor in the enhancement of the thermal conductivity of nanofluids. Due to the small size of nanoparticles, surface forces are predominant and use different energy modes for heat transfer within the nanofluid. It was theorized that the interparticle potential between nanoparticles can result in a phonon-like form of heat transfer. Phonon energy is where energy is passed as vibrational energy that oscillates atoms within a crystal. The interfacial layer aids phonon-like heat transfer, which has a significant influence on the thermal conductivity of nanofluids.

One argument against the importance of Brownian motion was studied by $\mathrm{Li}$ et al. [80]. It was determined that Brownian motion does not solely lead to significant thermal conductivity enhancements due to an increase in temperature. It was suggested that the temperature of the nanofluid plays a more significant role. Increased temperature leads to a decrease in the base fluid's viscosity, thus resulting in reduced agglomeration and increased Brownian motion.

Jang and Choi [84] looked into several different methods of heat transfer within a nanofluid. The different methods being: base fluid molecule collisions, collisions between nanoparticles, thermal diffusion of the nanoparticles, and finally the collisions between nanoparticles and base fluid molecules. It was then determined that heat transfer due to Brownian motion particle collisions with the base fluid molecules, was an order of magnitude lower and is negligible. The nanofluid does not have an overall bulk flow, and exhibits conduction due to the constant particle interaction. A combination of 
Brownian motion and aggregation structures were considered by Xuan et al. [85] for the development of their model. The cluster fractal structures along with the radius of gyration had significant effects on the effective thermal conductivity of the nanofluid. The radius of gyration is the distribution of the nanoparticles around an axis of the cluster. When there was a reduction in the radius of gyration, there was an increase in the thermal conductivity. With reduced cluster size, the particles can travel faster and farther, which increases the effective thermal conductivity.

\subsection{Molecular Dynamic Models}

The dynamic movements of molecules and atoms can be simulated through various computer simulations. The computer can simulate the interactions between a specified number of molecules for a set duration of time. It is almost impossible to accurately predict the thermal conductivity of nanofluids due to the inherent complexities of nanofluids [86]. With molecular dynamic models, researchers are able to account for the forces acting on the nanoparticle molecules, base fluid molecules, and any other added molecules, instead of trying to apply macroscopic thermal dynamic equations.

Molecular dynamic simulations were utilized in investigating the interfacial layer. Instead of relying on experimental data, Lin et al. [87] simulated how a base fluid's molecules interacted with the nanoparticles. The interfacial layer increased the thermal conductivity while reducing the density distribution of the nanofluid. The simulation was run several times to determine the optimum size for the nanoparticles. Clustering and aggregation were not included in the simulation. Summary of existing experimental investigations on thermal conductivity of nanofluids is given in Appendix A (Table A1).

\section{Conclusions}

The effects of characteristics of nanoparticles (material, size, shape), base liquid, surfactant, concentration and temperature on nanofluid thermal conductivity were studied in this paper, along with the effects of the addition of carbon nanotubes and combining multiple nanoparticles to form hybrid nanofluids. Additionally, the mechanisms which lead to increased thermal conductivity in nanofluids were briefly discussed, along with the numerical models used to obtain theoretical data. Several conclusions were made, such as that the thermal conductivity of nanofluids increases with both temperature and concentration, and the thermal conductivity of nanofluids may increase, decrease, or experience no change with the decrease of nanoparticle size. However, in most cases, the thermal conductivity of nanofluids increased when nanoparticle size was decreased. It was also concluded that the thermal conductivity of nanofluids increases with an increase in base liquid thermal conductivity, and an increase in nanoparticle surface area. The thermal conductivity of hybrid nanofluids increases with both temperature and concentration, possibly as a result of Brownian motion. However, further experimentation should be completed in order to determine the exact mechanisms which contributed to the increase in thermal conductivity of hybrid nanofluids. Finally, the thermal conductivity of nanofluids containing carbon nanotubes increases with both temperature and concentration, but further experimentation should be completed to determine the best way to prevent nanotube aggregation, in order to maintain nanofluid stability.

Overall, the majority of experimental data agrees with the conclusions stated above. However, as discussed in the preceding sections, many parameters, such as nanoparticle size, nanoparticle material, and the addition of surfactant should be further studied in order to better understand the controversial experimental data which is currently available.

Author Contributions: The manuscript was written by S.S., A.S., C.G. and advised by S.V.

Funding: This work is partially supported by Special Emphasis Program at Bradley University and Illinois Space Grant Consortium funding, USA.

Conflicts of Interest: The authors declare no conflict of interest. 


\section{Appendix A}

Table A1. Summary of existing experimental investigations on thermal conductivity of nanofluids.

\begin{tabular}{|c|c|c|}
\hline Reference & Specifications & Remarks \\
\hline Esfe et al. [57] (2018) & $\begin{array}{c}\text { Temperature Range }\left({ }^{\circ} \mathrm{C}\right): 30-50 \\
\text { Base Liquid: Ethylene Glycol } \\
\text { Nanoparticle Material: COOH Functionalized } \\
\text { Single-Walled Carbon Nanotubes } \\
\text { Nanoparticle Size }(\mathrm{nm}): \\
\text { Outer diameter- } 2 \\
\text { Inner diameter- } 1.6 \\
\text { Length- } 50,000 \\
\text { Concentration }(\varphi): 0.02 \%, 0.05 \%, 0.075 \%, 0.1 \% \text {, } \\
0.25 \%, 0.5 \%, 0.75 \%\end{array}$ & $\begin{array}{l}\text { The need for surfactant to maintain stability } \\
\text { was eliminated by functionalizing the } \\
\text { nanotubes with COOH group in order to make } \\
\text { them hydrophilic. } \\
\text { It was observed that the thermal conductivity } \\
\text { increased non-linearly with temperature. } \\
\text { The maximum thermal conductivity } \\
\text { enhancement of } 45 \% \text { was reached at } 50^{\circ} \mathrm{C} \text { and } \\
\qquad \varphi=0.75 \% \text {. }\end{array}$ \\
\hline Leong et al. [66] (2018) & $\begin{array}{c}\text { Temperature Range: Room Temperature } \\
\text { Base Liquid: 50/50 Ethylene Glycol-Water } \\
\text { Mixture } \\
\text { Nanoparticle Material: } \mathrm{Cu}, \mathrm{TiO}_{2} \\
\text { Nanoparticle Size (nm): } \\
\mathrm{Cu}-60 \\
\mathrm{TiO}_{2}-25 \\
\text { Surfactant: Gum Arabic, PVP, SDBS }\end{array}$ & $\begin{array}{l}\text { It was observed that the hybrid nanofluid } \\
\text { containing PVP surfactant had the highest } \\
\text { thermal conductivity, followed by that } \\
\text { containing SDBS surfactant, while that } \\
\text { containing Gum Arabic surfactant had the } \\
\text { lowest. }\end{array}$ \\
\hline Esfahani et al. [63] (2018) & $\begin{array}{c}\text { Temperature Range }\left({ }^{\circ} \mathrm{C}\right): 25-50 \\
\text { Base Liquid: Water } \\
\text { Nanoparticle Material: Ag, ZnO } \\
\text { Nanoparticle Size (nm): } \\
\text { Ag-30 } \\
\text { ZnO-30 } \\
\text { Concentration }(\varphi): 0.125-2.0 \% \\
\text { Nanoparticle Shape: Spherical }\end{array}$ & $\begin{array}{c}\text { An increase in thermal conductivity with } \\
\text { temperature was observed, with a greater } \\
\text { increase at higher nanoparticle concentrations, } \\
\text { likely as a result of increased collisions due to } \\
\text { Brownian motion } \\
\text { An increase in thermal conductivity with } \\
\text { nanoparticle concentration was observed, likely } \\
\text { due to nanoparticle clustering allowing for } \\
\text { more efficient heat transfer between the liquid } \\
\text { and solid. }\end{array}$ \\
\hline $\begin{array}{c}\text { Maheshwary et al. [25] } \\
\text { (2017) }\end{array}$ & $\begin{array}{c}\text { Temperature Range }\left({ }^{\circ} \mathrm{C}\right): 30-80 \\
\text { Base Liquid: water } \\
\text { Nanoparticle Material: } \mathrm{TiO}_{2} \\
\text { Nanoparticle Size (nm): spherical-22.9, } \\
\text { cubic-51.87, rod-43.08 } \\
\text { Nanoparticle Shape: cubic, spherical, rod }\end{array}$ & $\begin{array}{l}\text { Thermal conductivity increased with the } \\
\text { increase of particle concentration and } \\
\text { temperature and decrease of particle size. } \\
\text { It was concluded that the increase in thermal } \\
\text { conductivity with decrease in nanoparticle size } \\
\text { was a result of increased Brownian motion for } \\
\text { smaller nanoparticles. } \\
\text { It was concluded that concentration had a more } \\
\text { significant impact on the thermal conductivity } \\
\text { than particle size and shape. } \\
\text { The thermal conductivity of the nanofluid with } \\
\text { cubic } \mathrm{TiO}_{2} \text { nanoparticles had a higher thermal } \\
\text { conductivity than those with rod and spherical } \\
\text { shaped } \mathrm{TiO}_{2} \text { particles. It was concluded that } \\
\text { this was caused by the larger surface area of the } \\
\text { cubic nanoparticles. }\end{array}$ \\
\hline Das et al. [22] (2017) & $\begin{array}{c}\text { Temperature Range }\left({ }^{\circ} \mathrm{C}\right): 20-60 \\
\text { Base Liquid: Distilled Water } \\
\text { Nanoparticle Material: } \mathrm{Al}_{2} \mathrm{O}_{3} \\
\text { Nanoparticle Size }(\mathrm{nm}): 20-70 \\
\text { Nanoparticle Shape: rod } \\
\text { Concentration }(\varphi): 0.1-2.0 \% \\
\text { Surfactant: CTAB, SDBS, SDS }\end{array}$ & $\begin{array}{l}\text { The thermal conductivity increased with both } \\
\text { particle concentration and temperature. } \\
\text { It was concluded that stability of the nanofluid } \\
\text { is a major factor in application, and SDBS } \\
\text { surfactant showed that it has capability to } \\
\text { provide the highest stability. } \\
\text { The SDBS surfactant suppressed the thermal } \\
\text { conductivity of the base fluid by less than } 2 \% \text {. } \\
\text { For a given temperature and volume fraction, } \\
\text { the thermal conductivity for nanofluids with no } \\
\text { surfactant was higher than that of those } \\
\text { containing surfactant. } \\
\text { It was concluded that the increase in thermal } \\
\text { conductivity with temperature was caused by } \\
\text { increased Brownian motion at higher } \\
\text { temperatures. }\end{array}$ \\
\hline
\end{tabular}


Table A1. Cont.

\begin{tabular}{|c|c|c|}
\hline Reference & Specifications & Remarks \\
\hline Agarwal et al. [12] (2017) & $\begin{array}{c}\text { Temperature Range }\left({ }^{\circ} \mathrm{C}\right): 10-70 \\
\text { Base Liquid: Distilled Water, Ethylene Glycol } \\
\text { Nanoparticle Material: } \mathrm{Al}_{2} \mathrm{O}_{3} \\
\text { Nanoparticle Size }(\mathrm{nm}): 53 \\
\text { Concentration }(\varphi): 0-2 \%\end{array}$ & $\begin{array}{l}\text { The thermal conductivity increased with both } \\
\text { temperature and particle concentration. } \\
\text { Ethylene Glycol nanofluid showed a more } \\
\text { significant increase with particle concentration. } \\
\text { Water-based nanofluid showed a more } \\
\text { significant increase with temperature. } \\
\text { It was concluded that the rate of increase in } \\
\text { thermal conductivity with temperature and } \\
\text { concentration varies significantly between base } \\
\text { fluids. } \\
\text { It was concluded that the increase in thermal } \\
\text { conductivity with temperature was caused by } \\
\text { increased Brownian motion. }\end{array}$ \\
\hline Seyhan et al. [23] (2017) & $\begin{array}{c}\text { Base Liquid: Distilled Water, Ethylene Glycol, } \\
\text { Hexane } \\
\text { Nanoparticle Material: Hydrophilic Ag, } \\
\text { Hydrophobic Ag } \\
\text { Nanoparticle Size: hydrophilic Ag (nm): 3-17, } \\
\text { hydrophobic Ag: 4-17 } \\
\text { Nanoparticle Shape: spherical } \\
\text { Surfactant: Gum Arabic, Oleylamine, Oleic acid }\end{array}$ & $\begin{array}{c}\text { Gum Arabic surfactant lowered the thermal } \\
\text { conductivity of water, but did not have a } \\
\text { negative effect on the thermal conductivity of } \\
\text { Ethylene Glycol. } \\
\text { The results showed that only water-based } \\
\text { nanofluids at higher concentrations were } \\
\text { dependent on temperature. } \\
\text { Thermal conductivity increased with particle } \\
\text { concentration, but the rate of enhancement } \\
\text { slowed at higher concentrations due to } \\
\text { agglomeration of nanoparticles. } \\
\text { For water-based nanofluid at lower } \\
\text { concentrations, the thermal conductivity } \\
\text { increased with the increase of temperature, but } \\
\text { at higher concentrations the thermal } \\
\text { conductivity began to decrease with increase of } \\
\text { temperature. } \\
\text { The results showed that the thermal } \\
\text { conductivities of Ethylene Glycol and hexane } \\
\text { based nanofluids were independent of } \\
\text { temperature. }\end{array}$ \\
\hline Iqbal et al. [37] (2017) & $\begin{array}{c}\text { Base Liquid: water } \\
\text { Nanoparticle Material: } \mathrm{Al}_{2} \mathrm{O}_{3}, \mathrm{SiO}_{2}, \mathrm{ZrO}_{2} \\
\text { Nanoparticle Size }(\mathrm{nm}): \mathrm{Al}_{2} \mathrm{O}_{3}-40, \mathrm{SiO}_{2}-15 \\
\mathrm{ZrO}-25 \\
\text { Nanoparticle Shape: spherical } \\
\text { Concentration }(\varphi): 0.5 \%, 0.75 \%, 1.0 \% \\
\text { Surfactant: } \mathrm{ZrO}_{2}-\mathrm{Y} \text { ttrium Oxide }\end{array}$ & $\begin{array}{c}\text { Thermal conductivity increased with the } \\
\text { increase of particle concentration. } \\
\mathrm{Al}_{2} \mathrm{O}_{3} \text { / water nanofluid had the highest } \\
\text { thermal conductivity. } \\
\text { The increase in thermal conductivity with } \\
\text { volume fraction was contributed to increased } \\
\text { interaction between the nanoparticles and base } \\
\text { fluid. }\end{array}$ \\
\hline Sharifpur et al. [34] (2017) & $\begin{array}{c}\text { Temperature Range }\left({ }^{\circ} \mathrm{C}\right): 20-45 \\
\text { Base Liquid: Glycerol } \\
\text { Nanoparticle Material: } \alpha-\mathrm{Al}_{2} \mathrm{O}_{3} \\
\text { Nanoparticle Size (nm): } 31,55,134 \\
\text { Nanoparticle Shape: spherical } \\
\text { Concentration }(\varphi): 0.5-4 \%\end{array}$ & $\begin{array}{l}\text { Changes in volume concentration and particle } \\
\text { size had a significant impact on the thermal } \\
\text { conductivity, but changes in temperature did } \\
\text { not. } \\
\text { For a given nanoparticle diameter, the thermal } \\
\text { conductivity increased linearly with the } \\
\text { increase of particle concentration. } \\
\text { The results showed higher thermal conductivity } \\
\text { for nanofluids containing smaller nanoparticles } \\
\text { The change in thermal conductivity with } \\
\text { temperature followed the pattern of the base } \\
\text { fluid, glycerol. }\end{array}$ \\
\hline Asadi et al. [19] (2017) & $\begin{array}{c}\text { Temperature Range }\left({ }^{\circ} \mathrm{C}\right): 25-50 \\
\text { Base liquid: Water } \\
\text { Nanoparticle Material: } \mathrm{Mg}(\mathrm{OH}) 2 \\
\text { Nanoparticle Size }(\mathrm{nm}): 20 \\
\text { Concentration }(\varphi): 0.1-2.0 \% \\
\text { Surfactant: CTAB, SDS, OA }\end{array}$ & $\begin{array}{c}\text { Thermal conductivity of the nanofluid } \\
\text { increased with temperature and nanoparticle } \\
\text { volume concentration. } \\
\text { Of the } 3 \text { surfactants tested, CTAB produced the } \\
\text { most stable nanofluid. }\end{array}$ \\
\hline
\end{tabular}


Table A1. Cont.

\begin{tabular}{|c|c|c|}
\hline Reference & Specifications & Remarks \\
\hline Dehkardi et al. [58] (2017) & $\begin{array}{c}\text { Temperature Range }\left({ }^{\circ} \mathrm{C}\right): 30-50 \\
\text { Base Liquid: } 50 \% \text { Water, } 50 \% \text { Ethylene Glycol } \\
\text { Mixture } \\
\text { Nanoparticle Material: COOH Functionalized } \\
\text { Single-Walled Carbon Nanotubes } \\
\text { Nanoparticle Size }(\mathrm{nm}): \\
\text { Outer diameter-2 } \\
\text { Inner diameter-1.6 } \\
\text { Length- } 50000 \\
\text { Concentration }(\varphi): 0.025 \%, 0.055 \%, 0.08 \% \\
0.125 \%, 0.25 \%, 0.53 \%, 0.65 \%\end{array}$ & $\begin{array}{l}\text { It was observed that the thermal conductivity } \\
\text { increased with temperature and nanoparticle } \\
\text { volume concentration, having a more } \\
\text { significant increase at higher concentration. } \\
\text { It was observed that for the same base liquid, } \\
\text { the nanofluid containing nanotubes had a } \\
\text { significantly higher thermal conductivity than } \\
\text { that containing alumina nanoparticles, } \\
\text { demonstrating the superior characteristics of } \\
\text { nanotubes. }\end{array}$ \\
\hline
\end{tabular}

Temperature Range $\left({ }^{\circ} \mathrm{C}\right): 25-50$

Base Liquid: Water

Nanoparticle Material: MWCNT, CuO

Nanoparticle Size (nm):

CuO diameter-50

MWCNT-

Zadkhast et al. [65] (2017)

Outer diameter-15

Inner diameter-5

Length-50,000

Concentration $(\varphi)$ : $0.05 \%, 0.01 \%, 0.15 \%, 0.2 \%$, $0.4 \%, 0.6 \%$

\begin{tabular}{|c|c|c|}
\hline Trinh et al. [59] (2017) & $\begin{array}{c}\text { Temperature Range }\left({ }^{\circ} \mathrm{C}\right): 30-60 \\
\text { Base Liquid: Ethylene Glycol } \\
\text { Nanoparticle Material: MWCNT, Graphene, Cu } \\
\text { Nanoparticle Size }(\mathrm{nm}): \\
\text { Cu diameter-18 } \\
\text { Outer diameter-20 } \\
\text { Length-10,000 } \\
\text { Concentration }(\varphi): 0.005-0.035 \%\end{array}$ & $\begin{array}{c}\text { A non-linear increase with temperature and } \\
\text { nanoparticle volume concentration was } \\
\text { observed. It was suggested that the increase } \\
\text { with temperature was a result of Brownian } \\
\text { motion. } \\
\text { It was suggested that the addition of Cu and } \\
\text { MWCNTs prevented stacking of the graphene } \\
\text { sheets and increased the surface area for heat } \\
\text { transfer, thus leading to enhanced thermal } \\
\text { conductivity. }\end{array}$ \\
\hline Esfe et al. [60] (2017) & $\begin{array}{c}\text { Temperature Range }\left({ }^{\circ} \mathrm{C}\right): 30-50 \\
\text { Base Liquid: Ethylene Glycol } \\
\text { Nanoparticle Material: SWCNT, } \mathrm{Al}_{2} \mathrm{O}_{3} \\
\text { Nanoparticle Size }(\mathrm{nm}): \\
\mathrm{Al}_{2} \mathrm{O}_{3} \text { diameter-20 } \\
\text { Outer diameter-2 } \\
\text { Concentration }(\varphi): 0.04-2.5 \%\end{array}$ & $\begin{array}{l}\text { A non-linear increase in nanofluid thermal } \\
\text { conductivity was observed with both increased } \\
\text { temperature and nanoparticle concentration, } \\
\text { with a stronger dependency on temperature at } \\
\text { higher concentrations. }\end{array}$ \\
\hline Afrand [61] (2017) & $\begin{array}{c}\text { Temperature Range }\left({ }^{\circ} \mathrm{C}\right): 25-50 \\
\text { Base Liquid: Ethylene Glycol } \\
\text { Nanoparticle Material: MgO, Functionalized } \\
\text { MWCNT } \\
\text { Nanoparticle Size (nm): } \\
\text { MgO diameter- } 40 \\
\text { Functionalized MWCNT: } \\
\text { Outer diameter-5 } \\
\text { Inner diameter-5 } \\
\text { Length-50,000 } \\
\text { Concentration }(\varphi): 0-0.6 \%\end{array}$ & $\begin{array}{l}\text { A non-linear increase in thermal conductivity } \\
\text { with concentration was observed, likely due to } \\
\text { nanoparticle clustering at higher concentrations. } \\
\text { A non-linear increase in thermal conductivity } \\
\text { with temperature was also observed, having a } \\
\text { lower enhancement at higher nanoparticle } \\
\text { concentrations. It was suggested that this was a } \\
\text { result of limited Brownian motion due to } \\
\text { clustering. }\end{array}$ \\
\hline Esfe et al. [62] (2017) & $\begin{array}{c}\text { Temperature Range }\left({ }^{\circ} \mathrm{C}\right): 30-50 \\
\text { Base Liquid: } 50 / 50 \text { Ethylene Glycol-Water } \\
\text { Nanoparticle Material: ZnO, MWCNT } \\
\text { Nanoparticle Size }(\mathrm{nm}): \\
\text { ZnO diameter-30 } \\
\text { MWCNT: } \\
\text { Outer diameter-15 } \\
\text { Inner diameter-5 } \\
\text { Concentration }(\varphi): 0.02-1.0 \%\end{array}$ & $\begin{array}{l}\text { A non-linear increase in nanofluid thermal } \\
\text { conductivity with temperature was observed. It } \\
\text { was suggested that this increase was a result of } \\
\text { increased Brownian motion at higher } \\
\text { temperatures. } \\
\text { A non-linear increase in thermal conductivity } \\
\text { with nanoparticle volume fraction was also } \\
\text { observed, which was likely due to the increased } \\
\text { number of collisions with a greater number of } \\
\text { particles, and also the increased surface area to } \\
\text { volume ratio leading to more effective heat } \\
\text { transfer. }\end{array}$ \\
\hline
\end{tabular}

It was observed that the thermal conductivity of the nanofluid increased with nanoparticle concentration and temperature, having a greater increase at higher temperatures. 
Table A1. Cont.

\begin{tabular}{|c|c|c|}
\hline Reference & Specifications & Remarks \\
\hline Kannaiyan et al. [64] (2017) & $\begin{array}{c}\text { Temperature Range }\left({ }^{\circ} \mathrm{C}\right): 20-70 \\
\text { Base Liquid: } 50 / 50 \text { Ethylene Glycol-water, } \\
\text { Water } \\
\text { Nanoparticle Material: } \mathrm{CuO}, \mathrm{Al}_{2} \mathrm{O}_{3} \\
\text { Nanoparticle Size }(\mathrm{nm}): \\
\mathrm{CuO}-20 \\
\mathrm{Al}_{2} \mathrm{O}_{3}-20 \\
\text { Concentration }(\varphi): 0.05,0.1,0.2 \%\end{array}$ & $\begin{array}{l}\text { An increase in thermal conductivity with both } \\
\text { temperature and concentration was observed. } \\
\text { It was observed that the water-based nanofluid } \\
\text { had a higher thermal conductivity then the } \\
\text { Ethylene Glycol-water based nanofluid for a } \\
\text { given concentration and temperature, likely } \\
\text { due to the higher thermal conductivity of water. }\end{array}$ \\
\hline Das et al. [33] (2016) & $\begin{array}{c}\text { Temperature Range }\left({ }^{\circ} \mathrm{C}\right): 20-60 \\
\text { Base Liquid: Water } \\
\text { Nanoparticle Material: } \mathrm{TiO}_{2} \\
\text { Nanoparticle Size (nm): } 10-40 \\
\text { Surfactants: CTAB, AA, OA, SDS }\end{array}$ & $\begin{array}{c}\text { Thermal conductivity increased with the } \\
\text { increase of both volume fraction and } \\
\text { temperature. } \\
\text { Of the } 4 \text { surfactants used, only Acetic acid and } \\
\text { Cetyl trimethyl ammonium bromide produced } \\
\text { stable nanofluids. } \\
\text { It was observed that the increase of temperature } \\
\text { had a stronger effect on the thermal } \\
\text { conductivity at higher temperatures. It was } \\
\text { concluded that this was a result of increased } \\
\text { Brownian motion at higher temperatures. }\end{array}$ \\
\hline Khairul et al. [17] (2016) & $\begin{array}{c}\text { Temperature Range }\left({ }^{\circ} \mathrm{C}\right): 25 \\
\text { Base Liquid: Water } \\
\text { Nanoparticle Material: } \mathrm{Al}_{2} \mathrm{O}_{3}, \mathrm{CuO} \\
\text { Nanoparticle Size: } \mathrm{Al}_{2} \mathrm{O}_{3}-10 \mathrm{~nm}, \mathrm{CuO}-30-50 \\
\mathrm{~nm} \\
\text { Surfactant: Sodium Dodecyl Benzene Sulfonate }\end{array}$ & $\begin{array}{l}\text { The addition of negatively charged surfactant } \\
\text { altered the surface charge of the nanoparticles, } \\
\text { creating repulsion forces, and in turn leading to } \\
\text { a more stable nanofluid. } \\
\text { The thermal conductivity increased with } \\
\text { surfactant weight concentration, and then } \\
\text { began to decrease. It was suggested that the } \\
\text { decrease was caused by greater amounts of } \\
\text { surfactant on the surfaces of the nanoparticles } \\
\text { allowing a narrower area for heat transfer. }\end{array}$ \\
\hline Milanese et al. [44] (2016) & $\begin{array}{c}\text { Temperature Range }\left({ }^{\circ} \mathrm{C}\right): 30 \\
\text { Base Liquid: Water } \\
\text { Nanoparticle Material: } \mathrm{Cu}, \mathrm{CuO} \\
\text { Nanoparticle Size (nm): Cu- } 50 \mathrm{~nm}, \mathrm{CuO}-30 \mathrm{~nm} \\
\text { Concentration }(\varphi): 3 \%\end{array}$ & $\begin{array}{c}\text { Two shell like layers of water molecules were } \\
\text { observed on the surfaces of the } \mathrm{Cu} \\
\text { nanoparticles. } \\
\text { No significant layering was observed on the } \\
\text { surfaces of the } \mathrm{CuO} \text { nanoparticles. }\end{array}$ \\
\hline Sundar et al. [14] (2016) & $\begin{array}{c}\text { Temperature Range }\left({ }^{\circ} \mathrm{C}\right): 20-60 \\
\text { Base Liquid: } 20 \%: 80 \% \text { Ethylene Glycol-Water, } \\
40 \%: 60 \% \text { Ethylene Glycol-Water, } 60 \%: 40 \% \\
\text { Ethylene Glycol-Water } \\
\text { Nanoparticle Material: Nanodiamond } \\
\text { Nanoparticle Size (nm): } 5 \mathrm{~nm} \\
\text { Nanoparticle Shape: cubic } \\
\text { Concentration }(\varphi): 0.2 \%, 0.4 \%, 0.6 \%, 0.8 \%, 1.0 \%\end{array}$ & $\begin{array}{c}\text { A non-linear relationship between thermal } \\
\text { conductivity and nanoparticle concentration } \\
\text { was observed, with a higher slope at greater } \\
\text { concentrations. }\end{array}$ \\
\hline Sundar et al. [29] (2016) & $\begin{array}{c}\text { Temperature Range }\left({ }^{\circ} \mathrm{C}\right): 20-60 \\
\text { Base Liquid: Water } \\
\text { Nanoparticle Material: Nanodiamond } \\
\text { Nanoparticle Size }(\mathrm{nm}): 11.4 \\
\text { Concentration }(\varphi): 0.2 \%, 0.4 \%, 0.6 \%, 0.8 \%, 1.0 \%\end{array}$ & $\begin{array}{c}\text { Some advantages of nanodiamond particles are } \\
\text { their high thermal conductivity, high electrical } \\
\text { resistivity, and biocompatibility. } \\
\text { The thermal conductivity increased with } \\
\text { concentration and temperature. This increase } \\
\text { was caused by Brownian motion and } \\
\text { micro-convection. } \\
\text { The thermal conductivity enhancement was } \\
\text { greater at higher concentrations, which was } \\
\text { likely caused by agglomeration of the } \\
\text { nanodiamond particles. }\end{array}$ \\
\hline
\end{tabular}


Table A1. Cont.

\begin{tabular}{|c|c|c|}
\hline Reference & Specifications & Remarks \\
\hline Agarwal et al. [10] (2016) & $\begin{array}{c}\text { Temperature Range }\left({ }^{\circ} \mathrm{C}\right): 10-70 \\
\text { Base Liquid: Water, Ethylene Glycol, Engine Oil } \\
\text { Nanoparticle Material: CuO } \\
\text { Nanoparticle Shape: spherical } \\
\text { Nanoparticle Size }(\mathrm{nm}): 10-14 \\
\text { Concentration }(\varphi): 0-2 \%\end{array}$ & $\begin{array}{l}\text { The thermal conductivity increased with both } \\
\text { temperature and concentration. It was } \\
\text { concluded that the increase with concentration } \\
\text { was a result of greater surface area for heat } \\
\text { transfer, and increase with temperature was a } \\
\text { result of increased Brownian motion. } \\
\text { It was concluded that the difference in } \\
\text { enhancement of thermal conductivity for each } \\
\text { base liquid was caused by the variation in } \\
\text { thermal conductivity of the base liquids, and } \\
\text { differences in the strength of interactions } \\
\text { between the nanoparticles and each base liquid. } \\
\text { It was concluded that smaller nanoparticles } \\
\text { result in higher thermal conductivity because of } \\
\text { the greater surface area to volume ratio. }\end{array}$ \\
\hline
\end{tabular}

Temperature Range $\left({ }^{\circ} \mathrm{C}\right): 20-60$

Sundar et al. [14] (2016) Base Liquid: Ethylene Glycol / Water Mixture,

Nanoparticle Material: nanodiamond, $\mathrm{Co}_{3} \mathrm{O}_{4}$ Weight Concentration: $0-0.15 \%$

Temperature Range $\left({ }^{\circ} \mathrm{C}\right): 30-50$

Base Liquid: Hydrogenated Oil-based drilling fluid

Chai et al. [56] (2016) Nanoparticle Material: MWCNTs

Nanoparticle Size (nm):

Outer diameter-12

Inner diameter-6

It was observed that at low nanoparticle concentrations, the thermal conductivity improved by small amounts compared to at higher temperatures.

\begin{tabular}{c} 
Inner diameter-6 \\
\hline Temperature Range $\left({ }^{\circ} \mathrm{C}\right): 10-80$ \\
Base Liquid: De-ionized Water \\
Nanoparticle Material: Multi-Walled Carbon \\
Nanotubes \\
Particle \\
Nan et al. [52] (2015) \\
Outer diameter-30 nm Concentration $(\varphi):$ \\
$0.01 \%, 0.03 \%, 0.05 \%$ \\
$\operatorname{SDS}$
\end{tabular}

The thermal conductivity did not increase significantly with $0.01 \mathrm{~V} \%$ MWCNTs, but it did increase significantly with $0.03 \mathrm{~V} \%$.

The thermal conductivity increased with temperature and particle concentration. It was concluded that Brownian motion was the main contributor to the increase in thermal conductivity at high temperatures.

The MWCNTs/water nanofluid was very stable over time, making these nanofluids attractive for applications in cooling.

\begin{tabular}{|c|c|c|}
\hline Huminic et al. [39] (2015) & $\begin{array}{c}\text { Temperature Range }\left({ }^{\circ} \mathrm{C}\right): 10-70 \\
\text { Base Liquid: Water } \\
\text { Nanoparticle Material: FeC } \\
\text { Particle Concentration }(\varphi): 0.022 \%, 0.17 \%, 1 \% \\
\text { Surfactant: Low Viscosity Carboxymethyl } \\
\text { Cellulose Sodium Salt }(\mathrm{CMCNa}) \\
\text { Surfactant Concentration: } 3 \mathrm{~g} / \mathrm{L}\end{array}$ & $\begin{array}{l}\text { The thermal conductivity increased with both } \\
\text { temperature and particle concentration. } \\
\text { The addition of surfactant did not significantly } \\
\text { affect the thermal conductivity of the base fluid. }\end{array}$ \\
\hline Xing et al. [6] (2015) & $\begin{array}{c}\text { Temperature Range }\left({ }^{\circ} \mathrm{C}\right): 10-60 \\
\text { Base Liquid: De-ionized Water } \\
\text { Nanoparticle Material: Short Single-Walled } \\
\text { Carbon Nanotubes (S-SWNTs), long SWNTs } \\
\text { (L-SWNTs) and MWNTs } \\
\text { Nanotube Lengths: } \\
\text { S-SWNTs: } 1-3 \mu \mathrm{m} \\
\text { L-SWNTs: } 5-30 \mu \mathrm{mMWNT}: 30 \mu \mathrm{m} \\
\text { Surfactant: Hexadecyl Trimethyl Ammonium } \\
\text { Bromide }(\mathrm{CTAB}) \\
\text { Concentration }(\varphi): 0.05-0.48 \%\end{array}$ & $\begin{array}{l}\text { The thermal conductivity enhancement } \\
\text { increased almost linearly with temperature and } \\
\text { particle concentration. } \\
\text { The addition of surfactant slightly reduced the } \\
\text { thermal conductivity, but this reduction became } \\
\text { smaller with the increase of temperature. } \\
\text { It was found that within the concentration } \\
\text { range of } 0.025-0.25 \mathrm{wt} \% \text { the addition of } \\
\text { surfactant had a negligible effect on the thermal } \\
\text { conductivity. } \\
\text { The L-SWNTs were influenced most by the } \\
\text { change of concentration and temperature. }\end{array}$ \\
\hline Kim et al. [24] (2015) & $\begin{array}{c}\text { Nanoparticle Material: Bohemite Alumina } \\
\text { Base Liquid: Water } \\
\text { Nanoparticle Shape: Brick, Platelet, Blade } \\
\text { Concentration }(\varphi): 0.3-7.0 \% \\
\text { Nanoparticle Size }(\mathrm{nm}): \text { Brick-68.06, } \\
\text { Platelet-58.77, Blade-21.22 }\end{array}$ & $\begin{array}{c}\text { For all nanoparticle shapes, the thermal } \\
\text { conductivity increased with the increase of } \\
\text { volume fraction. } \\
\text { Nanofluids containing brick-shaped } \\
\text { nanoparticles had the highest thermal } \\
\text { conductivity enhancements, and those } \\
\text { containing blade-shaped nanoparticles had the } \\
\text { lowest. }\end{array}$ \\
\hline
\end{tabular}


Table A1. Cont.

\begin{tabular}{|c|c|c|}
\hline Reference & Specifications & Remarks \\
\hline Esfe et al. [3] (2015) & $\begin{array}{c}\text { Temperature Range: Room Temperature } \\
\text { Base Liquid: Water } \\
\text { Nanoparticle Material: magnetic Fe } \\
\text { Concentration }(\varphi): 0.0313-1.0 \% \\
\text { Nanoparticle Size }(\mathrm{nm}): 37,71,98 \\
\text { Nanoparticle Coating: Oxide }\end{array}$ & $\begin{array}{c}\text { Thermal conductivity increased with the } \\
\text { increase of particle concentration and decrease } \\
\text { of particle size. } \\
\text { Thermal conductivity and particle } \\
\text { concentration showed an almost linear } \\
\text { relationship. } \\
\text { The thermal conductivity of nanofluids } \\
\text { depends on many factors, including } \\
\text { temperature, base liquid, acidity, and } \\
\text { nanoparticle size, shape, material and } \\
\text { concentration. } \\
\text { Nanofluids have potential uses in the fields of } \\
\text { transportation, supply, heating, ventilation, and } \\
\text { air conditioning (HVAC), and microelectronics. }\end{array}$ \\
\hline Barbe’s et al. [9] (2014) & $\begin{array}{c}\text { Temperature Range }\left({ }^{\circ} \mathrm{C}\right): 25-65 \\
\text { Base Liquid: De-ionized Water, Ethylene Glycol } \\
\text { Nanoparticle Material: CuO } \\
\text { Nanoparticle Size (nm): } 23-37\end{array}$ & $\begin{array}{c}\text { The conclusion was made that the increase in } \\
\text { thermal conductivity with increase in } \\
\text { temperature is mainly due to the base fluids } \\
\text { rather than the nanoparticles, so the thermal } \\
\text { conductivity enhancement was temperature } \\
\text { independent. } \\
\text { For a given temperature, the relative thermal } \\
\text { conductivity increased almost linearly with } \\
\text { volume fraction. } \\
\text { For a given volume fraction, the thermal } \\
\text { conductivity of CuO/Ethylene Glycol and } \\
\text { CuO/water nanofluids increased with } \\
\text { temperature. }\end{array}$ \\
\hline Xia et al. [20] (2014) & $\begin{array}{c}\text { Temperature Range: Room Temperature } \\
\text { Base Liquid: Water } \\
\text { Nanoparticle Material: } \mathrm{Al}_{2} \mathrm{O}_{3} \\
\text { Nanoparticle Size (nm): } 13,20 \\
\text { Nanoparticle Shape: Spherical } \\
\text { Surfactant: SDS, PVP }\end{array}$ & $\begin{array}{l}\text { It was observed that surfactant had a negative } \\
\text { effect of the heat transfer capability of the base } \\
\text { liquid, but had a positive effect on the stability } \\
\text { of the nanofluid. } \\
\text { For larger nanoparticles, a higher concentration } \\
\text { of surfactant was needed to reach the } \\
\text { maximum thermal conductivity. }\end{array}$ \\
\hline Alawi and Sidik [38] (2014) & $\begin{array}{c}\text { Temperature Range }\left({ }^{\circ} \mathrm{C}\right): 27-47 \\
\text { Base Liquid: } \mathrm{R}-134 \mathrm{a} \\
\text { Nanoparticle Material: } \mathrm{CuO} \\
\text { Nanoparticle Size }(\mathrm{nm}): 20 \\
\text { Nanoparticle Concentration }(\varphi): 1-5 \%\end{array}$ & $\begin{array}{l}\text { The thermal conductivity increased with both } \\
\text { temperature and concentration. } \\
\text { It was concluded that the increase in thermal } \\
\text { conductivity with temperature was a result of } \\
\text { increased Brownian motion at higher } \\
\text { temperatures. }\end{array}$ \\
\hline
\end{tabular}


Table A1. Cont.

\begin{tabular}{c} 
Specifications \\
\hline Reference \\
\\
Temperature Range $\left({ }^{\circ} \mathrm{C}\right): 20-60$ \\
Base Liquid: Ethylene Glycol and Water \\
Mixture \\
Sundar et al. [13] (2013) $\quad$ Base Liquid Concentration $(\varphi): 0.2-2.0 \%$ \\
Nanoparticle Material: Magnetic Fe $\mathrm{O}_{4}$ \\
Nanoparticle Size $(\mathrm{nm}): 13$ \\
Nanoparticle Shape: Cubic
\end{tabular}

\begin{tabular}{cc} 
& \\
\hline & Temperature Range $\left({ }^{\circ} \mathrm{C}\right): 20-60$ \\
& Base Liquid: Water \\
& Nanoparticle Material: $\mathrm{Fe}_{3} \mathrm{O}_{4}$ \\
& Nanoparticle Shape: Cubic \\
& Nanoparticle Size (nm): 13 \\
Concentration $(\varphi): 0-2 \%$ & Surfactant: CTAB
\end{tabular}

Temperature Range $\left({ }^{\circ} \mathrm{C}\right): 20-80$

Base Liquid: Water

Nanoparticle Material: $\mathrm{ZnO}$

Jeong et al. [40] (2013) Nanoparticle Shape: Spherical, Rectangular

Nanoparticle Size(nm): spherical-20-40, rectangular-90-210

Surfactant: Ammonium Polymethacrylate

\begin{tabular}{|c|c|c|}
\hline $\begin{array}{l}\text { Fadhillahanafi et al. [53] } \\
\qquad \text { (2013) }\end{array}$ & $\begin{array}{c}\text { Temperature Range }\left({ }^{\circ} \mathrm{C}\right): 25 \\
\text { Base Liquid: Water } \\
\text { Nanoparticle Material: MWCNTs } \\
\text { Nanoparticle Size }(\mathrm{nm}): \\
\text { Outer diameter-30 } \\
\text { Inner diameter-10 } \\
\text { Surfactant: PVP }\end{array}$ & $\begin{array}{l}\text { It was observed that for a given nanotube } \\
\text { concentration, the nanofluid containing PVP } \\
\text { surfactant had a greater thermal conductivity } \\
\text { than that without, due to the greater stability. } \\
\text { It was observed that the thermal conductivity } \\
\text { generally increased with nanotube } \\
\text { concentration. }\end{array}$ \\
\hline Pang et al. [32] (2012) & $\begin{array}{l}\text { Temperature Range }\left({ }^{\circ} \mathrm{C}\right): 20 \\
\text { Base Liquid: Methanol } \\
\text { Nanoparticle Material: } \mathrm{SiO}_{2}, \mathrm{Al}_{2} \mathrm{O}_{3} \\
\text { Nanoparticle Size (nm): } \mathrm{SiO}_{2}-10-20 \text {, } \\
\qquad \mathrm{Al}_{2} \mathrm{O}_{3}-40-50\end{array}$ & $\begin{array}{l}\text { The thermal conductivity increased } \\
\text { non-linearly with volume fraction. } \\
\text { It was concluded that nanoparticle clustering } \\
\text { had a significant impact on thermal } \\
\text { conductivity. } \\
\text { For a given volume fraction, the } \mathrm{SiO}_{2} / \text { methanol } \\
\text { nanofluid had a higher thermal conductivity } \\
\text { than that of the } \mathrm{Al}_{2} \mathrm{O}_{3} / \text { methanol nanofluid. }\end{array}$ \\
\hline $\begin{array}{l}\text { Harikrishnan and } \\
\text { Kalaiselvam [51] (2012) }\end{array}$ & $\begin{array}{c}\text { Temperature Range }\left({ }^{\circ} \mathrm{C}\right): 25 \\
\text { Base Liquid: Oleic Acid } \\
\text { Nanoparticle Material: } \mathrm{CuO} \\
\text { Nanoparticle Size (nm): } 10-60\end{array}$ & $\begin{array}{l}\text { At low concentrations, the thermal conductivity } \\
\text { increased linearly with concentration. At } \\
\text { higher concentrations the relationship became } \\
\text { non-linear due to the agglomeration of } \mathrm{CuO} \\
\text { nanoparticles. }\end{array}$ \\
\hline Nisha et al. [50] (2012) & $\begin{array}{c}\text { Temperature Range: Room Temperature } \\
\text { Base Liqiuid: Water, Polyvinyl Alcohol (PVA) } \\
\text { Nanoparticle Material: } \mathrm{TiO}_{2} \\
\text { Nanoparticle Size (nm): 5, 20, 50, } 100\end{array}$ & $\begin{array}{l}\text { The thermal conductivity of } \mathrm{TiO}_{2}-\mathrm{PVA} \\
\text { nanofluid increased with the decrease of } \\
\text { nanoparticle size, due to the thickness of the } \\
\text { adsorption layers on the nanoparticle surfaces. } \\
\text { The thermal conductivity of } \mathrm{TiO}_{2} \text {-water } \\
\text { nanofluid increased with the increase of } \\
\text { nanoparticle size, due to clustering. }\end{array}$ \\
\hline Yu et al. [15] (2011) & $\begin{array}{c}\text { Temperature Range }\left({ }^{\circ} \mathrm{C}\right): 10-60 \\
\text { Base Liquid: Propylene Glycol, Ethylene Glycol } \\
\text { Nanoparticle Material: Aluminum Nitride } \\
\text { Nanoparticle Size }(\mathrm{nm}): 50\end{array}$ & $\begin{array}{l}\text { The thermal conductivity increased almost } \\
\text { linearly with volume fraction. } \\
\text { The temperature had a negligible effect on } \\
\text { thermal conductivity. }\end{array}$ \\
\hline
\end{tabular}

The thermal conductivity increased with the increase of particle concentration and temperature. It was suggested that this increase was caused by increased Brownian motion. The advantage of using magnetic particles is the possibility of separating the particles from the base fluid after the particles are fully dispersed in the base fluid.

20:80\% by weight Ethylene Glycol/Water based nanofluids exhibited more thermal conductivity enhancement than $40 \%: 60 \%$ and $60 \%: 40 \%$ Ethylene Glycol/Water based nanofluids. The thermal conductivity enhancement decreased with an increase of Ethylene Glycol in the mixture, because Ethylene Glycol has lower thermal conductivity than water.

Thermal conductivity increased with particle concentration and temperature.

It was concluded that the increase in thermal conductivity with temperature was caused by increased Brownian motion.

Thermal conductivity increased with temperature and particle concentration.

The results showed that nanoparticle shape influenced the thermal conductivity more than nanoparticle size.

It was observed that for a given nanotube concentration, the nanofluid containing PVP surfactant had a greater thermal conductivity than that without, due to the greater stability. was observed that the thermal conductivity concentration

The thermal conductivity increased non-linearly with volume fraction. as concluded that nanoparticle clusterin cant impact on thermal conductivity. than that of the $\mathrm{Al}_{2} \mathrm{O}_{3} /$ methanol nanofluid.

At low concentrations, the thermal conductivity higher concentrations the relationship becam non-linear due to the agglomeration of $\mathrm{CuO}$

The thermal conductivity of $\mathrm{TiO}_{2}-\mathrm{PVA}$ nanofluid increased with the decrease of nanoparticle size, due to the thickness of the The thermal conductivity of $\mathrm{TiO}_{2}$-water nanofluid increased with the increase of noparticle size, due to clustering.

The temperature had a negligible effect on
Therlth volume fraction. thermal conductivity. 
Table A1. Cont.

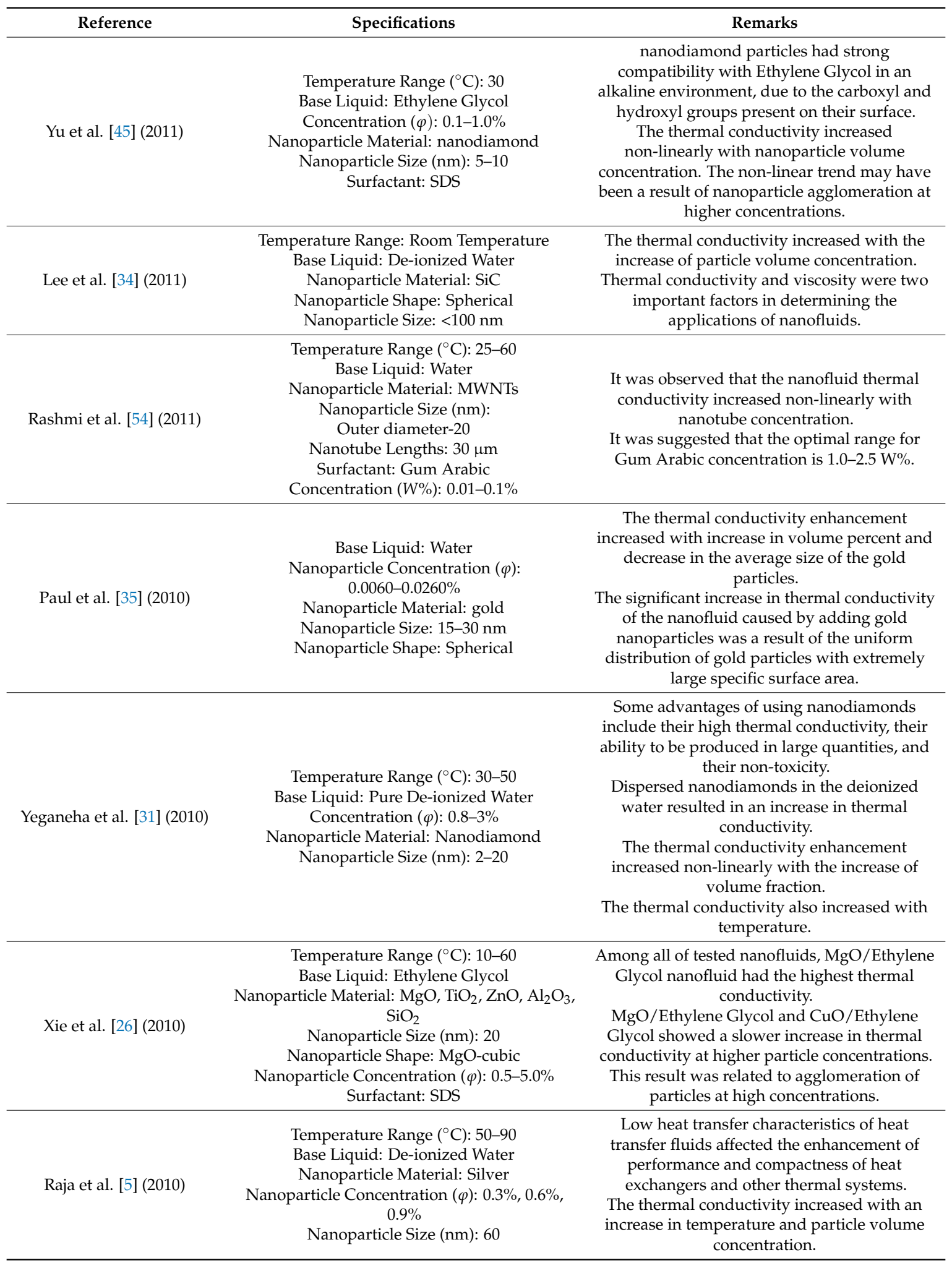


Table A1. Cont.

\begin{tabular}{|c|c|c|}
\hline Reference & Specifications & Remarks \\
\hline Patel et al. [28] (2010) & $\begin{array}{c}\text { Temperature Range }\left({ }^{\circ} \mathrm{C}\right): 20-50 \\
\text { Base Liquid: Water, Ethylene Glycol, } \\
\text { Transformer Oil } \\
\text { Nanoparticle Material: } \mathrm{Al}_{2} \mathrm{O}_{3}, \mathrm{CuO}, \mathrm{Cu}, \mathrm{Al} \\
\text { Nanoparticle Concentration }(\varphi): 0.5-3.0 \% \\
\text { Nanoparticle Size }(\mathrm{nm}): 11-150\end{array}$ & $\begin{array}{l}\text { The results showed a higher enhancement in } \\
\text { thermal conductivity for metallic nanofluids } \\
\text { than oxide nanofluids. } \\
\text { The thermal conductivity increased with } \\
\text { decrease in nanoparticle size, increase in } \\
\text { temperature, and increase in nanoparticle } \\
\text { concentration. } \\
\text { It was concluded that the increase in thermal } \\
\text { conductivity with decrease in nanoparticle size } \\
\text { was a result of higher Brownian velocity and } \\
\text { greater surface area per unit volume for smaller } \\
\text { nanoparticles. }\end{array}$ \\
\hline Yu et al. [27] (2009) & $\begin{array}{c}\text { Temperature Range }\left({ }^{\circ} \mathrm{C}\right): 10-60 \\
\text { Base Liquid: Ethylene Glycol } \\
\text { Nanoparticle Material: } \mathrm{ZnO} \\
\text { Nanoparticle Size }(\mathrm{nm}): 10-20 \\
\text { Nanoparticle Concentration }(\varphi): 0.2-5.0 \%\end{array}$ & $\begin{array}{c}\text { The thermal conductivity increased } \\
\text { non-linearly with the increase of particle } \\
\text { concentration. } \\
\text { The thermal conductivity increased with } \\
\text { temperature followed the pattern of increase of } \\
\text { the base fluid. }\end{array}$ \\
\hline Wang et al. [18] (2009) & $\begin{array}{c}\text { Temperature Range }\left({ }^{\circ} \mathrm{C}\right): 25 \\
\text { Base Liquid: Water } \\
\text { Nanoparticle Material: } \mathrm{Al}_{2} \mathrm{O}_{3}, \mathrm{Cu} \\
\text { Nanoparticle Size (nm): } 25 \\
\text { Nanoparticle Shape: } \mathrm{Al}_{2} \mathrm{O}_{3} \text {-plate, } \mathrm{Cu} \text {-spherical } \\
\text { Surfactant: Sodium Dodecyl Benzene Sulfonate }\end{array}$ & $\begin{array}{l}\text { The thermal conductivity of the nanofluid } \\
\text { increased with surfactant concentration and } \\
\text { then decreased. It was suggested that the } \\
\text { decrease was a result of greater amounts of } \\
\text { surfactant on the surfaces of the nanoparticles } \\
\text { allowing a narrow area for heat transfer. }\end{array}$ \\
\hline Beck et al. [49] (2009) & $\begin{array}{c}\text { Temperature Range }\left({ }^{\circ} \mathrm{C}\right): 25 \\
\text { Base Liquid: Water, Ethylene } \mathrm{Glycol} \\
\text { Nanoparticle Material: } \mathrm{Al}_{2} \mathrm{O}_{3} \\
\text { Nanoparticle Size (nm): } 8-282 \\
\text { Nanoparticle Shape: Spherical } \\
\text { Nanoparticle Concentration }(\varphi): 2-4 \%\end{array}$ & $\begin{array}{l}\text { The thermal conductivity was observed to be } \\
\text { fairly constant with the decrease in nanoparticle } \\
\text { size, until the size dropped below } 50 \mathrm{~nm} \text {, where } \\
\text { a decrease in thermal conductivity with the } \\
\text { decrease of nanoparticle size was observed. } \\
\text { It was suggested that this decrease was a result } \\
\text { of phonon scattering when the nanoparticles } \\
\text { became small enough to be affected. }\end{array}$ \\
\hline
\end{tabular}

Temperature Range $\left({ }^{\circ} \mathrm{C}\right): 21$

Base Liquid: 50/50 Ethylene Glycol/Water

Nanoparticle Material: $\mathrm{Al}_{2} \mathrm{O}_{3}$

Timofeeva et al. [43] (2009) Nanoparticle Shape: Platelet, Blade, Cylinder, Brick

Nanoparticle Size (nm): Platelet-9, Blade-60 $\times$

10, Cylinder- $80 \times 10$, Brick-40

Nanoparticle Concentration $(\varphi)$ : $0.2-8.5 \%$

Temperature Range $\left({ }^{\circ} \mathrm{C}\right): 27$

Base Liquid: Water, Ethylene Glycol

Nanoparticle Material: $\mathrm{Al}_{2} \mathrm{Cu}, \mathrm{Ag}_{2} \mathrm{Al}$

Nanoparticle Shape: $\mathrm{Ag}_{2} \mathrm{Al}$-spherical

Nanoparticle Size (nm): 20-30
The thermal conductivity increased linearly with nanoparticle volume concentration.

Yoo et al. [36] (2007)

Base Liquid: De-ionized Water $\left(\mathrm{TiO}_{2}\right.$ and $\left.\mathrm{Al}_{2} \mathrm{O}_{3}\right)$, Ethylene Glycol $\left(\mathrm{Fe}, \mathrm{WO}_{3}\right)$ Nanoparticle Material: $\mathrm{TiO}_{2}, \mathrm{Al}_{2} \mathrm{O}_{3}, \mathrm{Fe}, \mathrm{WO}_{3}$ Nanoparticle Size (nm):

$\mathrm{TiO}_{2}-25, \mathrm{Al}_{2} \mathrm{O}_{3}-48, \mathrm{Fe}-10, \mathrm{WO}_{3}-38$
Thermal conductivity increased non-linearly with decrease in nanoparticle size and increase in nanoparticle concentration.

Water-based nanofluids had higher thermal conductivity than Ethylene Glycol-based nanofluids.

The surface-to-volume ratio of nanoparticles in nanofluids had a significant impact on thermal conductivity.

Nanofluids containing metallic nanoparticles had a higher thermal conductivity than those containing ceramic nanoparticles.

The thermal conductivities of the nanoparticles themselves did not have a significant impact on the thermal conductivity of the nanofluids. 
Table A1. Cont.

\begin{tabular}{|c|c|c|}
\hline Reference & Specifications & Remarks \\
\hline Jana et al. [55] (2007) & $\begin{array}{c}\text { Temperature Range }\left({ }^{\circ} \mathrm{C}\right): 25 \\
\text { Base Liquid: Water } \\
\text { Nanoparticle Material: Cu, Au, Oxidation } \\
\text { treated Carbon Nanotubes }(\mathrm{CNT}) \\
\text { Nanoparticle Size (nm): } \\
\text { Cu-50 } \\
\text { Au-15 } \\
\text { CNT- } \\
\text { Outer Diameter-10 } \\
\text { Length-10,000 } \\
\text { Nanoparticle Concentration }(\varphi): 0.05-1.4 \% \\
\text { Surfactant: Laurent Salt in Nanofluids } \\
\text { containing Cu }\end{array}$ & $\begin{array}{l}\text { A non-linear increase with concentration was } \\
\text { observed for the CNT-water nanofluid, } \\
\text { whereas a linear increase was observed for the } \\
\text { Cu-water nanofluid. } \\
\text { The addition of CNT to Au-water and } \\
\text { Cu-water nanofluid to create hybrid nanofluids } \\
\text { resulted in reduced thermal conductivity, } \\
\text { which was likely a result of agglomeration. }\end{array}$ \\
\hline Zhu et al. [1] (2006) & $\begin{array}{c}\text { Base Liquid: Water } \\
\text { Nanoparticle Material: } \mathrm{Fe}_{3} \mathrm{O}_{4} \\
\text { Nanoparticle Size (nm): } 10 \\
\text { Nanoparticle Shape: Spherical }\end{array}$ & $\begin{array}{l}\text { The thermal conductivity increased } \\
\text { non-linearly with volume fraction. } \\
\text { Although } \mathrm{Fe}_{3} \mathrm{O}_{4} \text { has a higher thermal } \\
\text { conductivity than } \mathrm{Al}_{2} \mathrm{O}_{3}, \mathrm{CuO} \text {, and } \mathrm{TiO}_{2} \text {, } \\
\mathrm{Fe}_{3} \mathrm{O}_{4} \text { nanofluid had a higher thermal } \\
\text { conductivity than nanofluids composed of the } \\
\text { other oxide nanoparticles. } \\
\text { The number and length of alignments formed } \\
\text { increased with the increase of volume fraction, } \\
\text { and in all cases the alignments were random. It } \\
\text { was concluded that this increase in alignments } \\
\text { was the cause of the higher thermal } \\
\text { conductivity of } \mathrm{Fe}_{3} \mathrm{O}_{4} \text { nanofluid. }\end{array}$ \\
\hline
\end{tabular}


Table A1. Cont.

\begin{tabular}{|c|c|c|}
\hline Reference & Specifications & Remarks \\
\hline Murshed et al. [16] (2005) & $\begin{array}{c}\text { Temperature Range: Room Temperature } \\
\text { Base Liquid: Water } \\
\text { Nanoparticle Material: } \mathrm{TiO}_{2} \\
\text { Nanoparticle Shape: Spherical, Rod } \\
\text { Nanoparticle Size (nm): spherical-15, rod-10 } \\
\text { Surfactant: OA, } \\
\text { CTAB }\end{array}$ & $\begin{array}{l}\text { The thermal conductivity increased with the } \\
\text { increase of particle volume concentration. } \\
\text { Despite the high chemical and physical stability, } \\
\text { low cost, and high availably of } \mathrm{TiO}_{2} \text {, it is not } \\
\text { commonly used. } \\
\text { The results showed a more rapid increase in } \\
\text { thermal conductivity for the nanofluid } \\
\text { containing rod-shaped nanoparticles than the } \\
\text { nanofluid containing spherical nanoparticles. }\end{array}$ \\
\hline Wen et al. [2] (2004) & $\begin{array}{l}\text { Temperature Range }\left({ }^{\circ} \mathrm{C}\right): 10-70 \\
\text { Base Liquid: Water } \\
\text { Nanoparticle Material: MWCNTs } \\
\text { Nanoparticle Size }(\mathrm{nm}): \\
\text { Diameter-60 } \\
\text { length-10,000-30,000 } \\
\text { Concentration }(\varphi): 0-0.84 \% \\
\text { Surfactant: SDBS }\end{array}$ & $\begin{array}{l}\text { The thermal conductivity increased } \\
\text { non-linearly with particle concentration. } \\
\text { It was concluded that the networking of carbon } \\
\text { nanotubes was likely the main contributor to } \\
\text { the increased thermal conductivity of carbon } \\
\text { nanotube nanofluids. } \\
\text { The thermal conductivity increased with } \\
\text { temperature. The relationship was almost } \\
\text { linear at temperatures below } 30^{\circ} \mathrm{C} \text {, but this } \\
\text { relationship was not seen at temperatures } \\
\text { above } 30^{\circ} \mathrm{C} \text {. }\end{array}$ \\
\hline Das et al. [41] (2003) & $\begin{array}{c}\text { Temperature Range }\left({ }^{\circ} \mathrm{C}\right): 0-60 \\
\text { Base Liquid: Water } \\
\text { Nanoparticle material: } \\
\mathrm{Al}_{2} \mathrm{O}_{3}, \mathrm{CuONanoparticle} \mathrm{size}(\mathrm{nm}) \text { : } \\
\mathrm{Al}_{2} \mathrm{O}_{3}-38.4, \mathrm{CuO}-28.6\end{array}$ & $\begin{array}{l}\text { Nanofluids have potential applications in } \\
\text { enhancing heat transfer processes used in } \\
\text { present age technology. } \\
\text { The enhancement characteristics increased with } \\
\text { temperature, leading to an attraction to } \\
\text { applications with high energy density. } \\
\text { The usual heat transfer enhancement } \\
\text { techniques are not capable of meeting the } \\
\text { demand of heat removal in high energy } \\
\text { processes, such as those involving electronic } \\
\text { chips, laser applications, super conducting } \\
\text { magnets, high speed computing systems, fiber } \\
\text { manufacturing processes, high-speed } \\
\text { lubrication applications, and applications } \\
\text { involving similar high energy devices. } \\
\text { The effect of particle concentration was found } \\
\text { to be less for the CuO/water nanofluid } \\
\text { compared to the } \mathrm{Al}_{2} \mathrm{O}_{3} \text { nanofluid, which may } \\
\text { have been caused by the larger particle size of } \\
\text { Al }{ }_{2} \mathrm{O}_{3} \text {. } \\
\text { The effect of temperature was greater for the } \\
\text { CuO/water nanofluid, which was likely caused } \\
\text { by greater Brownian motion due to smaller } \\
\text { nanoparticle size in comparison to the Al }{ }_{2} \mathrm{O}_{3} \\
\text { nanoparticles. } \\
\text { The enhancement of conductivity increased } \\
\text { dramatically with temperature. } \\
\text { The main limitation of this experiment was the } \\
\text { lack of ability to indicate the full effect of } \\
\text { non-availability of nanoparticles of the same } \\
\text { material and different sizes. }\end{array}$ \\
\hline Choi et al. [47] (2001) & $\begin{array}{c}\text { Temperature Range: Room Temperature } \\
\text { Base Liquid: Synthetic Poly }(\alpha-\text { olefin) oil } \\
\text { Nanoparticle Material: Multi-walled Carbon } \\
\text { Nanotubes } \\
\text { Nanoparticle Size }(\mathrm{nm}): \text { diameter- } 25 \mathrm{~nm} \\
\text { length-50,000 nm } \\
\text { Concentration }(\varphi): 0-1.0 \%\end{array}$ & $\begin{array}{l}\text { It was suggested that the organized structure at } \\
\text { the solid-liquid interface allowed for more } \\
\text { significant heat conduction. } \\
\text { It was observed that the nanofluid thermal } \\
\text { conductivity increased non-linearly with } \\
\text { nanoparticle volume concentration, reaching an } \\
\text { enhancement of } 2.5 \% \text { at } \varphi=1 \% \text {. }\end{array}$ \\
\hline
\end{tabular}


Table A1. Cont.

\begin{tabular}{|c|c|c|}
\hline Reference & Specifications & Remarks \\
\hline Wang et al. [11] (1999) & $\begin{array}{c}\text { Temperature Range }\left({ }^{\circ} \mathrm{C}\right): 24 \\
\text { Base Liquid: Water, Vacuum Pump Fluid, } \\
\text { Engine Oil, Ethylene Glycol } \\
\text { Nanoparticle Material: } \mathrm{Al}_{2} \mathrm{O}_{3}, \mathrm{CuO} \\
\text { Nanoparticle Size (nm): } \mathrm{Al}_{2} \mathrm{O}_{3}-28, \mathrm{CuO}-23 \\
\text { Nanoparticle Shape: } \mathrm{Al}_{2} \mathrm{O}_{3} \text {-spherical }\end{array}$ & $\begin{array}{l}\text { The thermal conductivities of fluids containing } \\
\text { nanoparticles were higher than that of the base } \\
\text { fluids. } \\
\text { The thermal conductivity increased with the } \\
\text { increase of volume fraction for all nanofluids. } \\
\text { The stochastic and electrostatic forces are only } \\
\text { significant for very small particles, resulting in } \\
\text { a relationship between thermal conductivity } \\
\text { and nanoparticle size. } \\
\text { The transmission electron microscopy image } \\
\text { showed some chain-like structure for spherical } \\
\text { Al }{ }_{2} \mathrm{O}_{3} \text { nanoparticles. It is possible that this } \\
\text { chain structure enhanced heat transfer because } \\
\text { of the increased ability to transfer heat along } \\
\text { chains facing in the direction of heat flux. }\end{array}$ \\
\hline
\end{tabular}

\section{References}

1. Zhu, H.; Zhang, C.; Liu, S.; Tang, Y.; Yin, Y. Effects of nanoparticle clustering and alignment on thermal conductivities of $\mathrm{Fe}_{3} \mathrm{O}_{4}$ aqueous nanofluids. Appl. Phys. Lett. 2006, 89, 023123. [CrossRef]

2. Wen, D.; Ding, Y. Effective Thermal Conductivity of Aqueous Suspensions of Carbon Nanotubes (Carbon Nanotube Nanofluids). J. Thermophys. Heat Transf. 2004, 18, 481-485. [CrossRef]

3. Esfe, M.; Saedodin, S.; Wongwises, S.; Toghraie, D. An experimental study on the effect of diameter on thermal conductivity and dynamic viscosity of Fe/water nanofluids. J. Therm. Anal. Calorim. 2015, 119, 1817-1824. [CrossRef]

4. Chopkar, M.; Sudarshan, S.; Das, P.K.; Manna, I. Effect of Particle Size on Thermal Conductivity of Nanofluid. Metall. Mater. Trans. A 2008, 39A, 1535-1542. [CrossRef]

5. Raja, B.; Godson, L.; Lal, D.M.; Wongwises, S. Experimental Investigation on the Thermal Conductivity and Viscosity of Silver-Deionized Water Nanofluid. Exp. Heat Transf. 2010, 23, 317-332.

6. Xing, M.; Yu, J.; Wang, R. Experimental study on the thermal conductivity enhancement of water based nanofluids using different types of carbon nanotubes. Int. J. Heat Mass Transf. 2015, 88, 609-616. [CrossRef]

7. Park, S.; Kim, N. Influence of the oxidation treatment and the average particle diameter of graphene for thermal conductivity enhancement. J. Ind. Eng. Chem. 2014, 20, 1911-1915. [CrossRef]

8. Li, C.H.; Peterson, G.P. Experimental investigation of temperature and volume fraction variations on the effective thermal conductivity of nanoparticle suspensions (nanofluids). J. Appl. Phys. 2006, 99, 084314. [CrossRef]

9. Barbe's, B.; Pàramo, R.; Blanco, E.; Casanova, C.J. Thermal conductivity and specific heat capacity measurements of $\mathrm{CuO}$ nanofluids. Therm. Anal. Calorim. 2014, 115, 1883-1891.

10. Agarwal, R.; Verma, K.; Agrawal, N.K.; Duchaniya, R.K.; Singh, R. Synthesis, characterization, thermal conductivity and sensitivity of CuO nanofluids. Appl. Therm. Eng. 2016, 102, 1024-1036. [CrossRef]

11. Wang, X.; Xu, X.; Choi, S. Thermal Conductivity of Nanoparticle-Fluid Mixture. J. Thermophys. Heat Transf. 1999, 13, 474-480. [CrossRef]

12. Agarwal, R.; Verma, K.; Agrawal, N.; Singh, R. Sensitivity of thermal conductivity for $\mathrm{Al}_{2} \mathrm{O}_{3}$ nanofluids. Exp. Therm. Fluid Sci. 2017, 80, 19-26. [CrossRef]

13. Sundar, L.S.; Singh, M.K.; Sousa, A.C.M. Thermal conductivity of ethylene glycol and water mixture based $\mathrm{Fe}_{3} \mathrm{O}_{4}$ nanofluid. Int. Commun. Heat Mass Transf. 2013, 49, 17-24. [CrossRef]

14. Sundar, L.; Singh, M.; Sousa, A. Enhanced thermal properties of nanodiamond nanofluids. Chem. Phys. Lett. 2016, 644, 99-110. [CrossRef]

15. Yu, W.; Xie, W.; Li, Y.; Chen, L. Experimental investigation on thermal conductivity and viscosity of aluminum nitride nanofluid. Particuology 2011, 267, 187-191. [CrossRef]

16. Murshed, S.M.S.; Leong, K.C.; Yang, C. Enhanced thermal conductivity of $\mathrm{TiO}_{2}$-Water based nanofluids. Int. J. Therm. Sci. 2005, 44, 367-373. [CrossRef]

17. Khairul, M.A.; Shah, K.; Doroodchi, E.; Azizian, R.; Moghtaderi, B. Effects of surfactant on stability and thermo-physical properties of metal oxide nanofluids. Int. J. Heat Mass Transf. 2016, 98, 778-787. [CrossRef] 
18. Wang, X.; Zhu, D.; Yang, S. Investigation of $\mathrm{pH}$ and SDBS on enhancement of thermal conductivity in nanofluids. Chem. Phys. Lett. 2009, 470, 107-111. [CrossRef]

19. Asadi, A.; Asadi, M.; Siahmargoi, M.; Asadi, T.; Andarati, M.G. The effect of surfactant and sonication time on the stability and thermal conductivity of water-based nanofluid containing $\mathrm{Mg}(\mathrm{OH})_{2}$ nanoparticles: An experimental investigation. Int. J. Heat Mass Transf. 2017, 108, 191-198. [CrossRef]

20. Xia, G.; Jiang, H.; Liu, R.; Zhai, Y. Effects of surfactant on the stability and thermal conductivity of $\mathrm{Al}_{2} \mathrm{O}_{3} /$ de-ionized water nanofluids. Int. J. Therm. Sci. 2014, 84, 118-124. [CrossRef]

21. Colangelo, G.; Favale, E.; Miglietta, P.; Milanese, M.; de Risi, A. Thermal conductivity, viscosity and stability of $\mathrm{Al}_{2} \mathrm{O}_{3}$-diathermic oil nanofluids for solar energy systems. Energy 2016, 95, 124-136. [CrossRef]

22. Das, P.; Islam, N.; Santra, A.; Ganguly, R. Experimental investigation of thermophysical properties of $\mathrm{Al}_{2} \mathrm{O}_{3}$-water nanofluid: Role of surfactants. J. Mol. Liq. 2017, 237, 304-312. [CrossRef]

23. Seyhan, M.; Altan, C.; Gurten, B.; Bucak, S. The effect of functionalized silver nanoparticles over the thermal conductivity of base fluids. AIP Adv. 2017, 7, 2158-3226. [CrossRef]

24. Kim, H.; Lee, S.H.; Lee, J.H.; Jang, S. Effect of particle shape on suspension stability and thermal conductivities of water-based bohemite alumina nanofluids. Energy 2015, 90, 1290-1297. [CrossRef]

25. Maheshwary, P.B.; Handa, C.C.; Nemade, K.R. A comprehensive study of effect of concentration, particle size and particle shape on thermal conductivity of titania/water based nanofluid. Appl. Therm. Eng. 2017, 119, 79-88. [CrossRef]

26. Xie, H.; Yu, W.; Chen, W. MgO nanofluids: higher thermal conductivity and lower viscosity among ethylene glycol-based nanofluids containing oxide nanoparticles. J. Exp. Nanosci. 2010, 5, 463-472. [CrossRef]

27. Yu, W.; Xie, H.; Chen, L.; Li, Y. Investigation of thermal conductivity and viscosity of ethyleneglycol based ZnO nanofluid. Thermochim. Acta 2009, 491, 92-96. [CrossRef]

28. Patel, H.; Sundararajan, T.; Das, S.K. An experimental investigation into the thermal conductivity enhancement in oxide and metallic nanofluids. J. Nanopart. Res. 2010, 12, 1015-1031. [CrossRef]

29. Sundar, L.; Hortiguela, M.; Singh, M.; Sousa, A. Thermal conductivity and viscosity of water based nanodiamond (ND) nanofluids: An experimental study. Int. Commun. Heat Mass Transf. 2016, 76, 245-255. [CrossRef]

30. Sundar, L.; Singh, M.; Sousa, A. Investigation of thermal conductivity and viscosity of Fe3O4 nanofluid for heat transfer applications. Int. Commun. Heat Mass Transf. 2013, 44, 7-14. [CrossRef]

31. Yeganeha, M.; Shahtahmasebi, N.; Kompany, A.; Goharshadi, E.K.; Youssefi, A.; Šiller, L. Volume fraction and temperature variations of the effective thermal conductivity of nanodiamond fluids in deionized water. Int. J. Heat Mass Transf. 2010, 53, 3186-3192. [CrossRef]

32. Pang, C.; Jung, J.Y.; Lee, J.; Kang, Y. Thermal conductivity measurement of methanol-based nanofluids with $\mathrm{Al}_{2} \mathrm{O}_{3}$ and $\mathrm{SiO}_{2}$ nanoparticles. Int. J. Heat Mass Transf. 2012, 55, 5597-5602. [CrossRef]

33. Das, P.; Mallik, A.; Ganguly, R.; Santra, A. Synthesis and characterization of $\mathrm{TiO}_{2}-$ water nanofluids with different surfactants. Int. Commun. Heat Mass Transf. 2016, 75, 341-348. [CrossRef]

34. Lee, S.; Park, S.; Kang, S.; Bang, I.; Kim, J. Investigation of viscosity and thermal conductivity of SiC nanofluids for heat transfer applications. Int. J. Heat Mass Transf. 2011, 54, 433-438. [CrossRef]

35. Paul, G.; Pal, T.; Manna, I. Thermo-Physical property measurement of nano-gold dispersed water based nanofluids prepared by chemical precipitation technique. J. Colloid Interface Sci. 2010, 349, 434-437. [CrossRef] [PubMed]

36. Yoo, D.; Hong, K.S.; Yang, H.S. Study of thermal conductivity of nanofluids for the application of heat transfer fluids. Thermochim. Acta 2007, 455, 66-69. [CrossRef]

37. Iqbal, S.M.; Raj, C.S.; Michael, J.J.; Irfan, A.M. A Comparative Investigation of $\mathrm{Al}_{2} \mathrm{O}_{3} / \mathrm{H}_{2} \mathrm{O}, \mathrm{SiO}_{2} / \mathrm{H}_{20}$, and $\mathrm{ZrO}_{2} / \mathrm{H}_{2} \mathrm{O}$ Nanofluid for Heat Transfer Applications. Dig. J. Nanomater. Biostruct. 2017, 12, 255-263.

38. Alawi, O.; Sidik, N. Influence of particle concentration and temperature on the thermophysical properties of $\mathrm{CuO} / \mathrm{R} 134 a$ nanorefrigerant. Int. Commun. Heat Mass Transf. 2014, 58, 79-84. [CrossRef]

39. Huminic, A.; Huminic, G.; Fleaca, C.; Dumitrache, F.; Morjan, I. Thermal conductivity, viscosity and surface tension of nanofluids based on FeC nanoparticles. Powder Technol. 2015, 284, 78-84. [CrossRef]

40. Jeong, J.; Li, C.; Kwon, Y.; Lee, J.; Kim, S.; Yun, R. Particle shape effect on the viscosity and thermal conductivity of $\mathrm{ZnO}$ nanofluids. Int. J. Refrig. 2013, 36, 2233-2241. [CrossRef]

41. Das, S.K.; Putra, N.; Thiesen, P.; Roetzel, W. Temperature Dependence of Thermal Conductivity Enhancement for Nanofluids. J. Heat Transf. 2003, 125, 567-574. [CrossRef] 
42. Sharifpur, M.; Tshimanga, N.; Meyer, J.P.; Manca, O. Experimental Investigation and Model Development for Thermal Conductivity of $\alpha-\mathrm{Al}_{2} \mathrm{O}_{3}$-Glycerol Nanofluids. Int. Commun. Heat Mass Transf. 2017, 85, $12-22$. [CrossRef]

43. Timofeeva, E.; Routbort, J.; Singh, D. Particle shape effects on thermophysical properties of alumina nanofluids. J. Appl. Phys. 2009, 106, 014304. [CrossRef]

44. Milanese, M.; Iacobazzi, I.; Colangelo, G.; Risi, A. An investigation of layering phenomenon at the liquid-solid interface in $\mathrm{Cu}$ and $\mathrm{CuO}$ based nanofluids. Int. J. Heat Mass Transf. 2016, 103, 564-571. [CrossRef]

45. Yu, W.; Xie, H.; Li, Y.; Chen, L.; Wang, Q. Experimental investigation on the thermal transport properties of ethylene glycol based nanofluids containing low volume concentration diamond nanoparticles. Colloids Surf. A 2011, 380, 1-5. [CrossRef]

46. Senthilraja, S.; Vijayakumar, K.; Gangadevi, R. A comparative study on thermal conductivity of $\mathrm{Al}_{2} \mathrm{O}_{3} / \mathrm{Water}$, $\mathrm{CuO} /$ Water, and $\mathrm{Al}_{2} \mathrm{O}_{3}-\mathrm{CuO} /$ Water nanofluids. Dig. J. Nanomater. Biostruct. 2015, 10, 1449-1458.

47. Choi, S.; Zhang, Z.; Yu, W.; Lockwood, F.; Grulke, E. Anomalous thermal conductivity enhancement in nanotube suspensions. Appl. Phys. Lett. 2001, 79, 2252-2254. [CrossRef]

48. Xie, H.; Wang, J.; Xi, T.; Liu, Y.; Wu, F. Thermal conductivity enhancement of suspensions containing nanosized alumina particles. J. Appl. Phys. 2002, 91, 4568-4572. [CrossRef]

49. Beck, M.; Yuan, Y.; Warrier, P.; Teja, A. The effect of particle size on the thermal conductivity of alumina nanofluids. J. Nanopart. Res. 2009, 11, 1129-1136. [CrossRef]

50. Nisha, M.R.; Philip, J. Dependence of particle size on the effective thermal diffusivity and conductivity of nanofluids: role of base fluid properties. Heat Mass Transf. 2012, 48, 1783-1790. [CrossRef]

51. Harikrishnan, S.; Kalaiselvam, S. Preparation and thermal characteristics of CuO-oleic acid nanofluids as a phase change material. Thermochim. Acta 2012, 533, 46-55. [CrossRef]

52. Wan, M.; Yadav, R.; Singh, G.; Joshi, B. Temperature dependent heat transfer performance of Multi-Walled Carbon nanotube-based aqueous nanofluids at very low particle loadings. Johnson Matthey Technol. Rev. 2015, 59, 199-206. [CrossRef]

53. Fadhillahanafi, N.M.; Leong, K.Y.; Risby, M.S. Stability and Thermal Conductivity Characteristics of Carbon Nanotube Based Nanofluids. Int. J. Automot. Mech. Eng. 2013, 8, 1376-1384. [CrossRef]

54. Rashmi, W.; Ismail, A.F.; Sopyan, I.; Jameel, A.T.; Yusof, F.; Khalid, M.; Mubarak, N.M. Stability and thermal conductivity enhancement of carbon nanotube nanofluid using Gum Arabic. J. Exp. Nanosci. 2011, 6, 567-579. [CrossRef]

55. Jana, S.; Khojin, A.S.; Zhong, W.H. Enhancement of fluid thermal conductivity by the addition of single and hybrid nano-additives. Thermochim. Acta 2007, 462, 45-55. [CrossRef]

56. Chai, Y.; Yusup, Y.; Chok, V.; Arpin, M.; Irawan, S. Investigation of thermal conductivity of multi walled carbon nanotube dispersed in hydrogenated oil-based drilling fluids. Appl. Therm. Eng. 2016, 107, 1019-1025. [CrossRef]

57. Esfe, M.; Firouzi, M.; Afrand, M. Experimental and theoretical investigation of thermal conductivity of ethylene glycol containing functionalized single walled carbon nanotubes. Phys. E 2018, 95, 71-77. [CrossRef]

58. Dehkordi, R.; Esfe, M.; Afrand, M. Effects of functionalized single walled carbon nanotubes on thermal performance of antifreeze: An experimental study on thermal conductivity. Appl. Therm. Eng. 2017, 120, 358-366. [CrossRef]

59. Trinh, P.V.; Anh, N.N.; Thang, B.H.; Quang, L.D.; Hong, N.T.; Hong, N.M.; Khoi, P.H.; Minh, P.N.; Hong, P.N. Enhanced thermal conductivity of nanofluid-based ethylene glycol containing $\mathrm{Cu}$ nanoparticles decorated on a Gr-MWCNT hybrid material. Spec. Publ.-R. Soc. Chem. 2017, 7, 318-326.

60. Esfe, M.H.; Rejvani, M.; Karimpour, R.; Arani, A. Estimation of thermal conductivity of ethylene glycol-based nanofluid with hybrid suspensions of SWCNT- $\mathrm{Al}_{2} \mathrm{O}_{3}$ nanoparticles by correlation and ANN methods using experimental data. J. Therm. Anal. Calorim. 2017, 128, 1359. [CrossRef]

61. Afrand, M. Experimental study on thermal conductivity of ethylene glycol containing hybrid nano-additives and development of a new correlation. Appl. Therm. Eng. 2017, 110, 1111-1119. [CrossRef]

62. Esfe, M.; Esfandeh, S.; Saedodin, S.; Rostamian, H. Experimental evaluation, sensitivity analyzation and ANN modeling of thermal conductivity of ZnO-MWCNT/EG-water hybrid nanofluid for engineering applications. Appl. Therm. Eng. 2017, 125, 673-685. [CrossRef] 
63. Esfahani, N.N.; Toghraie, D.; Afrand, M. A new correlation for predicting the thermal conductivity of ZnO-Ag (50\%-50\%)/water hybrid nanofluid: An experimental study. Powder Technol. 2018, 323, 367-373. [CrossRef]

64. Kannaiyan, S.; Boobalan, C.; Umasankaran, A.; Ravirajan, A.; Sathyan, S.; Thomas, T. Comparison of experimental and calculated thermophysical properties of alumina/cupric oxide hybrid nanofluids. J. Mol. Liq. 2017, 244, 469-477. [CrossRef]

65. Zadkhast, M.; Toghraie, D.; Karimipour, A. Developing a new correlation to estimate the thermal conductivity of MWCNT-CuO/water hybrid nanofluid via an experimental investigation. J. Therm. Anal. Calorim. 2017, 129, 859-867. [CrossRef]

66. Leong, K.Y.; Razali, I.; Ahmad, K.Z.; Ong, H.C.; Ghazali, M.J.; Rahman, M.R.A. Thermal conductivity of an ethylene glycol/water-based nanofluid with copper-titanium dioxide nanoparticles: An experimental approach. Int. Commun. Heat Mass Transf. 2018, 90, 23-28. [CrossRef]

67. Hamid, K.; Azmi, W.; Nabil, M.; Mamat, R.; Sharma, K. Experimental investigation of thermal conductivity and dynamic viscosity on nanoparticle mixture ratios of $\mathrm{TiO}_{2}-\mathrm{SiO}_{2}$ nanofluids. Int. J. Heat Mass Transf. 2018, 116, 1143-1152. [CrossRef]

68. Parsian, A.; Akbari, M. New experimental correlation for the thermal conductivity of ethylene glycol containing $\mathrm{Al}_{2} \mathrm{O}_{3}-\mathrm{Cu}$ hybrid nanoparticles. J. Therm. Anal. Calorim. 2017. [CrossRef]

69. Lee, J.; Jang, S.P. Mechanisms and Models of Thermal Conductivity in Nanofluids; CRC Press: Boca Raton, FL, USA, 2015; pp. 73-102.

70. Maxwell, J.C. A Treatise on Electricity and Magnetism. In A Treatise on Electricity and Magnetism; Clarendon Press: Oxford, UK, 1891.

71. Davis, R.H. The effective thermal conductivity of a composite material with spherical inclusions. Int. J. Thermophys. 1986, 7, 609-620. [CrossRef]

72. Hamilton, R.L.; Crosser, O.K. Conductivity of heterogeneous two-component systems. Ind. Eng. Chem. Fundam. 1962, 1, 182-191. [CrossRef]

73. Xie, H.; Fujii, M.; Zhang, X. Effect of interfacial nanolayer on the effective thermal conductivity of nanoparticle-fluid mixture. Int. J. Heat Mass Transf. 2005, 48, 2926-2932. [CrossRef]

74. Yu, W.; Choi, S.U.S. The role of interfacial layers in the enhanced thermal conductivity of nanofluids: A renovated maxwell model. J. Nanopart. Res. 2003, 5, 167-171. [CrossRef]

75. Jung, J.Y.; Yoo, J.Y. Thermal conductivity enhancement of nanofluids in conjunction with electrical double layer (EDL). Int. J. Heat Mass Transfer. 2009, 52, 525-528. [CrossRef]

76. Leong, K.C.; Murshed, S.M.S. A model for the thermal conductivity of nanofluids the effect of interfacial layer. J. Nanoparticle Res. 2006, 8, 245-254. [CrossRef]

77. Wang, B.X.; Zhou, L.P. A fractal model for predicting the effective thermal conductivity of liquid with suspension of nanoparticles. Int. J. Heat Mass Transf. 2003, 46, 2665-2672. [CrossRef]

78. Lu, S.Y.; Lin, H.C. Effective conductivity of composites containing aligned spheroidal inclusions of finite conductivity. J. Appl. Phys. 1996, 79, 6761-6769. [CrossRef]

79. Shima, P.D.; Philip, J.; Baldev, R. Role of microconvection induced by brownian motion of nanoparticles in the enhanced thermal conductivity of stable nanofluids. Appl. Phys. Lett. 2009, 94, 223101. [CrossRef]

80. Yu-Hua, L.; Wei, Q.; Jian-Chao, F. Temperature Dependence of Thermal Conductivity of Nanofluids. Chin. Phys. Lett. 2008, 25, 3319. [CrossRef]

81. Bhattacharya, P.; Phelan, P.E.; Prasher, R. Brownian-motion-based convective-conductive model for the effective thermal conductivity of nanofluids. J. Heat Transf. 2006, 128, 588-595.

82. Kumar, D.H.; Patel, H.E.; Kumar, V.R.R.; Sundararajan, T.; Pradeep, T.; Das, S.K. Model for heat conduction in nanofluids. Phys. Rev. Lett. 2004, 93, 144301-144304. [CrossRef]

83. Prasher, R.; Bhattacharya, P.; Phelan, P.E. Thermal conductivity of nanoscale colloidal solutions (nanofluids). Phys. Rev. Lett. 2005, 94, 025901. [CrossRef] [PubMed]

84. Jang, S.P.; Choi, S.U.S. Role of brownian motion in the enhanced thermal conductivity of nanofluids. Appl. Phys. Lett. 2004, 84, 4316-4318. [CrossRef]

85. Xuan, Y.; Li, Q.; Hu, W. Aggregation structure and thermal conductivity of nanofluids. J. Am. Inst. Chem. Eng. 2003, 49, 1038-1043. [CrossRef] 
86. Yang, B. Thermal conductivity equations based on brownian motion in suspensions of nanoparticles (nanofluids). J. Heat Transf. 2008, 130, 042408. [CrossRef]

87. Lin, Y.S.; Hsiao, P.Y.; Chieng, C.C. Roles of nanolayer and particle size on thermophysical characteristics of ethylene glycol-based copper nanofluids. Appl. Phys. Lett. 2011, 98, 153105. [CrossRef]

(c) 2018 by the authors. Licensee MDPI, Basel, Switzerland. This article is an open access article distributed under the terms and conditions of the Creative Commons Attribution (CC BY) license (http:// creativecommons.org/licenses/by/4.0/). 